\title{
Energy and nutrient dietary reference values for children in Europe: methodological approaches and current nutritional recommendations
}

\author{
Ann Prentice ${ }^{1}$, Francesco Branca ${ }^{2}$, Tamás Decsi ${ }^{3}$, Kim Fleischer Michaelsen ${ }^{4}$, Reg J. Fletcher ${ }^{5}$, \\ Pierre Guesry ${ }^{6}$, Friedrich Manz ${ }^{7}$, Michel Vidailhet ${ }^{8}$, Daphne Pannemans ${ }^{9}$ and Sonia Samartín ${ }^{9}$ \\ ${ }^{1}$ MRC (Medical Research Council), Human Nutrition Research, Elsie Widdowson Laboratory, Fulbourn Road, \\ Cambridge CB1 9NL, UK \\ ${ }^{2}$ INRAN (Istituto Nazionale di Ricerca degli Alimenti e la Nutrizione), Via Ardeatina 546, I-00178 Rome, Italy \\ ${ }^{3}$ University of Pecs, Department of Paediatrics, József A.u. 7, H-7623 Pecs, Hungary \\ ${ }^{4}$ Royal Veterinary \& Agricultural University, Research Department of Human Nutrition, Rolighedsvej 30, \\ DK-1958 Frederiksberg C, Denmark \\ ${ }^{5}$ Kellogg's Company of Great Britain Ltd, The Kellogg Building, Talbot Road, Manchester M16 OPU, UK \\ ${ }^{6}$ Nestlé Research Centre, PO Box 44, Vers-chez-les-Blanc, CH-1000 Lausanne 26, Switzerland \\ ${ }^{7}$ Research Institute of Child Nutrition, University Witten/Herdecke, Heinstueck 11, D-44225 Dortmund, Germany \\ ${ }^{8}$ Hôpitaux de Brabois, Hôpital d'Enfants, Service de Pédiatrie Centre Hospitalier Universitaire, F-54511 Nancy, France \\ ${ }^{9}$ ILSI Europe, Av. E. Mounier 83, Box 6, B-1200 Brussels, Belgium
}

\begin{abstract}
The Expert Group on the Methodological Approaches and Current Nutritional Recommendations in Children and Adolescents was convened to consider the current situation across Europe with regard to dietary recommendations and reference values for children aged $2-18$ years. Information was obtained for twenty-nine of the thirty-nine countries in Europe and a comprehensive compilation was made of the dietary recommendations current up to September 2002. This report presents a review of the concepts of dietary reference values and a comparison of the methodological approaches used in each country. Attention is drawn to the special considerations that are needed for establishing dietary reference values for children and adolescents. Tables are provided of the current dietary reference values for energy and for the macronutrients, vitamins, minerals, trace elements and water. Brief critiques are included to indicate the scientific foundations of the reference values for children and to offer, where possible, an explanation for the wide differences that exist between countries. This compilation demonstrated that there are considerable disparities in the perceived nutritional requirements of European children and adolescents. Although some of this diversity can be attributed to real physiological and environmental differences, most is due to differences in philosophy about the best methodological approach to use and in the way the theoretical approaches are applied. The report highlights the main methodological and technological issues that will need to be resolved before harmonisation can be fully considered. Solving these issues may help to improve the quality and consistency of dietary reference values across Europe. However, there are also considerable scientific and political barriers that will need to be overcome and the question of whether harmonisation of dietary reference values for children and adolescents is a desirable or achievable goal for Europe requires further consideration.
\end{abstract}

Nutritional reference values: Children: Adolescents: Europe

\section{Introduction: The role of the Expert Group 1} Committee and the purpose of the paper

The Expert Group on the Methodological Approaches and Current Nutritional Recommendations in Children and Adolescents was convened to consider the current situation across Europe with regard to dietary recommendations and reference values for children aged 2-18 years. The Expert Group was given the following remit by the Task Force on the Nutritional Needs of Children of the European branch of the International Life Sciences Institute (ILSI Europe):

1. To consider:

A. What are the methodological approaches used to establish the nutritional needs of children/adolescents?

B. What are the energy recommendations for children/ adolescents?

C. What are the recommendations for macronutrients in

Abbreviations: AI, Adequate Intake; AR, Average Requirement; DRI, Dietary Reference Intake; DRV, Dietary Reference Value; EAR, Estimated Average Requirement; FBDG, Food Based Dietary Guidelines; GPx, glutathione peroxidase; ILSI, International Life Sciences Institute; LOAEL, Low Observed Adverse Effect Level; LRNI, Lower Reference Nutrient Intake; LTI, Lowest Threshold Intake; NOAEL, No Observed Adverse Effect Level; PRI, Population Reference Intake; RDA, Recommended Dietary Allowance; RNI, Reference Nutrient Intake; UL, Tolerable Upper Level; UL, Upper Tolerable Nutrient Intake Level; ULI, Upper Limit of Intake.

* Corresponding author: ILSI Europe, 83 Avenue E. Mounier, Box 6, B-1200 Brussels, fax + 32276200 44, email publications@ilsieurope.be 
children/adolescents: fats (type of fat, ratio); carbohydrates and fibre (type of carbohydrates); protein?

D. What are the recommendations for micronutrients in children/adolescents: minerals, vitamins; trace elements?

E. What are the recommendations for fluids in children/ adolescents?

2. To determine what is currently known, based on (i) the available literature and (ii) current recommendations or guidelines, on whether:

A. These recommendations are based on data derived from children and adolescents or derived via extrapolation from adult data?

B. There are differences between specific age groups or are groups divided on the basis of growth velocity, height or other parameters?

C. Whether some of the current recommendations are unsatisfactory? What ways could be proposed to overcome them?

The purpose of this report is to present an overview of the methodological approaches used for establishing dietary reference values (Section 1), to compare and contrast the current recommendations for children and adolescents in different European countries (Section 2) and to summarise the causes underlying the wide disparities in dietary reference values (Section 3). The report concludes with the views of the Expert Group about the potential for resolving the methodological and technical issues that give rise to many of these disparities and about some of the likely benefits and barriers to the harmonisation of dietary reference values for children and adolescents across Europe.

\section{Section 1: Methodological approaches}

Methods used to formulate nutritional guidelines for children are not homogeneous across Europe. The purpose of this section is to describe the methodological issues underlying the definition of dietary reference values and nutritional recommendations for children, in order to provide a basis for a comparison of the guidelines that currently exist in different European countries.

\section{Physiological requirements}

The formulation of dietary reference values and nutritional recommendations is based on an understanding of the physiological requirements of an individual in good health. First, a physiological requirement refers to the amount of a nutrient or energy needed to ensure good physiological and metabolic function and to maintain adequate body stores. The precise definition varies, but the wording recently given by a committee of the European Society for Paediatric Gastroenterology, Hepatology and Nutrition is particularly clear and concise:

'The ideal definition of a physiological requirement is the amount and chemical form of a nutrient that is needed systematically to maintain normal health and development without disturbance of the metabolism of any nutrient. The corresponding dietary requirement would be the intake sufficient to meet the physiological requirement.'

(Aggett et al. 1997)

Second, the formulation needs to take account of the fact that physiological requirements differ between individuals. Third, the physiological requirement needs to be translated into the amount of the nutrient or energy that individuals have to ingest daily to meet these needs, in their everyday life, by considering the environment in which they live and the foods that are commonly available. This translation into real life has to take into account current eating patterns, such as, for example, the tendency to an oversupply of certain nutrients or the possibility, still historically meaningful in twenty-first century Europe, that the food supply is suddenly disrupted. This public health-oriented concept appears in the Austria-Germany-Switzerland document (DACH, 2000):

'The purpose of...nutritional reference values (recommendations, estimated values, guiding values) is to maintain and promote health and quality of life. ...they are to ensure the vital metabolic, physical and psychic function in nearly all healthy individuals in the population. Intake corresponding to the reference values is to prevent nutrient-specific deficiency diseases...and deficiency symptoms...but also to avoid oversupply with energy or certain nutrients such as fat or alcohol...). They are, furthermore, intended to produce certain body reserves, which in case of sudden increased needs are immediately available without impairment of health.'

\section{Nutrient bioavailability}

Central to the construction of dietary reference values and recommendations is an understanding of the bioavailability of nutrients from the diet; that is, the amount that is available to the body for its metabolic and physiological functions. Once a food has been ingested, the proportion of individual nutrients absorbed is dictated by a number of factors. In the past, this was referred to as the 'bioavailability' of the nutrient. However, the amount of a nutrient available for its metabolic and physiological functions also depends on factors that become important once the nutrient has entered the body, including tissue compartmentation and excretion. The term 'bioavailability' is now used in its wider sense to incorporate considerations of absorption, distribution, metabolism and excretion.

Several nutrients have a low bioavailability from common diets. Examples are $\mathrm{Fe}, \mathrm{Zn}$ and $\mathrm{Ca}$, for which typical rates of absorption are $10 \%, 20 \%$ and $30 \%$, respectively. However, bioavailability is influenced by several factors of which the most important are the composition of the diet, the chemical form of the nutrient and the nutritional status of the individual regarding that nutrient. Differences in bioavailability for a nutrient have important implications for estimating requirements.

Diet composition. The composition of the diet has important consequences for the bioavailability of some nutrients. For example, the overall fat content of the diet affects the absorption of fat-soluble vitamins. The effect can be remarkable: for example, the addition of olive oil 
improves carotenoid absorption from 5 to $25 \%$. As a second example, the balance between promoters of absorption, like vitamin $\mathrm{C}$ and the 'meat factor', and inhibitors, like phytates and phenols, determines the bioavailability of $\mathrm{Fe}$ in that diet. Knowing the approximate composition of a diet makes it possible to make estimates of the level of bioavailability of specific nutrients. This approach has been used by the FAO/WHO (FAO/WHO/International Atomic Energy Agency, 1996) for Fe and Zn. They defined different dietary reference values for $\mathrm{Fe}$ and $\mathrm{Zn}$ for diets of low, medium and high bioavailability.

Diet composition can also influence bioavailability of a nutrient through effects on excretion. An example is the urinary excretion of $\mathrm{Ca}$, which is correlated with protein and $\mathrm{Na}$ intake and can be affected by a range of other dietary constituents (Nordin \& Marshall, 1988). Differences in assumptions made about the extent of such excretory losses on a typical diet can lead to differences in nutritional recommendations between countries.

Effects of age, physiological stage and nutritional status. Bioavailability varies with age, with physiological state (e.g. puberty, pregnancy, lactation) and with nutritional status. For example, the absorption of many minerals increases during puberty and pregnancy, and excretion decreases. Metabolic adaptation in individuals with small body stores can lead to increased absorption efficiency in some situations but can also lead to smaller physiological requirements in others. These differences need to be considered when setting nutritional recommendations for specific ages or physiological stages. In addition, physiological requirements differ between different organs/tissues of the body. Therefore, the efficiency of nutrient delivery to, and partitioning of the nutrient between, tissues need to be considered. A major example of this is the active transport of nutrients across the placenta during pregnancy. The fetus might have sufficient nutrient delivery, but unless there is physiological adaptation, this could be at the expense of the mother. In this case, a larger intake is required to cover the needs of both the fetus and the mother.

\section{Different concepts of nutritional recommendations and reference values}

Historically, the concept of dietary recommendations for populations or groups goes back several centuries (Aggett et al. 1997). However, the definition of a Recommended Dietary Allowance (RDA) for a nutrient was formulated in 1941: 'to serve as a guide for planning adequate nutrition for the civilian population'. The definition of an RDA has varied, but can be generalised as representing: 'an average amount of the nutrient, which should be provided per head of a group of people if the needs of practically all members of the group are to be met' (Department of Health, 1991). Since it was first introduced, the concept of nutritional recommendations has evolved to take into account not only the avoidance of clinical deficiency, but also the reduction in the risk of chronic degenerative diseases. More recently, the use of the word 'recommendation' has been largely discontinued in favour of the term 'reference value' to avoid misunderstandings about the derivation and use of nutritional guidelines.

Over the past five decades, scientific and public health experts in different countries have elaborated extensively on the concepts of nutritional requirements, recommendations and reference values, and have used these to establish nutritional guidelines for their own populations. In general, their deliberations have been based on the same fundamental principles: that physiological requirements differ between individuals and that the handling of nutrients by the body may be substantially affected by environmental and individual factors. However, there have been many different approaches to the derivation and terminology of nutritional guidelines, and to their interpretation. The latest concepts used in Europe, the USA/Canada and by FAO/WHO are summarised below.

The Scientific Committee on Food of the EU (Scientific Committee on Food, 1993) defined three reference values to describe the distribution of required dietary intakes within age- and gender-specific subgroups of the population:

1. The mean intake to meet the average physiological requirement, termed the Average Requirement (AR);

2. The 97.5th centile $($ mean $+2 \mathrm{SD})$, termed the Population Reference Intake (PRI), representing 'the intake that will meet the needs of nearly all healthy people in the population or group'; and

3. The 2.5th centile (mean-2SD), termed the Lowest Threshold Intake (LTI), representing 'the intake below which nearly all individuals in the population or group will be unable to maintain metabolic integrity according to the criterion chosen'.

These definitions were based on those developed by the Committee on the Medical Aspects of Food Policy in the UK (Department of Health, 1991), but the UK used different terminology for the three Dietary Reference Values (DRV):

1. Estimated Average Requirement (EAR);

2. Reference Nutrient Intake $(\mathrm{RNI}=\mathrm{EAR}+2 \mathrm{SD})$; and

3. Lower Reference Nutrient Intake (LRNI $=\mathrm{EAR}-$ 2SD).

Figure 1 illustrates the conceptual framework for the different reference values and their position in the hypothetical distribution of required intakes. All the definitions assume that the distribution is normal so that the standard deviation can be used to describe upper and lower values.

More recently, in the USA/Canada, the Standing Committee on the Scientific Evaluation of Dietary Reference Intakes (Food and Nutrition Board, 1997) adopted a similar framework for the derivation of Dietary Reference Intakes (DRI) and defined:

1. Estimated Average Requirement (EAR) as 'the average daily nutrient intake level estimated to meet the nutrient requirement of half the healthy individuals in a particular life stage and gender group'; and

2. Recommended Dietary Allowance (RDA) as 'the average daily nutrient intake level estimated to meet the nutrient requirement of nearly all ( 97 to 98 per cent) healthy individuals in a particular life stage and gender group'. 




Nutrient requirements

Fig. 1. Definitions used to indicate different points of the population distribution of requirements. LTI, Lowest Threshold Intake; AR, Average Requirement; PRI, Population Reference Intake; ULI, Upper Limit of Intake.

Unlike the European committee and the UK, however, USA/Canada established no definition for a lower threshold intake. In most European countries and by FAO/WHO, the mean $+2 \mathrm{SD}$ concept has been used to set the population reference intake, but terminology varies considerably and the value is often referred to as a 'recommendation', or 'recommended intake' or 'suggested intake'. The mean $+2 \mathrm{SD}$ concept relates specifically to reference values for nutrients; dietary energy requirements for a population are generally set at a level equivalent to the AR.

In order for an AR to be determined, data about the relationship between intake and the specific criteria on which the requirement is to be based (e.g. risk of deficiency disease, biochemical parameters of nutritional status or indicators of the risk of chronic disease) have to be available, as well as data on possible losses and extra needs in relation to a particular physiological state, such as pregnancy and lactation. The AR is an estimate of the dietary intake required to cover average physiological needs, and, therefore, data are also required about the absorption efficiency of the nutrient from the customary diet of the population or group. For a PRI or LTI to be formulated, knowledge on the distribution of the AR is necessary, to allow for individual variability in physiological requirements and in absorption efficiency.

In situations where the available information is insufficient, then estimates of the reference values have to be made; for example, by extrapolating data from other population groups or by making judgements about the adequacy of dietary intakes. To cover this situation, the US/Canadian committee defined an additional concept, that of Adequate Intake (AI), which they regard as a 'recommended average daily nutrient intake level', but it is used 'when an RDA cannot be determined' and is 'based on observed or experimentally determined approximations or estimates of nutrient intake by a group (or groups) of apparently healthy people that are assumed to be adequate'. For the same purpose Austria-Germany-Switzerland (DACH, 2000) introduced the concepts of Estimated Values (Schätzwerte) - based on the intakes of healthy, well-nourished groups, although not properly validated by experimental data and of Guiding Values (Richtwerte), meant to orient people's intake when a wide range of dietary intakes is compatible with good health. The Guiding Value is used in situations when 'less stringent regulation of intake is necessary for health reasons'. This can be a lower limit for e.g. water, fluoride and dietary fibre or an upper limit e.g. for total fat, cholesterol and table salt $(\mathrm{NaCl})$. Other names have been given to reference values developed when there are insufficient data, including 'safe intakes' (Department of Health, 1991), 'safe-and-adequate range' and 'acceptable range' (Scientific Committee on Food, 1993). In practice, these values are deemed sufficient to meet the needs of practically all members of the group or population and therefore can be compared with PRI values (i.e. AR $+2 \mathrm{SD}$ ) with the understanding that they are based on less evidence and are therefore less secure.

In addition to the general set of reference values, FAO/ WHO/International Atomic Energy Agency (1996) have introduced two new concepts for trace elements, to differentiate between the intake needed to "prevent pathologically relevant and clinically detectable signs of impaired function attributable to inadequacy of the nutrient' (basal requirement) and the intake needed to 'maintain a level of tissue storage or other reserve that is judged...to be desirable' (normative requirement). This allows the construction of population recommendations of minimum intakes to meet the basal requirement or the normative requirement.

In recent years, the concept of an upper limit has been introduced, to allow consideration of the situation when nutrient intakes might be considered excessive and potentially detrimental to health. The European Commission (Scientific Committee on Food, 1993) defined an Upper Limit of Intake (ULI), FAO/WHO/International Atomic Energy Agency (1996) an Upper Tolerable Nutrient Intake Level (UL) and USA/Canada (Food and Nutrition Board, 1997) a Tolerable Upper Level (UL). The US/Canadian definition is: 'the highest average daily nutrient intake level likely to pose no risk of adverse health effects to almost all individuals in the general population (including sensitive individuals)'.

Table 1 summarises the different definitions used by recent committees in Europe, in the USA/Canada and by FAO/WHO, indicating that some are fairly close to each other and can be used to make comparisons across countries. For the purposes of clarity in this publication, we have standardised throughout the text on the terminology used by the Scientific Committee on Food (1993), but have indicated the original name for each value in the tables. However, it should be borne in mind that the definition of dietary reference values varies between countries, subtly in some instances and considerably in others, and we refer the reader back to the source documents for a fuller explanation.

\section{Use of nutritional recommendations and reference values}

Nutritional recommendations and reference values are used for several different purposes. They may be used for assessing the diets of individuals or groups of individuals, 
Table 1. Comparison of names used for different nutritional recommendations

\begin{tabular}{|c|c|c|c|c|c|}
\hline Source & Mean - 2SD & Mean & Mean $+2 \mathrm{SD}$ & $\begin{array}{l}\text { Definition used in } \\
\text { absence of clear info } \\
\text { on distribution of } \\
\text { requirements }\end{array}$ & $\begin{array}{l}\text { Upper limit } \\
\text { of intake }\end{array}$ \\
\hline $\begin{array}{l}\text { Scientific } \\
\text { Committee on } \\
\text { Food (1993) }\end{array}$ & $\begin{array}{l}\text { Lowest } \\
\text { Threshold } \\
\text { of Intake (LTI) }\end{array}$ & $\begin{array}{l}\text { Average } \\
\quad \text { Requirement (AR) }\end{array}$ & $\begin{array}{l}\text { Population } \\
\text { Reference } \\
\text { Intake (PRI) }\end{array}$ & Acceptable ranges & \\
\hline $\begin{array}{l}\text { Food and } \\
\text { Nutrition } \\
\text { Board (1997) }\end{array}$ & & $\begin{array}{l}\text { Estimated Average } \\
\text { Requirement } \\
\text { (EAR) }\end{array}$ & $\begin{array}{l}\text { Recommended } \\
\text { Dietary Allowance } \\
\text { (RDA) }\end{array}$ & $\begin{array}{l}\text { Adequate } \\
\text { Intake (AI) }\end{array}$ & $\begin{array}{l}\text { Tolerable } \\
\text { Upper Intake } \\
\text { Level (UL) }\end{array}$ \\
\hline $\begin{array}{l}\text { Department of } \\
\text { Health (1991) }\end{array}$ & $\begin{array}{l}\text { Lowest } \\
\text { Reference } \\
\text { Nutrient Intake } \\
\text { (LRNI) }\end{array}$ & $\begin{array}{l}\text { Estimated Average } \\
\text { Requirements } \\
\text { (EAR) }\end{array}$ & $\begin{array}{l}\text { Reference } \\
\text { Nutrient Intakes } \\
\text { (RNI) }\end{array}$ & Safe intakes & \\
\hline $\begin{array}{l}\text { Health Council } \\
\text { of The } \\
\text { Netherlands (2001) }\end{array}$ & & $\begin{array}{l}\text { Average } \\
\text { requirement }\end{array}$ & $\begin{array}{l}\text { Recommended } \\
\text { Dietary Allowance }\end{array}$ & Adequate Intake & $\begin{array}{l}\text { Tolerable } \\
\text { Upper Intake } \\
\text { Level }\end{array}$ \\
\hline DACH (2000) & & & $\begin{array}{l}\text { Empfehlungen } \\
\text { (Recommendations) }\end{array}$ & $\begin{array}{l}\text { Schätzwerte } \\
\text { (Estimated Values) } \\
\text { Richtwerte } \\
\text { (Guiding Values) }\end{array}$ & \\
\hline $\begin{array}{l}\text { Nordic Council } \\
\text { of Ministers (1996a) } \\
\text { Società Italiana } \\
\text { di Nutrizione } \\
\text { Umana (1996) } \\
\text { CNERNA-CNRS (2001) }\end{array}$ & & $\begin{array}{l}\text { Average } \\
\text { Requirement }\end{array}$ & $\begin{array}{l}\text { Recommended } \\
\text { Intake } \\
\text { Livelli di Assunzione } \\
\text { Raccomandati di } \\
\text { Nutrienti Intakes (LARN) } \\
\text { Apports Nutritionnels } \\
\text { Conseillés }\end{array}$ & & $\begin{array}{l}\text { Upper Limit } \\
\text { of Intake }\end{array}$ \\
\hline
\end{tabular}

for planning diets or provision of food supplies and for food labelling purposes. In all situations, use of these values applies only to healthy people and presupposes that the dietary requirements for all other nutrients and energy are met.

For individuals it is possible only to estimate the probability of an inadequate intake, as it is not known where in the distribution of dietary requirements the individual is situated. To assess the dietary adequacy of an individual, the mean (habitual) intake of that individual should be measured and compared with the AR. If an accurate enough estimate of habitual intake is available, based on a sufficient number of days in relation to the betweenday variability of intake, then risk can be calculated by taking into account the standard deviation of the requirements in the age group of that individual. Thus, if the difference between habitual intake and AR is more than 2SD above AR, that individual has almost certainly an adequate intake, while she/he will almost certainly have an inadequate diet if the difference is $2 \mathrm{SD}$ below the $\mathrm{AR}$. Smaller differences would lead to a lower probability of adequacy or inadequacy. If an AR is unavailable and an $\mathrm{AI}$ is instead given, it is still possible to say if the intake of an individual is adequate, when intake is above the AI. It is, however, difficult to establish inadequacy. We should keep in mind that we can only state a probability of inadequacy, as the actual requirement of the individual is not known and it is difficult to measure an individual's long-term nutrient intake. If, however, an inadequate intake has been in place for long enough, then biochemical, anthropometric or clinical determinations might indicate the presence of a deficiency of that nutrient.

When the assessment is carried out on a population group, it is possible to calculate the expected proportion of individuals at risk of inadequacy by comparing the distributions of requirements and intakes. For group assessments, as for individual assessments, the AR should be used as reference. The probabilistic approach to risk assessment for groups is illustrated in Fig. 2 and is based on the assumption of a normal distribution of requirements and a normal distribution of intakes for a particular nutrient. If the mean intake in a population is low (curve A), the risk of an individual having an inadequate intake is high, while the risk of adverse effects of high intakes is low. With a population mean intake at the level of the PRI (curve B), the risk of inadequacy for the individual is low, and the risk of adverse effects of high intakes is

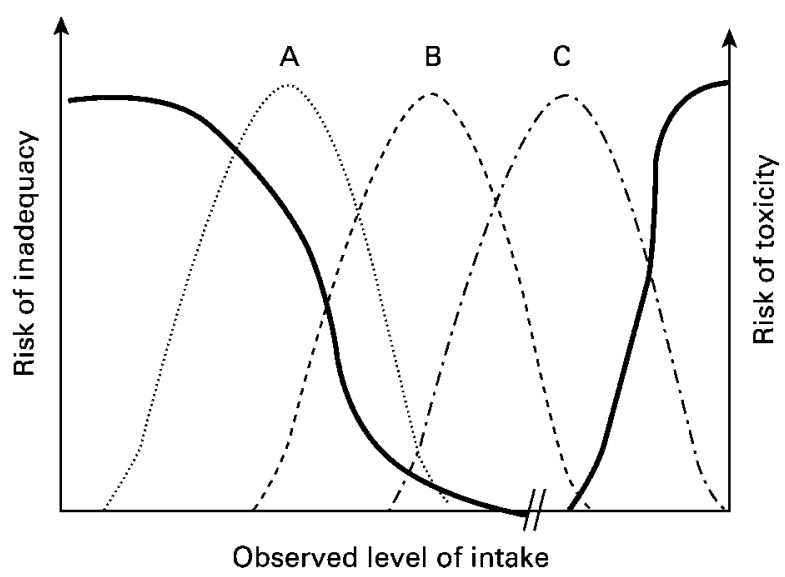

Fig. 2. Risk of inadequacy at different levels of nutrient intake. The risk is indicated for a population with: a low mean intake (curve A), a mean intake equal to the Population Reference Intake (curve B) and a high mean intake (curve $\mathrm{C}$ ). 
also low. Only $2.5 \%$ of the individuals in a population, who may have very high requirements, may be at risk of inadequacy. If the population intake is high (curve $\mathrm{C}$ ), the risk of inadequacy is very low, while some individuals may be at risk of having an intake so high that it has adverse effects, for those nutrients where the ULI is close to the PRI.

Nutritional reference values can also be used for planning the diets of communities or population groups. In this case, one will have to take into account the demographic composition of that community, the environmental conditions and the life-style. Traditionally, such uses have been based on the intake of energy and individual nutrients. However, most people are not able to translate these into the design of their daily diet. This is also a challenge for specialists, since food consumption patterns are influenced by social and cultural factors and can differ even between neighbouring countries.

In the last decade, some international expert groups have advocated for the introduction of Food Based Dietary Guidelines (FBDG), that consider dietary habits and lifestyles of different age groups in each country (FAO/ WHO, 1998). Several countries have since undertaken the design of food-based educational tools, that are accompanied by graphical representations such as food pyramids, circles and boats. A limitation of this approach is that FBDG deal with the food consumed in $24 \mathrm{~h}$. However, food is normally consumed in structured meals and meal habits are influenced even more by cultural backgrounds than total food consumption. To address this, Germany has recently developed Food and Meal Based Dietary Guidelines for children, adolescents and their parents ('Optimix'). These are based on an analysis of present-day dietary practices in these groups and deduce quantitative and qualitative recommendations for food consumption per day and per meal (Alexy et al. 2000).

Use of nutritional recommendations and reference values for labelling purposes is beyond the scope of this paper. It should be noted, however, that although reference values used for labelling are obviously related to those used for nutritional surveillance and planning, there are important distinctions. In the EU, labels report the AR for the adult man or, for products addressed to children, the PRI for children aged 6 months to 3 years. In the USA, food labels report a Daily Reference Value for each nutrient that has been selected by taking the highest RDA for that nutrient from all age and sex groups.

\section{Nutritional recommendations and reference values for children and adolescents}

Additional considerations are required for the development of nutritional recommendations and reference values for children and adolescents. In children, energy and nutrients are required not only for the maintenance of normal function and body stores, as in adults, but also for growth and development. An inadequate dietary supply may result in reduced growth velocity, which can have negative effects on both health and development.

Children also differ from adults in their relationship between the requirements for energy and for nutrients.
While infants and young children typically have an energy requirement that is three times higher than adults' calculated on a body weight basis, the difference in their requirements for other nutrients relative to body weight is not as great. This implies that, for some nutrients, children can cover their needs with a diet that has a lower nutrient density, when expressed per unit energy. The most obvious example is protein, where the requirement of an infant at 12 months is about $1 \mathrm{~g} / \mathrm{kg}$ body weight, while that of an adult is about $0.7 \mathrm{~g} / \mathrm{kg}$ body weight. An infant of 12 months, therefore, can cover the physiological requirement for protein with a diet containing 5-6\% of energy as protein, close to the content of human milk, while an adult male needs about $7-8 \%$.

Furthermore, the relationship between the intake of a given nutrient and the functional outcome of the process in which that nutrient is involved may be different for children and adults. First, nutrient handling is different. A typical example is the relationship between $\mathrm{Ca}$ intake and absorption at different ages, with infants and adolescents having greater absorption efficiency than adults (Matkovic $\&$ Heaney, 1992). Second, the metabolic fate of nutrients may be different. An important example is related to fat intake. There has been a long-standing discussion about when and how to reduce the fat content of the diet relative to energy from the high values characteristic of the first months of life (breast milk has a fat content of about $52 \%$ of energy) to that of the family diet, which is generally recommended to be lower (about 30\%), and with a low proportion of saturated fat, to minimise risks of cardiovascular disease in later life. The concern is that if fat is reduced too early it may affect energy intake and thereby growth. Thus, there has been a discussion about finding an optimal balance between support of early growth and prevention of disease later in life. Most authorities currently consider that the transition should happen slowly and not reach adult values for the amount and quality of fat before the age of 2 or 3 years, but there are still major differences of opinion between countries, reflecting that it is difficult to balance these two considerations.

\section{Methods used to estimate nutritional recommendations and reference values for children and adolescents}

Despite these major biological differences, nutritional requirements are often not specifically determined for children and adolescents, but rather are extrapolated from adult data. Furthermore, methods used to formulate these nutrient requirements are not homogeneous across countries. The different approaches and methodological issues underlying the definition of nutrient requirements in children are briefly summarised below. Although not part of the current review, the approaches used for infants and children under 2 years of age are included for completeness. A more detailed overview has been published recently by the Committee of Nutrition of the European Society for Paediatric Gastroenterology, Hepatology and Nutrition (Aggett et al. 1997).

Intakes of healthy children. Breast-fed infants have been considered the model for estimating the requirements for energy and nutrients of infants between 0 and 6 months 
of age. The content of nutrients in breast milk is not always relevant to non-breast-fed infants, as the bioavailability of many nutrients from infant formulas is lower than from breast milk. Also, there are two nutrients, vitamins $\mathrm{K}$ and $\mathrm{D}$, that may not be provided in sufficient amounts by breast milk, and supplementation is often advised. For older infants (7-12 months), population reference intakes are generally constructed by measuring the combined intake of breast milk and complementary food. For those countries that set population reference intakes for infants, allowance is made for the reduced bioavailability of nutrients from non-breast milk sources and for inter-individual variation, using the mean $+2 \mathrm{SD}$ approach. Thus dietary reference values for infants are applicable to non-breastfed infants only.

Factorial approach. According to the factorial approach, total requirements are divided into those for maintenance and those for growth. Maintenance requirements are derived from estimates of unavoidable losses from the body (urine, faeces, sweat, menstrual blood, semen, etc.) in a steady-state situation. In adults, these estimates are mainly based on experiments where the intake of the nutrient under consideration for a period is negligible. Practically no such data are available for children. The requirements for growth are based on data on body composition and body content of nutrients at different ages. The increase in body content of a nutrient (accretion) from one age to another is multiplied by a factor that takes the metabolic cost of accretion into account. From these data, the daily amount of each nutrient needed for growth is calculated. A major limitation of this approach is the lack of body composition data. Some data are available for infants and adults but there are very limited data available for children and adolescents. The use of dualenergy X-ray absorptiometry in assessing $\mathrm{Ca}$ accretion over a given period is an example of how new technologies can be used as part of the factorial approach.

Balance studies. Balance studies are difficult to perform in infants and young children. While there are some studies in term and pre-term infants, very few studies have been conducted in older children. To extrapolate nutrient requirements from balance studies, subjects should be in equilibrium, i.e. in a steady state, at the intake of the nutrient in question, which is difficult to determine in children with a high growth velocity. The intake should be manipulated such that it balances losses. This is difficult to achieve in children, in whom nutrients are also used for accretion. The length of the study period also depends on the size of the body stores of the nutrient and the rate at which the stores are mobilised. Extreme examples are $\mathrm{Ca}$, with a very large store that is slowly mobilised, and $\mathrm{Zn}$, with relatively small stores that are rapidly mobilised. Some of the difficulties with balance studies can be overcome with the use of stable isotopes. This makes it possible to study the dynamics of specific metabolic pools. It is likely that these methods will provide important information on the requirements of nutrients in the future.

Measures based on functional outcomes. Requirements are often based on a detection threshold below which a specific biological function is impaired. Examples include the dark adaptation test used to evaluate marginal vitamin A deficiency, and the measurement of thyroid size to evaluate the adequacy of long-term I intakes. Indicators of function may also provide information to target requirements to health protection and not just to the prevention of clinical deficiencies. Examples are the evaluation of psychomotor development and cognitive function in infants in relation to $\mathrm{Fe}$ status and, even more challenging, the establishment of requirements on the basis of promoting future good health. This type of argument is used, for example, in the discussion about fat intake and prospective risk of cardiovascular disease. Although, at present, there is insufficient information on which to base dietary recommendations, there is concern about possible relationships between nutritional status in early life and future health risks, particularly in relation to the later development of non-communicable diseases, such as hypertension, obesity, type II diabetes and cardiovascular disease. There is an increasing body of evidence that early growth, both intra-uterine and postnatal, is associated with later risk of these diseases, but the mechanisms are still poorly understood. Although it is likely that nutrition plays an important role, we are still far from understanding the effect of specific nutrients or from defining nutritional reference values on this basis.

Extrapolation from infant and adult data. For many nutrients, information about the requirements of children and adolescents obtained with the above methods is insufficient or non-existent for some age groups, and extrapolation from infant and adult data is used. Although intake measurements can provide data for infants until 1 year of age and balance studies or measures of functional outcomes can be performed in school-aged children, the age group of 1-3 years is the one for whom information is most difficult to collect and it is therefore the group for whom this approach is most frequently used. Examples of nutrients in which such extrapolation is carried out are vitamin $\mathrm{A}, \mathrm{Cr}, \mathrm{Cu}$ and $\mathrm{I}$. The approach for extrapolation suggested used by the USA/Canada (Food and Nutrition Board, 2001) is based on a separate consideration of maintenance needs and growth needs. Maintenance needs are expressed relative to metabolic body weight ([kg body weight $]^{0.75}$ ), while the additional requirements for growth are calculated as the additional amount of the nutrient required for growth. The extrapolation from adult data is then performed as a two-step process: (i) $\mathrm{EAR}_{\text {child }}=$ $\mathrm{EAR}_{\text {adult }} \times F$ and (ii) $F=\left(\text { Weight }_{\text {child }} / \text { Weight }_{\text {adult }}\right)^{0.75}$ $\times(1-$ growth factor $)$, where the growth factor is a value obtained from the proportional increase in protein requirements. The growth factor is 0.3 (i.e. $30 \%$ ) for children aged between 7 months and 3 years, and $0 \cdot 15$ (i.e. $15 \%$ ) for older children.

\section{Factors modifying nutritional recommendations and reference values in children and adolescents}

Physical characteristics: patterns of growth and development. Judgements about the adequacy of dietary intakes in children are based for some nutrients on normal growth. However, doubts can be expressed about which growth pattern is associated with the highest level 
of health and functional performance in the short and long term. Growth velocity differs with age, with the highest growth rates occurring during the first two years of life and during puberty. Some nutrients are essential for growth, like protein, $\mathrm{Zn}$ and $\mathrm{K}$, and a marked reduction in intake will result in an immediate reduction in growth velocity, while deficiencies of other nutrients, like $\mathrm{Fe}$ and vitamin $\mathrm{A}$, do not have the same direct effect on growth (Golden, 1988).

For some nutrients, daily requirements are calculated by multiplying the estimated needs per $\mathrm{kg}$ of body weight by an average weight for the age group, based on a reference population. The reference data used for this calculation differ between countries, and this can be a factor in the differences in dietary reference values between countries. Individual European countries have used either nationally derived reference data or international references. This can lead to some remarkable discrepancies. Differences in the time at which puberty is considered to have started account for some of the major differences in dietary reference values for 9- to 12-year-olds between European countries (see Section 2). In addition, differences in developmental stages have also been described and these interact with growth rates. For example, development is delayed by about two years in growth-retarded children and linear growth can continue well beyond the age of 18 years in children with developmental delay. Developmental differences are also affected by body weight and composition; for example, children with a raised BMI (overweight) have an earlier puberty.

At present, there are no universally accepted growth or developmental reference data and there is disagreement about the appropriateness of applying the same data to different populations. There are increasing attempts to provide some consistency in the use of growth data across Europe. For the estimation of dietary reference values by the Scientific Committee on Food (1993), growth data were obtained by pooling national data sets from nine European countries, weighted on the basis of each country's population at any given age. Data are now available from the Euro-Growth project, a longitudinal, observational study that involved 2245 healthy term infants from twenty-two study centres in eleven European countries (Haschke \& van't Hof, 2000). The Euro-Growth references have been constructed in such a way that factors influencing growth such as breast-feeding, mid-parental height and prematurity can be included in the interpretation of measurements of individual children. However, the EuroGrowth reference data only cover the first three years, and do not extend into later childhood.

A second issue relates to the extent to which growth retardation can be considered to impair function and health, and, therefore, to the emphasis that should be placed on preventing or correcting poor growth. Physical and mental development is delayed in growth-retarded children, and the duration of the maturation period is lengthened (Golden, 1994). Growth-retarded children may have developed adaptive mechanisms that enable them to survive with lower nutrient intakes than other children. Indeed, if their nutrient intake is at the same level as that of children who are growing normally, they may be at increased risk of developing chronic diseases in later life, such as hypertension or impaired glucose tolerance (Barker, 1995; Forsen et al. 2000). Thus, inducing catchup growth by the provision of additional nutrients may be appropriate in some situations and harmful in others.

Factors based on diet and life-style. Other important aspects specific to children and adolescents that can produce differences in nutritional recommendations and reference values are linked to dietary patterns and life-styles. The quality of foods, their combination in different preparations and meal design, their processing and storage will all contribute to differences in nutrient absorption and subsequent metabolic handling, and these concepts need to be taken into account when formulating guidelines.

\section{Section 2: Current nutritional reference values for children and adolescents in Europe}

Appendix A tabulates the current reference intakes for children and adolescents in Europe. In collating this information, the Expert Group had access to a multiplicity of sources representing the reference intakes currently used by twenty-nine of the thirty-nine countries in Europe. These sources are given in the reference list of the present paper and identified in Tables A1-A42 by serial numbers; the preliminary table in Appendix A, entitled 'Description of the dietary reference values in use in Europe', links the references and serial numbers. The five Scandinavian countries (Denmark, Finland, Iceland, Norway and Sweden) considered and published jointly their Nordic nutrient recommendations (NNR) as did the three German-speaking countries, Austria, Germany and Switzerland (DACH-R). In the tables, data from these two sources are given as a single entry each except where different reference values apply within the consortia of countries. Reference values from the EU, the USA, Canada and FAO/ WHO are also included, for comparison. For practical reasons, only the most current reference values for each country and formally published by September 2002 are included. Any document published after this date or undergoing public consultation has not been included in either the tables or the commentaries below. Notable are the recent considerations of upper intake levels (ULI) by the EU Scientific Committee on Food and the UK Expert Committee on Vitamins and Minerals, which were at only the consultation stage in September 2002 and so are not included, but which complement those discussed in the commentaries.

The data are presented as separate tables for energy and for each nutrient. Each table is set out in a similar manner, with the contributing sources listed in the same order. Because the review was limited to children and adolescence, the age range considered was from 2.0 to 18.9 years inclusive. No data on infants and children under 2 years of age are included. Separate entries are given for each year of age (defined as the period between two successive birth anniversaries i.e. 2.0-2.9, 3.0-3.9, etc.), and dark bars show the limits for groups of ages as used in the source material. For clarity, the data for boys and girls are provided either in separate tables or in the same table identified as male value/female value. Values for the general population of adults are given for comparison. 
In all tables, the reference intakes included are those that most closely match the definition by the Scientific Committee on Food (1993) of a population reference intake (PRI), i.e. the amount considered to be sufficient to cover the needs of $97.5 \%$ of the population, or, when a PRI has not been set, the intake that is considered to be safe and adequate. Because of the potential for ambiguity, the name given to the reference intake in the original source material is stated in each table. For brevity, these are referred to generically as 'reference intake'. Some countries have also developed reference values corresponding to a lower threshold intake (LTI) and an upper limit of intake (ULI). Where appropriate, these values are referred to in the commentaries by abbreviation. This classification proved problematic for the electrolytes $(\mathrm{Na}, \mathrm{K}, \mathrm{Cl})$ because the estimated minimum requirement for these nutrients given by a number of countries does not imply a value that is insufficient for $97.5 \%$ of the population. To draw readers' attention to this difficulty, the classifications for these nutrients in the commentaries and tables are given in square brackets.

Below we give brief commentaries on each table prepared by members of the Working Group. The purpose of these commentaries is not to provide a detailed description of the biological functions and essentiality of each nutrient, but to illustrate the diversity of reference values currently in use across Europe, indicate the scientific foundations of the reference values for children and offer, where possible, an explanation for the differences that exist between countries. It should be noted that relatively few source documents provide detailed critiques of the evaluation of evidence that led to the series of reference values for each country.

\section{Energy}

There are considerable differences in the energy reference intakes (Tables A1 and A2) for children and adolescents across Europe. These discrepancies and the fact that countries use different ways of expressing the values lead to considerable variations from country to country, even in neighbouring countries like the Baltic States or between the UK and Ireland.

Reference intakes for energy differ from those of nutrients in that they are set at a level that represents the average energy requirement for the population. The scientific basis for energy reference intakes in children and adolescents varies from country to country. Most countries calculate resting energy expenditure from equations published by WHO in 1985 (Joint FAO/WHO/United Nations University Expert Consultation, 1985), and estimate the energy requirement from the energy intake of healthy children growing normally. An adjustment is made to resting energy expenditure to take account of the different energy requirement at varying levels of activity according to age. To this is added a calculated allowance for the energy cost of growth. More recently, the UK (Department of Health, 1999), France (CNERNA-CNRS, 2001) and Austria-Germany-Switzerland (DACH, 2000) have used the 'doubly labelled water' technique (Ritz \& Coward, 1995), or the recording of cardiac rate in children, to try to improve accuracy and specificity of the measurement of energy expenditure and to improve the overall reference intake. In spite of this, the respective reference intakes are different from each other and are well within the range of reference intakes made by those countries that have not based their estimates on direct measurements. Certain countries give a different reference intake for males and females from the second year of age onwards, while others give the same reference intake for both sexes in early childhood but separate them in later childhood and in adolescence to take account of the greater requirements of males. The Austria-Germany-Switzerland reference intakes (DACH, 2000) also make allowance for differing levels of physical activity.

The differences in energy reference intakes across Europe are not systematic. The discrepancies can largely be explained by differences in the way the age groups are aggregated. Certain countries give a different value for each year of age between 2 and 18 years; others aggregate three or four years together. When age groups are aggregated, the energy requirement will be over-estimated at the lower end of the group and under-estimated at the higher end. Because the cut-offs between age groups differ between countries and certain ages can fall either side of an age boundary depending on the country, some comparisons of energy reference intakes at each age are made between an under-estimated value in a younger age band in one country and an over-estimated value in an older age band in another. For example, at age 10 years, the reference intake for girls ranges from 7.3 MJ/d (Department of Health, 1999) to $10 \cdot 5 \mathrm{MJ} / \mathrm{d}$ (Institute of Public Health, 1990; Catovic et al. 2000).

\section{Macronutrients}

\section{Protein}

Protein reference intakes (Tables A3-A6) are expressed differently in different countries, either as $\mathrm{g} / \mathrm{d}$ or $\mathrm{g} / \mathrm{kg}$ per $\mathrm{d}$, and often without an indication of a representative weight at each age to allow conversion of one to the other. For clarity, data are presented in Tables A3-A6 according to the original mode of expression in the source material.

The basis on which protein reference intakes have been established in many Western European countries and in North America is roughly the same. The values are based on the factorial method (Joint FAO/WHO/United Nations University Expert Consultation, 1985) and on the assumption that children have a similar mean maintenance requirement to adults when expressed relative to body weight. An allowance is added to take account of the protein costs of growth, estimated from body composition and growth velocity measurements. Despite such a similar basis of evaluation, there are substantial differences between reference intakes at different ages across these countries. These can be ascribed largely to differences in the corrections used to take account of: (i) day-to-day variability in growth, (ii) the efficiency of dietary proteins for specific protein synthesis in the body and (iii) the relative quality of dietary proteins $v$. reference protein (milk or egg protein). In other 
European countries, especially the Balkan, Baltic and Nordic countries (Nordic Council of Ministers, 1996b) and in Austria-Germany-Switzerland (DACH, 2000), protein requirements are calculated as a fixed percentage of estimated energy requirements. These values depend on the selected value for this percentage (commonly 10$15 \%$ but $8-10 \%$ in Austria-Germany-Switzerland; $\mathrm{DACH}, 2000)$ and are generally higher than requirements estimated directly. In reality, however, protein reference intakes based on either method of estimation are well below actual protein consumption in Europe or North America. These are about $40 \mathrm{~g} / \mathrm{d}$ at 2 years (about $3.5 \mathrm{~g}$ / $\mathrm{kg}$ per d), $60 \mathrm{~g} / \mathrm{d}$ at 3 years (above $3 \mathrm{~g} / \mathrm{kg}$ per d) and exceed $100 \mathrm{~g} / \mathrm{d}$ at $13-15$ years, corresponding to quantities three to five times higher than recommended. It was stated in the Nordic recommendations (Nordic Council of Ministers, 1996a) that they felt it would be unrealistic to plan diets with lower protein values. Few countries differentiate between males and females in the reference intake for protein expressed on a body weight basis, but this leads to differences expressed as a daily intake in adolescence, with higher reference intakes for males. No country gives guidance about an LTI or ULI for protein that is specific to children.

\section{Lipids}

The reference intakes for lipids are presented in several ways. Those in Tables A7-A10 are expressed as a percentage of energy intake, and are given for total fat, total PUFA, $n-6$ PUFA and $n-3$ PUFA.

Total fat. Although reference intakes for total fat only expressed as percentage of energy intake are given in Table A7, a small number of countries also give guidance for the intake of total saturated fatty acids, total MUFA and total trans isomeric fatty acids. In general, current reference intakes for total fat limit intake to about $30-35 \%$ of total energy intake. Only three countries set a value that is lower than $30 \%$ of energy intake (Ukrainian Ministry of Health; Battelino, 1998; Health Council of The Netherlands, 2001). Several countries allow for a relatively higher fat intake in younger age groups, usually without a clear explanation (it should be re-emphasised that the period covered in this review does not include infancy). Data for boys and girls are discussed separately by only two countries: Poland (Ziemlanski et al. 1996) and Lithuania (Ministry of Health, 2000). No countries have set an LTI or ULI for total fat.

Only the Nordic countries (Nordic Council of Ministers, $1996 a$ ) indicate a specific target range (10-15\%) for total MUFA intake. Guidance on intakes of saturated and trans isomeric fatty acids is given as an upper limit of intake. Recommendations for total saturated fatty acids expressed as percentage of energy intake are given by four countries (Ministry of Health, 1994; DACH, 2000; CNERNACNRS, 2001; Health Council of The Netherlands, 2001). With the exception of France (CNERNA-CNRS, 2001), most countries give $10 \%$ as the upper limit. France sets the limit in the range of $8-12 \%$. As to trans isomeric fatty acids, only Austria-Germany-Switzerland (DACH, 2000) gives an explicit recommendation for children and adolescents that intake should not exceed $1 \%$ of energy intake. Although the Nordic countries (Nordic Council of Ministers, 1996a) do not provide guidance specifically for trans isomeric fatty acids, it limits hard fatty acid intake (defined as saturated fatty acids + trans isomeric unsaturated fatty acids) to less than $10 \%$ of energy intake.

Total PUFA. Different countries express their guidance for total PUFA in different ways, resulting in apparent discrepancies of over fourfold (Table A8). Poland (Ziemlanski et al. 1996) sets a minimum intake (3\% of energy intake), the Nordic countries (Nordic Council of Ministers, 1996a) set a target range of PUFA intakes (5$10 \%$ ) whereas The Netherlands (Health Council of The Netherlands, 2001) defines a ULI for PUFA intake (12\% of energy intake). In contrast, the considerably higher recommendation given by Hungary (György \& Károly, 1999) for children aged less than 3 years may be due to the fact that their guidance covers the period of 1 to 3 years, i.e. it is close to infancy. With the exception of Hungary (György \& Károly, 1999), no age-related modification of PUFA intakes is considered necessary by any European country.

n-6 PUFA. In those countries that provide one, reference intakes for $n-6$ PUFA are expressed variously as a percentage of energy intake (Table A9) and as g/d (EU: Scientific Committee on Food, 1993; Belgium: Conseil Supérieur d'Hygiène, 2000; Italy: Società Italiana di Nutrizione Umana, 1996; Canada: Minister of National Health and Welfare, 1990). The reference intake for $n-6$ PUFA expressed as a percentage of energy intake is in the range of $2-4 \%$ in most countries. After $2-3$ years of age, most countries set a slightly lower reference intake for $n-6$ PUFA, expressed as percentage of energy intake, except for Italy where it is higher. Italy also gives different reference intakes for boys and girls after 10 years, in spite of the fact that the reference intake is expressed as percentage of energy intake, which acts to normalise for differences in body size. When expressed as $\mathrm{g} / \mathrm{d}$, all countries that set a reference intake for $n-6$ PUFA allow for an increase with age and for a higher intake in boys than in girls. The increase with age is mostly between 25 and $50 \%$ (EU, Belgium, Italy). This contrasts with Canada, which allows for an increase of $100 \%$ by 10 years of age as well as a further $75 \%$ enhancement by the age of 16 years. No country provides guidance on a ULI for $n$ - 6 PUFA intake.

Three countries - France (CNERNA-CNRS, 2001), the UK (Department of Health, 1999) and The Netherlands (Health Council of The Netherlands, 2001) - set a reference intake for linoleic acid (data not shown). The reference intake for linoleic acid, expressed as a percentage of energy intake, is $1 \%$ (UK), $2 \%$ (The Netherlands) and $2-5 \%$ (France), without adjustment for age or sex.

$n-3$ PUFA. Reference intakes for $n-3$ PUFA are expressed both as percentage of energy intake (Table A10) and as g/d (EU: Scientific Committee on Food, 1993; Belgium: Conseil Supérieur d'Hygiène, 2000; Italy: Società Italiana di Nutrizione Umana, 1996; Canada: Minister of National Health and Welfare, 1990). Three countries - France (CNERNA-CNRS, 2001), the UK (Department of Health, 1999) and The Netherlands (Health Council of The Netherlands, 2001) - also give specific reference intakes for $\alpha$-linolenic acid intakes 
(data not shown). Expressed as a percentage of energy intake, most countries suggest that $n-3$ PUFA intakes should be maintained over $0.5 \%$ of total energy intake. No modification according to age or sex is indicated. Expressed as $\mathrm{g} / \mathrm{d}$, those countries that set a reference intake give $0.7 \mathrm{~g} / \mathrm{d}$ intake up to the age of 4 years and $1 \mathrm{~g} / \mathrm{d}$ intake thereafter up to the age of 7 years. There is considerable diversity in the way that the reference intake, expressed as $\mathrm{g} / \mathrm{d}$, changes with age and varies between boys and girls. The reference intake set by Italy (Società Italiana di Nutrizione Umana, 1996) and Belgium (Conseil Supérieur d'Hygiène, 2000) increases considerably with age and, after 15 years, is $50 \%$ higher in boys than in girls. On the other hand, Canada (Ministry of National Health and Welfare, 1990) allows for a gradual increase in $n-3$ PUFA intake in boys at the ages of 7,10 and 13 years, as well as a one-step increase for girls at the age of 10 years. The other three countries that set a reference intake indicate that $n$ - 3 PUFA intake should be enhanced by $50 \%$ in boys at the age of 15 years, but not in girls, to take account of their higher energy requirements.

Several data sources state that $n-6$ PUFA: $n-3$ PUFA, which represents a classical parameter in recommendations for fatty acid intakes, should be kept under 5:1 (DACH, 2000) or at least under 13:1 (e.g. Italy). However, in each case, this is given as a general recommendation and it is questionable whether it should be regarded as applying to children. With the exception of $n-6: n-3$ PUFA, no ULI for $n-3$ PUFA intake is indicated by any country.

The reference intake for $\alpha$-linolenic acid expressed as percentage of energy intake is set at $0.2 \%$ (UK), $1 \%$ (The Netherlands) and 0.4-1\% (France) with no adjustment for age or sex.

\section{Carbohydrates (starches and sugars)}

Reference intakes for carbohydrates are generally set at an amount that balances the dietary energy not provided by the other macronutrients. Relatively few European countries define specific reference intakes for carbohydrates. When they are defined, they are expressed either as $\mathrm{g} / \mathrm{d}$ or as a percentage of energy intake. Both sets of data are given in the tables (Tables A11 and A12). In addition, sugars are defined variously as simple sugars (CNERNA-CNRS, 2001), refined sugars (Nordic Council of Ministers, 1996b), saccharose (Ziemlanski et al. 1996) and non-milk extrinsic sugars (Department of Health, 1999) which, when discussed, are recommended to contribute not more than $10 \%$ to energy intake (e.g. UK: Department of Health, 1999 ) or guidance is given 'to be moderate' (DACH, 2000).

Where set, reference intakes for children and adolescents are identical to those for adults. Some countries make small adjustments for gender and physical activity levels. However, in young children some set a higher reference intake for fat to allow for the higher energy density needed to facilitate optimal growth. Therefore the reference intake for carbohydrates may be lower for young children. Notable exceptions to the use of the macronutrient balance approach make estimates of the amount of glucose required for optimal central nervous system function, e.g. the USA/Canada (Food and Nutrition Board, 2002), or of endogenous glucose production to minimise breakdown of body protein, e.g. The Netherlands (Health Council of The Netherlands, 2001). The latter approach produces significantly lower values compared with other methods used. For children over 2 years of age, both approaches provide reference intakes that are similar or identical to those for adults. No reference intakes have been set based on glycaemic index, due to the lack of sufficient evidence in generally healthy individuals.

Guidance for non-milk extrinsic sugars is generally based on the association between frequency of intake and dental caries, translated into a percentage of the energy reference intake. Concerns about the dilution of micronutrient density are also given as reasons to limit addition of free simple sugars to the diet. The recently published reference intakes for the USA/Canada (Food and Nutrition Board, 2002) found insufficient data for an evidencedbased ULI for simple sugars. However, this evaluation suggested a 'maximal intake level' of $25 \%$ or less of energy from added sugars, based on possible dilution of micronutrient density above this level of intake.

\section{Fibre/NSP}

Differences of more than tenfold in reference intakes of dietary fibre for children and adolescents exist across Europe (Table A13). Consensus on the reference intakes for dietary fibre has been limited by a lack of agreement on the definition of dietary fibre and differences in analytical techniques. The two most commonly used analytical definitions are NSP and total fibre as measured by the method defined by the Association of Official Analytical Chemists. NSP methodology identifies a chemically defined fraction of the dietary fibre, which can be subdivided into soluble and non-soluble fractions. The Association of Official Analytical Chemists' methodology includes retrograded starch and lignin, giving higher values than NSP for a given food. The recent evaluation for USA/Canada (Food and Nutrition Board, 2002) defines dietary fibre as 'nondigestible carbohydrates and lignin that are intrinsic and intact in plants'. They also introduced the concept of functional fibre, defined as 'isolated, nondigestible carbohydrates that have been shown to have beneficial physiological effects'. Total fibre is the sum of dietary and functional fibre.

The estimation of fibre reference intakes in adults is based on the amount required to promote normal laxation and the levels associated with reduced risk of cardiovascular disease, some cancers and adult-onset diabetes. In the $\mathrm{UK}$, the reference intake is based on the occurrence of small stool weights at low NSP intakes, which is associated with increased risk of bowel disease (Department of Health, 1999). The recent USA/Canada evaluation (Food and Nutrition Board, 2002) used intakes considered to provide the greatest protection against coronary heart disease calculated from median energy intakes. Reference intakes given for adult populations are normally about $18 \mathrm{~g} / \mathrm{d}$ (NSP) or $25-30 \mathrm{~g} / \mathrm{d}$ (Association of Official Analytical Chemists). This may be expressed in terms of $\mathrm{g} / \mathrm{d}$ (Department of Health, 1999; CNERNA-CNRS, 2001), g/kg body weight (Ministry of Health, 2000) or percentage of energy 
intake (Nordic Council of Ministers, 1996a,b; DACH, 2000). Where values are given for children, they are mostly adult values expressed on a body weight or energy intake basis (Ministry of Health, 1994; Nordic Council of Ministers, 1996a,b; Ministry of Health, 2000). Exceptions are Portugal, which gives progressively increasing daily crude fibre values (Trichopoulou \& Vassilakou, 1990), and Italy (Società Italiana di Nutrizione Umana, 1998) and France (CNERNA-CNRS, 2001), who use the 'Age +5 ' concept. The latter states that children older than 2 years of age should consume, as a minimum, an amount of dietary fibre equivalent to their age in years plus $5 \mathrm{~g} / \mathrm{d}$. This allows for an increase in fibre intake at a rate of $1 \mathrm{~g}$ per annum. The variation in reference intakes across Europe can be explained by differences in interpretation of the evidence base, in the use of different disease end-points and in the analytical methodology used.

Only a few countries in Europe set either an LTI or a ULI for dietary fibre. A safe range for children is considered to be between age in years plus 5 and age in years plus $10 \mathrm{~g} / \mathrm{d}$ (Tables - Società Italiana di Nutrizione Umana, 1998; CNERNA-CNRS, 2001). This range of dietary fibre intake is considered to be safe even if intake of some vitamins and minerals is marginal, should provide enough fibre for normal laxation, and may help prevent future chronic disease. In the USA/Canada, it is considered that there are insufficient data to set a ULI for either dietary or functional fibre (Food and Nutrition Board, 2002).

\section{Water-soluble vitamins}

\section{Thiamin (vitamin $B_{1}$ )}

The thiamin reference intakes for children across Europe vary two- to threefold at each age (Table A14). Most countries draw a distinction between boys and girls in adolescence, some only at the older ages, as a consequence of their higher energy intake. The exceptions are Latvia (Ministry of Welfare, 2001), Spain (Departamento de Nutrición de la Universitad Complutense, 1995), Slovenia (Battelino, 1998) and The Netherlands (Health Council of The Netherlands, 2000). Estimates of average requirements for thiamin, and hence reference intakes, use data extrapolated from adults, based on the assumption that the thiamin requirement is the same at all ages when expressed per unit energy intake. This assumption is supported by a limited number of studies measuring thiamin status in children on typical diets, by adult data on intakes required to prevent beriberi, and by changes in biochemical status during adult depletion-repletion experiments. Differences between countries can be accounted for largely by differences in the body weight and energy intake assumptions made at each age, and in the definition of the age bands. Only the UK (Department of Health, 1999) and the Nordic countries (Nordic Council of Ministers, 1996a), for age 15 years and above only, define an LTI for thiamin that is specific for children and none sets a ULI.

\section{Riboflavin (vitamin $B_{2}$ )}

The range of riboflavin reference intakes for children across Europe is up to two- to threefold at each age
(Table A15). Reference intakes for children are extrapolated from adult values or by interpolation between the values for breast-fed infants and those for adults. Reference intakes in adults are based on a combination of criteria such as erythrocyte glutathione reductase activity coefficient, urinary riboflavin excretion and red-cell riboflavin level. The red-cell riboflavin concentration is currently regarded as the most stable and sensitive method. Limited studies in children, based on urinary riboflavin excretion at different levels of daily riboflavin intake, suggest that their riboflavin needs are, like in adults, proportional to energy intake, at about $0.5 \mathrm{mg} / 1000 \mathrm{kcal}(0 \cdot 12 \mu \mathrm{g} / \mathrm{MJ})$. Setting requirements against energy needs allows for the increase in riboflavin requirement that occurs during periods of rapid growth and intense physical activity. Only the UK (Department of Health, 1999) and the Nordic countries (Nordic Council of Ministers, 1996a), for ages 15 years and above only, define an LTI for riboflavin that is specific for children and no European country sets a ULI.

\section{Niacin}

Niacin reference intakes for children across Europe range two- to fourfold at each age (Table A16). Most countries draw a distinction between boys and girls in adolescence, some only in the older ages, as a reflection of their higher energy intake. The exceptions are Latvia (Ministry of Welfare, 2001), Spain (Departamento de Nutrición de la Universitad Complutense, 1995), Slovenia (Battelino, 1998) and FAO/WHO (Joint FAO/WHO Expert Consultation, 2002). Estimates of average requirement for children and adolescents, and hence reference intakes, for niacin are based on data extrapolated from adults, which includes clinical observations on intakes required to prevent pellagra and biochemical information from depletion-repletion experiments. Extrapolation is generally on an energy intake basis, although, unlike thiamin, there is no evidence of a relationship between niacin requirement and energy expenditure despite theoretical justifications for this approach (Food and Nutrition Board, 1998). Differences between European countries can be accounted for largely by differences in the body weight and energy intake assumptions made at each age, and in the definition of the age bands. Only the UK (Department of Health, 1999) and the Nordic countries (Nordic Council of Ministers, 1996a), for ages 15 years and above only, define an LTI for niacin that is specific to children. Moreover, only one European country - The Netherlands - sets a ULI (Health Council of The Netherlands, 2000), as does the USA/Canada (Food and Nutrition Board, 1998).

\section{Vitamin $B_{6}$}

The range in reference intakes for vitamin $\mathrm{B}_{6}$ for children across Europe is up to threefold at each age (Table A17). Most countries draw a distinction between boys and girls in adolescence, some only at older ages, as a reflection of their higher protein and energy intake. The exceptions are Latvia (Ministry of Welfare, 2001) and Slovenia (Battelino, 1998). Many vitamin $\mathrm{B}_{6}$ reference intakes for children and adolescents are set relative to protein intake, 
the assumption being that the relationship is the same in children as in adults. Conversion to $\mathrm{mg} / \mathrm{d}$ is generally made by assuming that a typical percentage of energy intake is derived from protein (e.g. $15 \%$ ) and then using age-specific energy expenditures. The adult reference intakes for vitamin $\mathrm{B}_{6}$ are based on changes in biochemical markers during depletion-repletion experiments. These assumptions have been challenged by the USA/Canada (Food and Nutrition Board, 1998), who estimated reference intakes using an alternative method but still extrapolated from adults to obtain values for children. Differences in reference intakes between countries can be ascribed to differences in assumptions made about the proportion of energy derived from protein and energy expenditure at each age, and in the definition of the age bands. Only the UK (Department of Health, 1999) and the Nordic countries (Nordic Council of Ministers, 1996a), for ages 15 years and above only, define an LTI for vitamin $\mathrm{B}_{6}$ that is specific for children and no European country sets a ULI, unlike the USA/Canada (Food and Nutrition Board, 1998).

\section{Vitamin $B_{12}$}

Across Europe, the range in reference intakes for vitamin $\mathrm{B}_{12}$ is up to two- to fourfold at each age (Table A18). Reference intakes for children and adolescents are extrapolated from adult values in similar way to other group B vitamins or interpolated between infant and adult values. Reference intakes for adults are based on the amount of vitamin $\mathrm{B}_{12}$ necessary to maintain normal haematological status and concentrations of serum $\mathrm{B}_{12}$ and methylmalonic acid. Reference intakes for infants are based on normal breast milk content and on the daily supplement $(0 \cdot 1 \mu \mathrm{g} /$ $\mathrm{kg}$ ) necessary to cure megaloblastic anaemia in breast-fed infants of vegan mothers. Only the UK (Department of Health, 1999) and the Nordic countries (Nordic Council of Ministers, 1996a), for ages 15 years and above only, define an LTI for vitamin $\mathrm{B}_{12}$ that is specific for children and none sets a ULI.

\section{Folate}

Reference intakes for folate are sometimes given as dietary folate equivalents (DFE), which adjust for the approximately $50 \%$ lower bioavailability of food folate $v$. folic acid (Food and Nutrition Board, 1998). Reference intakes for children and adolescents across Europe vary considerably, with differences of up to fivefold occurring at certain ages (Table A19). These are constructed by interpolation between infant and adult values (Ministry of National Health and Welfare of Canada, 1990; Netherlands Food and Nutrition Council, 1992; Food and Nutrition Board, 1998; Department of Health, 1999). Adult reference intakes for folate requirements are derived in a number of ways. Some are based on estimates of the folate intake required to reverse folate deficiency, with appropriate adjustments for bioavailability and individual variability (Scientific Committee on Food, 1993; Ministry of Public Health, 2000). Others are derived with reference to intakes of populations that show no signs of clinical deficiency (Ministry of National Health and Welfare of Canada, 1990; Department of Health, 1999). Alternatively, controlled metabolic studies are used to determine a maintenance intake level, with erythrocyte folate and homocysteine concentrations as end-points, after appropriate adjustments for variability and bioavailability (Food and Nutrition Board, 1998). Reference intakes for infants are generally based on the amount in breast milk $(\sim 50 \mu \mathrm{g} / \mathrm{l})$ and on experimental data indicating that diets providing $3.6 \mu \mathrm{g}$ of folate $/ \mathrm{kg}$ body weight per $\mathrm{d}$ are nutritionally adequate for young children up to 2 years of age (Ministry of National Health and Welfare of Canada, 1990; Food and Nutrition Board, 1998; Department of Health, 1999). Variation in reference intakes across Europe appears to reflect the application of different evidence bases, estimates of bioavailability (Netherlands Food and Nutrition Council, 1992; Ziemlanski et al. 1996) and the perceived need to maintain elevated intakes to protect against neural tube defects in some countries (Food Safety Authority of Ireland, 1999). Only the UK defines an LTI for folate that is specific to children and no European country sets a ULI, unlike the USA/Canada. In 2000, the European Commission's Scientific Committee on Food (2000) published an opinion on ULIs for folate: 'Although there is no conclusive evidence in humans, there is a risk of misdiagnosis of vitamin $\mathrm{B}_{12}$ deficiency at intakes of $5 \mathrm{mg} /$ day of folic acid (LOAEL). An uncertainty factor of 5 is applied to derive a ULI for adults of $1,000 \mu \mathrm{g} /$ day folic acid. ULIs for children and adolescents are derived relative body weight. There is no evidence for risk associated with high intakes of naturally occurring folates.'

\section{Pantothenic acid}

Comparatively few countries provide a reference intake for pantothenic acid. For those that do, the values for children vary up to twofold (Table A20). Adults consume 3-12 mg pantothenic acid daily and such intakes appear to be adequate. No European country has set an LTI or ULI for pantothenic acid.

\section{Biotin}

In several countries biotin requirements are not mentioned and in others only as safe level of intake (Table A21). Adults consume between 15 and $100 \mu \mathrm{g} / \mathrm{d}$ and such intakes are sufficient to prevent biotin deficiency. No European country has set an LTI or ULI for biotin.

\section{Vitamin $C$}

There are major differences between countries in vitamin $\mathrm{C}$ reference intakes for children (Table A22). For the youngest age groups, the range of reference intakes is $15-60 \mathrm{mg} / \mathrm{d}$, and a two- to threefold range exists at older ages. While the lower of these values is mainly defined as the intake that can prevent deficiency symptoms, the reference intake in most countries is based on an estimate of an optimal level that can strengthen the immune system and prevent degenerative chronic disease. However, the data available to estimate such an optimal intake are very limited. Estimates for children have been interpolated from infant and adult values. Only the UK (Department of Health, 1999) defines an LTI for vitamin C and no 
European country sets a ULI, unlike the USA/Canada (Food and Nutrition Board, 2000).

\section{Fat-soluble vitamins}

\section{Vitamin A}

Vitamin A reference intakes for children and adolescents vary two- to threefold across Europe (Table A23). Reference intakes of vitamin $A$ are expressed as retinol equivalents (RE) that take into account retinol, which comes essentially from animal foodstuffs, and carotenoids, which are derived mainly from plant foods. The present consensus is that $6 \mu \mathrm{g}$ of $\beta$-carotene and $12 \mu \mathrm{g}$ of other provitamin A carotenoids are equivalent to $1 \mu \mathrm{g}$ of retinol. Despite the provitamin A activity of carotenoids, their absence of toxicity and their specific properties, particularly of $\beta$-carotene (e.g. antioxidant activity and potential preventative action against several types of cancer), there are currently no reference intakes in Europe for carotenoids, independently of retinol. The advice is generally limited to support for a greater reliance on fruits and vegetables as sources of vitamin A activity.

As there are no specific data, reference intakes in childhood are based on a progressive transition between values for infants, calculated from the composition of breast milk, and for adults, based on estimates of intake to achieve adequate vitamin A status. Although it is now recognised that serum retinol concentration is of little value in evaluating vitamin A status and that the vitamin A content of the liver is the best index of status, the available data are very limited. Other methods such as the 'relative doseresponse test' and the oral dose necessary to maintain serum retinol concentration above $30 \mu \mathrm{g} / 100 \mathrm{ml}$ have been proposed.

Only countries such as UK and the Nordic countries, for ages 15 years and above only, define an LTI for vitamin A. In addition, only one European country (Department of Health, 1999) and the USA/Canada (Food and Nutrition Board, 2001) set a ULI for vitamin A that is specific for children at each age, in recognition of the risks of acute and chronic toxicity of excessive vitamin A intakes.

\section{Vitamin D}

Vitamin D is not an essential nutrient unless there is limited exposure of the skin to sunlight of the wavelengths required for endogenous synthesis. Opinions are divided about how to account for the relative contributions of endogenous synthesis of vitamin D under the action of sunlight and of dietary vitamin D. Some advocate setting a reference intake and indicating that this may only apply to those with limited sunshine exposure (e.g. USA/ Canada: Food and Nutrition Board, 1997), some take the view that no reference intake is necessary except for those at risk of limited sunshine exposure (e.g. UK: Department of Health, 1998) while others take a position between these two extremes. Because of the differences in philosophy, in Europe there are large differences in reference intakes (Table A24), generally depending on the wording, in the range of $0-15 \mu \mathrm{g} / \mathrm{d}$. Vitamin D reference intakes in children and adolescents are generally not based on data from children and the values are often the same as given for young adults. Some countries allow for higher requirements during adolescence, such as Italy (Società Italiana di Nutrizione Umana, 1996), Ireland (Food Safety Authority of Ireland, 1999) and the EU (Scientific Committee for Food, 1993); and others for higher dietary requirements in younger children, e.g. Poland (Ziemlanski et al. 1996) and the UK (Department of Health, 1999). No distinction is drawn between boys and girls at any age. It is recognised that more research is needed on the definition of optimal vitamin D status in childhood/adolescence and on the importance of dietary vitamin $\mathrm{D}$ in achieving it in different environments. Variations between European countries reflect differences in philosophy about how to account for the relative contributions of endogenous synthesis of vitamin $\mathrm{D}$ under the action of sunlight and of dietary vitamin D. Some differences are due to provision being made for the possibility of increased vitamin D requirements during adolescence and in younger children. No country sets an LTI for vitamin D. Two European documents (DACH, 2000; Health Council of The Netherlands, 2000) and the USA/Canada (Food and Nutrition Board, 1997) set a ULI.

\section{Vitamin E}

Although there is some variation, there is comparative consistency in vitamin $\mathrm{E}$ reference intakes for children and adolescents around Europe (Table A25). Vitamin E activity is generally expressed in terms of the equivalent amount of the biologically most active form, RRR- $\alpha$-tocopherol. The vitamin E:PUFA intake also represents a traditional expression of vitamin E requirement. Several countries, e.g. Italy (Società Italiana di Nutrizione Umana, 1996) and the USA (Food and Nutrition Board, 2002), emphasise the need to consider vitamin $\mathrm{E}$ intake in relation to PUFA intake and suggest that vitamin $\mathrm{E}$ intake should exceed $0.4 \mathrm{mg}$ vitamin $\mathrm{E}: 1 \mathrm{~g}$ PUFA. It is unclear, however, whether this is a general recommendation or is specific for children. All countries that set a reference intake for vitamin $\mathrm{E}$ indicate the need for a $100-150 \%$ increase in dietary vitamin $\mathrm{E}$ intakes between the ages of 2 and 18 years. Most countries set a 10-25\% higher reference intake for boys than for girls, and in the case AustriaGermany-Switzerland (DACH, 2000) this differential applies from 2 years of age. No European country defines an LTI for vitamin E and only Austria-Germany-Switzerland sets a ULI, as do the USA/Canada (Food and Nutrition Board, 2000).

\section{Vitamin $K$}

Few European countries provide a dietary reference intake for vitamin K (Table A26), and mostly only in the form of a guideline. For these countries, values for children vary over a range of two- to fourfold. USA/Canada (Food and Nutrition Board, 2001) stands out as having higher reference values for vitamin $\mathrm{K}$ than Europe. Few countries give a scientifically argued case for the guideline. Those that do generally assume an adult daily allowance of $1 \mu \mathrm{g} / \mathrm{kg}$ body weight and extrapolate to children using 
typical weights at different ages. Differences between countries largely reflect variations in body weight assumptions, and in the definition of the age bands. Several countries draw a distinction between boys and girls in adolescence, generally in the older age bands. The USA/ Canada (Food and Nutrition Board, 2001) sets a guideline for pregnant and lactating girls 18 years or younger that is lower than that for adult women, but no European country makes this distinction. No country has set an LTI or a ULI for vitamin $\mathrm{K}$.

\section{Minerals and trace elements}

\section{Calcium}

The range in $\mathrm{Ca}$ reference intakes for children and adolescents across Europe is two- to threefold at each age (Table A27). Only a few countries have different values for boys and girls, and only during adolescence. A few countries set a higher value for pregnancy and lactation in girls 18 years or younger than for adult women. Estimates of average requirements for $\mathrm{Ca}$, and hence reference intakes, are based on the factorial approach. Ca accretion is estimated by interpolating data from a limited number of cadaver studies in babies and adults, from balance studies and, more recently, especially for pubertal children, from studies using dual-energy X-ray absorptiometry. Estimates of $\mathrm{Ca}$ absorption, excretion and dermal losses are made from adult data with inference about adaptation during periods of high $\mathrm{Ca}$ requirement. There is no country that stands out as being different in the concept or approach adopted. Discrepancies between countries are due to differences in assumptions made about absorption, excretion and growth rates in children, the magnitude of obligatory losses and the ages at which requirements change. Ca reference intakes for children are largely based on data from children (accretion) but more data are needed to provide evidence of absorption, excretion and dermal losses in different environments and with different diets. Only the UK (Department of Health, 1999) and the Nordic countries (Nordic Council of Ministers, 1996a), for ages 15 years and above only, define an LTI for Ca that is specific to children and, among European countries, only The Netherlands (Health Council of The Netherlands, 2000) sets a ULI, as does the USA/Canada (Food and Nutrition Board, 1997).

\section{Magnesium}

The $\mathrm{Mg}$ reference intakes for children at each age range two- to threefold across Europe (Table A28). Some countries have different values for boys and girls, but only during adolescence. In those countries where they make a distinction, higher values tend to be given for girls in the early years of puberty but higher values for boys later in adolescence. A few countries set a higher value for pregnancy and lactation in girls aged 18 years or younger than in adult women. Most estimates of average requirement, and hence reference intakes, for $\mathrm{Mg}$ are based on a limited number of balance studies conducted in adults and adolescents with extrapolation to children on a body weight basis. The recent FAO/WHO values (Joint FAO/
WHO Expert Consultation, 2002) also draw on data from studies on the $\mathrm{Mg}-\mathrm{K}$ relationships in muscle and the clinical rehabilitation of children with protein-energy malnutrition. Differences between countries can be accounted for largely by differences in the body weight assumptions made at each age, and in the definition of the age bands. Only the UK (Department of Health, 1998) defines an LTI for Mg and no European country sets a ULI that is specific to children, unlike the USA/Canada (Food and Nutrition Board, 1997).

\section{Phosphorus}

The range in $\mathrm{P}$ reference intakes for children and adolescents across Europe is three- to fourfold at each age (Table A29), paralleling but greater than the range of differences in $\mathrm{Ca}$ reference intakes. The Russian Federation (Ministry of Health Care, 1991) has reference intakes considerably above other countries for children aged 4 years and older. A few countries have different values for boys and girls, and only during adolescence. A few countries set a higher value for pregnancy and lactation in girls 18 years or younger than in adult women. Estimates of average requirements for $\mathrm{P}$, and hence reference intakes, assume that there is an optimal $\mathrm{Ca}: \mathrm{P}$ in the diet. Using this ratio, $\mathrm{P}$ reference intakes are based on the reference intakes for $\mathrm{Ca}$. In the older documents, $\mathrm{Ca}: \mathrm{P}$ of $1: 1 \mathrm{mg} / \mathrm{mg}$ was taken as optimal; more recent evaluations of reference intakes are based on a ratio of $1: 1 \mathrm{mmol} / \mathrm{mmol}(1 \cdot 3: 1 \mathrm{mg} /$ $\mathrm{mg})$. Reference intakes for children are based largely on data from children ( $\mathrm{Ca}$ accretion) but the suitability of the assumption about optimal $\mathrm{Ca}: \mathrm{P}$ for children needs research. Variations between countries lie in the differences in $\mathrm{Ca}$ reference intakes and in choice of optimal Ca:P. Only the UK (Department of Health, 1999) and the Nordic countries (Nordic Council of Ministers, 1996a), for ages 15 years and above only, define an LTI for P and no European country sets a ULI that is specific for children, unlike the USA/Canada (Food and Nutrition Board, 1997).

\section{Sodium}

In most European countries, $\mathrm{Na}$ is not on the list of nutrients with dietary reference values. Only a few countries such as UK (Department of Health, 1999), Belgium (Conseil Supérieur d'Hygiène, 2000), Bulgaria (Ministry of Health, 1994) and Poland (Ziemlanski et al. 1996) give reference intakes for $\mathrm{Na}$ (Table A30). These are, however, not based on an estimation of average Na requirements. No differences in reference intakes are given between boys and girls. The values of the UK and Belgium are identical. Bulgaria and Poland give higher values. Four European documents and the USA (Food and Nutrition Board, 2002) set very similar [LTI] values for $\mathrm{Na}$, but only three give values that are specific to children. In toddlers these values are $200-250 \mathrm{mg} / \mathrm{d}$ or about $10 \mathrm{mmol} / \mathrm{d}$, and in adults $500-575 \mathrm{mg} / \mathrm{d}$ or a little more than $20 \mathrm{mmol} / \mathrm{d}$. The [LTI] set by Poland is higher than other evaluations in all age groups and shows an unexplained outlier in the age group of 7-9 years. Two European documents 
(Scientific Committee for Food, 1993; DACH, 2000) and the USA give a [ULI] ranging from 2400 to $3500 \mathrm{mg} / \mathrm{d}$. These are given for adults and are not specifically for children. Usually the reference nutrient intake values are lower than the actual mean intakes and this corresponds to an aspiration (except in France) to work towards a 'decrease the current intake of sodium'.

\section{Potassium}

In many European countries, $\mathrm{K}$ is not on the list of nutrients with dietary reference values. There are large differences; e.g. in the age group of 2 years, reference intake ranges from 325 to $1800 \mathrm{mg} / \mathrm{d}$ and the [LTI] ranges from 325 to $1400 \mathrm{mg} / \mathrm{d}$. As can be seen from Table A31, some countries set an [LTI] that is higher than the reference intake of some other countries. This may reflect the emphasis on advising consumption of high intakes of unprocessed foods, especially fruit and vegetables by some countries. In Poland (Ziemlanski et al. 1996) there are remarkable inconsistencies between the different age groups. A sex difference is presented only in adults in the Nordic countries. There is an unexplained difference of an upper level of satisfactory intake between adolescents and adults in Belgium (Conseil Supérieur d'Hygiène, 2000). In Poland the minimum level of $\mathrm{K}$ intake $(\mathrm{mg} / \mathrm{d})$ is lower than $\mathrm{Na}$ intake in 2- to 6-year-olds.

\section{Chloride}

Only a few countries set reference intakes for $\mathrm{Cl}^{-}$(Table A32). The data reflect $\mathrm{Na}$ intake on a molar basis of 1:1, and thus variations in $\mathrm{Cl}^{-}$reference intakes reflect variations in the values for Na. Only Poland (Ziemlanski et al. 1996) and the USA (Food and Nutrition Board, 2002) provide an [LTI] for $\mathrm{Cl}^{-}$in children. Austria-Germany-Swizerland (DACH, 2000) sets a [ULI] for $\mathrm{Cl}^{-}$but this is for adults and not specifically for children.

\section{Iron}

Across Europe, reference values for Fe differ considerably between countries (Table A33). For several age groups, there is a twofold difference between the highest and the lowest value. $\mathrm{Fe}$ is a special nutrient that differs in two aspects from most other nutrients. Fe balance is mainly regulated through absorption, as there are no mechanisms to excrete $\mathrm{Fe}$ in the healthy individual. Fe absorption is affected not only by $\mathrm{Fe}$ status but also by the composition of the diet. The average absorption from a diet can differ from 5 to $15 \%$, as reflected in the new reference intakes from the Joint FAO/WHO Expert Consultation (2002). In this publication, for each age group, a reference value is given for each of four absorption levels - 5\%, $10 \%$, $12 \%$ and $15 \%$, with a threefold difference in reference intake between the lowest and highest absorption levels. The only way a healthy person loses Fe from the body, except for the small amounts lost by desquamation, is through menstruation. Several countries, therefore, include two reference values for adolescent girls, depending on whether they have reached menarche, and, in most, a higher reference intake is given for adolescent girls than boys. Part of the difference between countries may be explained by the different assumptions made about $\mathrm{Fe}$ absorption from local diets. While a few countries have provided an LTI for Fe, only the USA/Canada (Food and Nutrition Board, 2001) has provided ULI values that are specific to children.

\section{Zinc}

There are considerable differences in the reference intakes for children and adolescents around Europe (Table A33). The absorption of $\mathrm{Zn}$ is highly dependent on the composition of the diet, in the same way as for Fe. Thus, a reference intake depends on assumptions about the absorption of $\mathrm{Zn}$ in the diet. This is reflected in the FAO/WHO reference intakes, which gives three values for each age group, for low, medium and high $\mathrm{Zn}$ absorption. There is more than a threefold difference between the reference intakes according to whether absorption is considered to be low or high. Requirements are extrapolated from basal losses in adults with allowance for growth. The need for $\mathrm{Zn}$ is often based on a requirement per $\mathrm{kg}$ body weight. Consequently many countries give different values for males and females in adolescence. For the youngest age groups there is a threefold difference in reference intake with the lowest being in The Netherlands (2-3 years: 3-4 mg; The Netherlands Food and Nutrition Council, 1992), which is similar to the USA/ Canada (2-3 years: $3 \mathrm{mg}$; Food and Nutrition Board, 2001), and the highest being $10 \mathrm{mg}$ in some of the former Soviet republics. Several countries provide guidance on lower levels that are specific to children. The Nordic countries (Nordic Council of Ministers, 1996b), FAO/ WHO (Joint FAO/WHO Expert Consultation, 2002) and the USA/Canada (Food and Nutrition Board, 2001) set ULI values.

\section{Copper}

Reference intakes for $\mathrm{Cu}$ vary up to threefold across Europe (Table A35). They are based on the observation of clinical deficiencies such as in those receiving enteral diets containing low $\mathrm{Cu}$. Further research is required to establish the link between $\mathrm{Cu}$ status and cardiovascular function, blood pressure and metabolism of catecholamines. At present, adult data are based on balance studies and evaluation of markers of $\mathrm{Cu}$ deprivation such as superoxide dismutase and cytochrome oxidase activities and the metabolism of enkephalins. Balance studies are difficult in the absence of information on initial $\mathrm{Cu}$ status and give variable results. Very few studies have been performed in children and most reference intakes, including those in the USA/Canada (Food and Nutrition Board, 2001), are based on an interpolation between infant and adult data. The UK (Department of Health, 1999) used a factorial calculation in infancy on the basis of tissue content, an estimated percentage of losses and assumed an absorptive efficiency of $50 \%$. Differences in reference intakes around Europe can be ascribed to differences in the method of estimation used and in the assumptions made about $\mathrm{Cu}$ absorption, taking into account variation in 
food patterns. For example, France (CNERNA-CNRS, 2001) based their estimate on balance studies and on absorption of $20-40 \%$. This took into consideration interactions with other nutrients in the diet. In the Nordic countries (Nordic Council of Ministers, 1996a), absorption was estimated at 35-70\%. No country provides an LTI for $\mathrm{Cu}$ in children. UL values have been established by FAO/ WHO (Food and Nutrition Board, 2002) and by the USA/ Canada (Food and Nutrition Board, 2001). These are based on a No Observed Adverse Effect Level (NOAEL) obtained in adults, using liver function as the outcome measure.

\section{Selenium}

In some countries no specific reference intakes are given for $\mathrm{Se}$, due to uncertainties over average requirements. Where they are set for children and adolescents, they vary over a considerable range (Table A36). Reference intakes in childhood are deduced from adult values on the basis of body weight. Se requirements in adults are based on the intakes necessary to achieve a satisfactory plasma glutathione peroxidase (GPx) activity. Variations in reference intakes between countries reflect differences in the choice of what represents a satisfactory or optimal adult value of GPx activity (e.g. 2/3 of maximum GPx activity, maximum GPx activity, or higher than that to achieve maximum GPx activity to optimise immune function). In addition, the chemical form of ingested Se affects the response of selenoenzymes and assumptions on the dietary source of Se can result in differences in reference intakes. Only the UK (Department of Health, 1999) sets an LTI for Se that is specific for children, and two other countries provide a general recommendation for adults. A ULI is proposed in several countries. These are set for adults and, except for the USA/Canada (Food and Nutrition Board, 2000), are not specific for children.

\section{Molybdenum}

Only four countries or group of countries in Europe give guidelines for Mo intakes in children and adolescents (Table A37) - Latvia (Ministry of Welfare, 2001), Austria-Germany-Switzerland (DACH, 2000), Belgium (Conseil Supérieur d'Hygiène, 2000) and the UK (Department of Health, 1999) - as do FAO/WHO (Joint FAO/ WHO Expert Consultation, 2002) and the USA/Canada (Food and Nutrition Board, 2001). These are not equivalent to population reference intakes, but to safe-and-adequate intakes. Large discrepancies exist between the guidelines for this trace element. For example, at 2 years of age, the UK value is $5-15 \mu \mathrm{g} / \mathrm{d}$ whereas that for the Nordic countries (Nordic Council of Ministers, 1996a) is 50$100 \mu \mathrm{g} / \mathrm{d}$. The Austria-Germany-Switzerland value is intermediate $(25-50 \mu \mathrm{g} / \mathrm{d})$, but its minimum is higher than the maximum for the UK and its maximum is at the minimum of the Nordic guideline. Safe-and-adequate intakes for children are interpolated between intake of breast-fed infants and mean intake of healthy adults. No European country sets a ULI for Mo intake, unlike the USA/Canada.

\section{Manganese}

Four European countries or group of countries include $\mathrm{Mn}$ in their reference intake document for children (Table A38): the UK (Department of Health, 1999), Belgium (Conseil Supérieur d'Hygiène, 2000), Latvia (Ministry of Welfare, 2001) and Austria-Germany-Switzerland (DACH, 2000). The USA/Canada also provides guidance on this trace element for children (Food and Nutrition Board, 2001). These are presented as safe-and-adequate intakes. There is relatively little variation with age, since the range varies between $1.0-1.5 \mathrm{mg} / \mathrm{d}$ at 2 years of age and $2.0-3.0 \mathrm{mg} / \mathrm{d}$ at 18 years of age. The Scientific Committee for Food (1993) and Italy (Società Italiana di Nutrizione Umana, 1996) prefer to give an acceptable range of $1-10 \mathrm{mg} / \mathrm{d}$, which is set for all ages and is not specific to children. There are no differences in reference intakes between males and females. No European country sets a ULI for Mn intake, unlike the USA/Canada.

\section{Chromium}

For Cr, most European countries and international organisations acknowledge that there are not enough data to make sound recommendations. Only six countries or group of countries in Europe give reference intakes, generally in the form of safe-and-adequate levels of intake, and only four of these are specific to children (Table A39). The FAO/WHO and USA/Canada also provide guidance. It is notable that the maximum of the range given by the UK (Department of Health, 1999) is equal to or lower than the minimum given by all other countries. Values for children are interpolated from the intake by breast-fed infants (from 0.051 to $1.326 \mu \mathrm{g} / \mathrm{d}$ ) and the intake of adults (from 13 to $49 \mu \mathrm{g} / \mathrm{d}$ ). There are no differences in the reference intakes between boys and girls. No country gives an LTI or ULI for $\mathrm{Cr}$ intake.

\section{Iodine}

Reference intakes for children are available for I in eighteen countries or group of countries (Table A40) but most countries base their guidance on US/Canadian RDAs (Food and Nutrition Board, 2001) and EU PRIs (Scientific Committee for Food, 1993). In consequence there is relatively little variation. I reference intakes are based on measures of thyroid I accumulation and turnover, on measures of urinary I, of thyroid size, balance studies and the synthesis of thyroid hormones. Thyroid I turnover data are available only from euthyroid adults. Balance studies are available in children but were performed in the 1960s and are flawed by methodological limitations as well as experimental inaccuracies, such as not taking account of usual I intake or the size of the thyroidal compartment, and the sensitivity of the laboratory methodologies used was not sufficiently high. Urinary I excretion data are available for large populations, but only reflect short-term intake. However, urinary I excretion is correlated with the occurrence of goitre. Long-term I nutrition is better assessed from the synthesis of thyroid hormones. Serum levels of thyroglobulin are correlated 
with I deficiency but dose-response data are scarce. In practice, most reference intakes have been established in relation to the prevention of deficiencies. The UK, in the absence of data on I requirements in children, sets a reference intake for children by extrapolating from adult values, based on the reference intakes for energy. More recently, the USA/Canada accepted data from children obtained from balance studies and from the relationship between urinary I excretion and goitre prevalence.

Reasons for advising different reference intakes include the presence of goitrogens (present in Brassicaceae), cooked food as the main source of intake (cooking reduces I content), the presence of malnutrition (I absorption is delayed in protein-energy malnutrition; systemic utilisation of I may be impaired in Se-deficient individuals) and the level of salt iodisation in the country. A lower value for the reference intake has been given by Switzerland, in comparison to Germany and Austria (DACH, 2000). In Switzerland, iodised salt (containing 20$30 \mathrm{mg} \mathrm{I} / \mathrm{kg}$ ) has been available for decades. As a result, the incidence of goitre is now very low. On the contrary, in Germany, I deficiency is still present and a higher reference intake has been given. In the Russian Federation (Ministry of Health Care, 1991), Estonia (Kuivogu et al. 1995) and Ukraine (Ministry of Health) the reference intakes are set higher for schoolchildren aged 6 years compared with children not attending schools.

Only the UK defines LTI values for I that are specific for children. Only FAO/WHO (Joint FAO/WHO Expert Consultation, 2002) and USA/Canada (Food and Nutrition Board, 2001) have established a ULI for I intake in childhood. Individuals who have a compensated autonomia of the thyroid gland have an increased risk of hyperthroidism (Austria-Germany-Switzerland) and individuals with autoimmune thyroid disease have adverse effects even at intakes considered safe for the general population. The USA/Canada committee considered studies in adults that calculated a Low Observed Adverse Effect Level (LOAEL) using concentration of thyroid-stimulating hormone as an outcome. Because of the mild, reversible nature of elevated thyroid-stimulating hormone over baseline, the committee used an uncertainty factor of 1.5 to establish a ULI. Such limits are set lower in the UK $(1 \mathrm{mg} / \mathrm{d})$, on the basis of the possible presence of a small number of elderly people who may be sensitive to high intakes, and even lower $(500 \mu \mathrm{g} / \mathrm{d})$ in Germany and Austria, based on the greater sensitivity of elderly individuals who have been exposed to I deficiency. In children, the US/Canadian ULI was obtained by extrapolation. No European country currently sets a child-specific ULI.

\section{Fluorine (fluoride)}

The ability of $\mathrm{F}$ as fluoride to inhibit and even to reverse the initiation and progression of dental caries, and to stimulate new bone formation, is well accepted. However, in a majority of countries there is no specific reference intake for $\mathrm{F}$ and the 'physiological' nature of this trace element is still under dispute. In several countries (Table A41), reference intakes are replaced by recommended daily supplementation depending on the $\mathrm{F}$ concentration in drinking water as advised by FAO/WHO. Due to the risk of F excess (fluorosis), several countries define ULI values, the difference between the ULI and corresponding reference intake being relatively small.

\section{Water}

In most European countries, water is not on the list of nutrients with dietary reference values. Several countries (Table A42) give the same guidance as the National Research Council of the USA in 1989 (Food and Nutrition Board, 1989): for practical purposes $1 \mathrm{ml} / \mathrm{kcal}$ $(240 \mathrm{ml} / \mathrm{mJ})$ in children and adults is recommended under average conditions of energy expenditure and environmental exposure. Only Austria-Germany-Switzerland (DACH, 2002) give detailed values for practical purposes (Richtwerte) for daily total water and beverage intake based on age-specific mean energy intake values, a urine osmolality of $500 \mathrm{mosm} / \mathrm{kg}$, an assumed mean water density of food of $0.33 \mathrm{ml} / \mathrm{kcal}(80 \mathrm{ml} / \mathrm{mJ})$ and a potential urine solute load of $650 \mathrm{mosm} / \mathrm{d} \times 1.73 \mathrm{~m}^{2}$ body surface area. Reference intakes for water are not specified separately for boys and girls. The physiological requirement for water is highly variable and quite complex. It depends on climate, physical activity and renal solute load. Thus it is impossible to set a general reference intake for water.

\section{Section 3: Overview and concluding remarks}

The remit of the Expert Group was to appraise the methodological approaches used to establish the nutritional needs of children and adolescents, and to review the nutritional recommendations current in the different countries of Europe. The compilation of the dietary reference values in Section 2 demonstrates that there are considerable disparities in the perceived nutritional requirements of European children and adolescents. Although this diversity can be attributed partly to real differences between populations and to differences in philosophy about the best approach to use, in reality most of the variability reflects methodological differences in how the reference intakes were constructed.

There are several environmental factors that may justify different nutritional reference intakes for different European countries. For instance, the average duration and intensity of sunshine may modify the need for a dietary supply of vitamin D, the abundance of I in the geographical milieu will affect considerations about the need for I supplementation, and differences in diet composition will alter the assumptions made about $\mathrm{Fe}$ and $\mathrm{Zn}$ absorption. Several other genetic, environmental and life-style factors may also modify reference intakes for any given population of children. To cover these situations there is clearly a need for local consideration of the issues, and this is most appropriately done at the regional or national level.

In contrast, many of the differences across Europe are the result of disparities in methodology, which could benefit from discussion and harmonisation at the European level. Some of these discrepancies originate 
from the different frameworks used to construct reference intakes. These conceptual differences are reflected in the multiplicity of ways in which recommendations and reference intakes are currently expressed (as described in Section 1). Another important factor lies in the different way each country defines the age groups within which a given reference intake is aggregated. Some make small adjustments in reference intake from year to year with advancing age while others consolidate several years into one age category. The boundaries of these age bands vary between countries, and can result in marked discrepancies, most notably when chronological age does not necessarily match biological age, such as at the onset of puberty. Similar problems arise from the use of different normative data at each age for converting requirements constructed on a body weight basis or as a percentage of energy or protein intake to daily nutrient intake. The selection criteria for these normative data are often not specified in the source material. This not only raises questions about what should be regarded as an optimal growth rate in childhood and adolescence, but also suggests that some degree of harmonisation could be achieved across Europe by the use of consensus definitions. Putative standard categories need not necessarily be defined as chronological ages but could, for example, be identified in relation to pubertal milestones for growth and development, which would allow for different rates of maturation in different countries.

Solving these methodological and technical issues by discussion and reaching consensus at the European level may not only help to improve the quality and consistency of dietary reference intakes for children and adolescents, but also may lead to other advantages. For example, standardisation of the age groups that require different reference intakes would better facilitate international discussion, would improve clarity and might remove some of the barriers to eventual harmonisation across Europe. In addition, there is increasing recognition that several important new concepts are likely to impact on the future setting of nutritional guidelines. These include: gene-nutrient interactions, genetic polymorphisms and intergenerational effects on optimal health and disease risk, nutrient-nutrient interactions and the importance of considering the whole diet as opposed to separate nutrients. Such issues may well be best tackled at the European-wide level. Differences in the construction of reference intakes can be attributed partly to the variable workload devoted to the development of the dietary guidelines. Small ad hoc committees meeting only a few times and working without appreciable financial support are less able to carry out an in-depth analysis of the science base than are larger, more well-supported committees. Given the enormity of the task in considering the wealth of new information that is likely to become available, it is questionable whether, in the future, small local committees will be able to cope unless they make use of already available consensus statements on critical aspects debated at the European level.

Some non-technical barriers would also need to be overcome before attempting harmonisation of dietary reference values for children and adolescents in Europe. Most of the dietary reference values discussed in the present review are based either on the factorial approach or on the extrapolation of adult reference intakes to children and adolescents. Because the classical diseases caused by nutrient deficiencies are less prevalent in industrialised countries than they were (with the exception of Fe deficiency), functional health outcome parameters are being increasingly considered as indicators of the quality of nutrition for better health. Surprisingly few evidence-based data are available on the relationship of any biomarker to health outcome within the paediatric age group. For instance, a high plasma cholesterol concentration is clearly related to various diseases in the adult population, whereas little is known about the impact of high plasma cholesterol in childhood on health outcomes. Biomarkers relevant to health outcomes in children may be different from those validated for health risk assessment in adults. However, ethical and economic considerations limit the possibilities of carrying out health-related research in children and extrapolation of adult data is likely to provide the only feasible way of estimating the health risks related to 'unfavourable' biomarker values for some time into the future. A greater emphasis is needed on producing the evidence base specific for children and considerable research investment is required to take these issues forward.

Even after solving the technical issues and dealing with the problem of the relative paucity of health outcome data, there remain some basic questions about the potential harmonisation of nutritional recommendations across Europe. In particular:

- Is harmonisation of dietary reference values for children and adolescents a useful and achievable goal? The costs and benefits of an international initiative to harmonise reference values need to be carefully evaluated. If the benefits appear to exceed the costs, the target population(s) for harmonisation need to be clearly defined.

- Are dietary reference values useful and to what extent are they implemented? Do the different reference intakes among populations really result in significant differences in actual intakes or in health outcomes? For instance, it remains to be determined whether setting the upper limit of fat intake at $32 \%$ of energy intake (several Central or Eastern European countries) influences fat intake and, consequently, offers cardiovascular advantages over defining the upper limit of intake at $40 \%$ (The Netherlands).

- Is it worthwhile to consider European children and adolescents as a single population, or it is more practical to attempt harmonisation of dietary reference values only for some subsets of this population? Geographical, environmental, genetic and life-style factors may influence some of the nutritional needs of children and adolescents, mitigating against the use of a single set of reference values in all European countries. In addition, there may be subgroups within each population that require special attention. For instance, children with a high level of sports activity have different nutritional needs to less active children and may 
require a separate set of nutritional guidelines. In contrast, children with an unusually low level of physical activity are at high risk of developing obesity and may also benefit from recommendations tailored to their needs. Thus, the best approach may be to define some basic issues that would lend themselves to conceptual harmonisation at the European level, but leave the fine-tuning of reference intakes for the individual countries.

The benefits for Europe of the harmonisation of dietary reference values could occur at several levels. Standardised reference values could be used for the evaluation of dietary adequacy and for surveillance of the nutritional status across Europe. Accepted nutrient-based reference values are also prerequisites for the construction of food-based guidelines needed to translate nutritional messages into practical guidance. Well-defined nutritional goals may enhance the efficacy of health education promotion programmes and could contribute to the improvement of mutual understanding among the scientific community, policy-makers, food producers and consumers. Harmonisation of population reference intakes could also be of value to the European food industry. An example comes from the experience of harmonising reference values for labelling purposes. EU legislation currently lays down reference labelling values for eighteen vitamins and minerals, based on the FAO/WHO expert consultation in Helsinki in 1988 (FAO/WHO/Ministry of Trade and Industry, 1988). This has greatly simplified the labelling of foods marketed in more than one European country: previously, diverse national reference values required apparently different nutrition information for the same foods in each country. This contrasts with the situation for companies wishing to communicate the nutritional value of foods for specific population groups, for example in advertising or to health professionals, because they must refer in each country to the national PRI, with the attendant duplication and potential confusion this entails.

In view of the diversity of current recommendations that exist in Europe, as documented in this review, and the considerable scientific and political barriers that will need to be overcome, the question of whether harmonisation of dietary reference values for children and adolescents is a desirable or achievable goal for Europe needs further consideration.

\section{Acknowledgements}

This work was supported by a grant from the Nutritional Needs of Children Task Force of the European branch of the International Life Sciences Institute (ILSI Europe). Industry members of this task force are Barilla, Coca-Cola, Danone Vitapole, Ferrero, Friesland Coberco, Masterfoods, Nestlé and Numico. Further information about ILSI Europe can be obtained from +32 (0)2 7710014 or info@ ilsieurope.be. The opinions expressed herein are those of the authors and do not necessarily represent the views of ILSI and ILSI Europe.

The authors of the paper would like to thank Mrs Lene Schack-Nielsen, Ms Valérie Rolland, Ms Lisa Coneyworth,
Ms Alison Mcafee and Ms Arianna Bonazzi for their contribution to this publication.

\section{References}

Aggett PJ, Bresson J, Haschke F, et al. (1997) Recommended Dietary Allowances (RDAs), Recommended Dietary Intakes (RDIs), Recommended Nutrient Intakes (RNIs) and Population Reference Intakes (PRIs) are not 'recommended intakes'. J Pediatr Gastroenterol Nutr 25, 236-241.

Alexy U, et al. (2000) The 'Optimized Mixed Diet': evaluation of a food guide system for children and adolescents. J Nutr Educ 32, 94-99.

Barker DJ (1995) Fetal origins of coronary heart disease. Br Med J 311, 171-174.

Battelino T (1998) Dietary recommendations in Slovenia - nutritional needs of infants, children and adolescents. Slov Pediatr 5, Suppl. 1, 17-23.

Catovic A, Catovic S \& Kendic S (2000) Higijena ishrane sa dijetetikom (Nutrition hygiene and dietetics), Fakultet Spurta Sarajevo, SVJETLOST, Fojnica (Bosnia and Herzegovina).

Centre National d'Études et de Recommandations sur la Nutrition et l'Alimentation-Centre National de Recherche Scientifique (2001) Apports Nutritionnels Conseillés pour la Population Française, 3rd ed. Paris: CNERNA-CNRS.

Conseil Supérieur d'Hygiène, Ministère des Affaires Sociales, de la Santé Publique et de l'Environnement (2000) Recommendations Nutritionnelles pour la Belgique - Révision. Brussels: Service Public Fédéral de la Santé Publique, de la Securité de la Chaine Alimentaire et de l'Enivironnement.

DACH (2000) Referenzwerte für die Nährstoffzufuhr, Deutsche Gesellschaft für Ernährung $\mathrm{eV}$ (DGE), Österreichische Gesellschaft für Ernährung (ÖGE), Schweizerische Gesellschaft für Ernährungsforchung (SGE), Schweizerische Vereinigung für Ernährung (SVE). English version published 2002.

Department of Health (1991) Dietary Reference Values for Food Energy and Nutrients for the United Kingdom, 10th impression (with revised section on fluoride) Report on Health and Social Subjects no. 41. London: HMSO.

Department of Health (1998) Nutrition and Bone Health: With Particular Reference to Calcium and Vitamin D. Report on Health and Social Subjects no. 49. London: The Stationery Office.

Department of Health (1999) Dietary Reference Values for Food Energy and Nutrients for the United Kingdom, 10th impression (with revised section on fluonde). London: The Stationery Office.

Department of Health (2000) Folic Acid and the Prevention of Disease. Report on Health and Social Subjects no. 50. London: The Stationery Office.

Food and Agriculture Organization/World Health Organization/ Ministry of Trade and Industry, Finland (1988) Recommended Nutrient Reference Values for Food Labelling Purposes. Report of a Joint FAO/WHO Expert Consultation, Helsinki, Finland, 12-16 September. Geneva: WHO.

Food and Agriculture Organization/World Health Organization/ International Atomic Energy Agency (1996) Trace Elements in Human Nutrition and Health. Geneva: WHO.

Food and Agriculture Organization/World Health Organization (1998) Preparation and Use of Food-based Dietary Guidelines. Technical Report Series no. 880. Geneva: WHO.

Food and Nutrition Board, Institute of Medicine (1989) Recommended Dietary Allowances, 10th ed. Washington, DC: National Academy Press.

Food and Nutrition Board, Institute of Medicine (1997) Dietary 
Reference Intakes for Calcium, Phosphorus, Magnesium, Vitamin D and Fluoride. Washington, DC: National Academy Press.

Food and Nutrition Board, Institute of Medicine (1998) Dietary Reference Intakes for Thiamin, Riboflavin, Niacin, Vitamin $B_{6}$, Folate, Vitamin $B_{12}$, Pantothenic Acid, Biotin and Choline. Washington, DC: National Academy Press.

Food and Nutrition Board, Institute of Medicine (2000) Dietary Reference Intakes for Vitamin C, Vitamin E, Selenium and Carotenoids. Washington, DC: National Academy Press.

Food and Nutrition Board, Institute of Medicine (2001) Dietary Reference Intakes for Vitamin A, Vitamin K, Arsenic, Boron, Chromium, Copper, Iodine, Iron, Manganese, Molybdenum, Nickel, Silicon, Vanadium and Zinc. Washington, DC: National Academy Press.

Food and Nutrition Board, Institute of Medicine (2002) Dietary Reference Intakes for Energy, Carbohydrate, Fiber, Fat, Fatty Acids, Cholesterol, Protein, and Amino Acids (Macronutrients). Washington, DC: National Academy Press.

Food Safety Authority of Ireland (1999) Publication on Recommended Dietary Allowances for Ireland. Dublin: Food Safety Authority of Ireland.

Forsen T, Eriksson J, Tuomilehto J, Osmond C \& Barker D (2000) The fetal and childhood growth of persons who develop type 2 diabetes. Ann Intern Med 133, 176-182.

Golden MH (1988) The role of individual nutrient deficiencies in growth retardation of children as exemplified by zinc and protein. In Linear Growth Retardation in Less Developed Countries, pp. 143-163 [JC Waterlow, editor]. New York: Raven Press.

Golden MH (1994) Is complete catch-up possible for stunted and malnourished children? Eur J Clin Nutr 48, 59S-71S.

György B \& Károly L (1999) Tápanyagtáblázat (Dietary Recommendations in Hungary - Nutrient Tables - Dietetics and Nutrient Composition). Budapest: Medicina Könyvkiadó RT.

Haschke F \& van't Hof MA (2000) Euro-Growth references for length, weight, and body circumferences. Euro-Growth Study Group. J Pediatr Gastroenterol Nutr 31, Suppl. 1, S14-S38.

Health Council of The Netherlands (2000) Voedingsnormen Calcium, Vitamine D, Thiamine, Riboflavine, Niacine, Pantotheenzuur en Biotine. Publication no. 2001/12. The Hague: Health Council of The Netherlands.

Health Council of The Netherlands (2001) Dietary Reference Intakes in The Netherlands: Energy, Proteins, Fats, and Digestible Carbohydrates. Publication no. 2001/19. The Hague: Health Council of The Netherlands.

Institute of Public Health, Ministry of Health and Family (1990) Food-Based Recommendations in Children and Adolescents in Romania. Bucharest: Ministry of Health and Family.

Joint Food and Agriculture Organization/World Health Organization/United Nations University Expert Consultation (1985) Energy and Protein Requirements. Technical Report Series no. 724. Geneva: WHO.

Joint Food and Agriculture Organization/World Health Organization Expert Consultation (2002) Human Vitamin and Mineral Requirements. Rome: FAO.

Kuivjogi K, Saava M, Liebert T \& Teesalv S (1995) Recommended Dietary Allowances in Estonia. Tallinn: Department of Food Processing, Tallinn Technical University (14 Dec-Decree 62).

Matkovic V \& Heaney RP (1992) Calcium balance during human growth: evidence for threshold behavior. Am J Clin Nutr $\mathbf{5 5}$, 992-996.

Ministry of Health. Dietary Recommendations in Children in Ukraine (source from Ministry of Health, no reference specified)
Ministry of Heath (1994) Regulations Nr 16/16 July 1994 concerning Physiological Norms/requirements for the Nutrition of the Bulgarian Population. State Newspaper no. 64, p. 10, Sofia.

Ministry of Health, Republic of Lithuania, National Nutrition Centre (2000) Recommended Dietary Allowances in Lithuania - Lithuanian Population. Vilnius: Solidarity.

Ministry of Health Care (1991) Ministry of Health Care Dietary Recommendations for Russian Children, 28 May 1991. Regulation no. 5786-91. Moscow: Ministry of Health Care.

Ministry of National Health and Welfare of Canada (1990) Nutrition Recommendations - The Report of the Scientific Review Committee. Ottawa, Ont., Canada: Canadian Government Publishing Centre Supply and Services.

Ministry of Public Health (2000) Dietary Recommendations in Turkey. The Turkish Health Inventory Study. Ankara: Ministry of Public Health.

Ministry of Welfare of the Republic of Latvia (2001) Dietary Recommendations in Latvia - Decree 233, August. Riga: Ministry of Welfare of the Republic of Latria..

Netherlands Food and Nutrition Council (1992) Dietary Recommendations in The Netherlands. The Hague: The Health and Nutrition Council of The Netherlands.

Nordic Council of Ministers, Nordic Working Group on Diet and Nutrition (1996a) Nordic nutrition recommendations. Scand $J$ Nutr/Näringsforskning 40, 161-165.

Nordic Council of Ministers (1996b) Nordiska närings-rekommendationer 1996 (Nutrient Recommendations for the Nordic Countries). Nord 1996:28. Copenhagen: Nordic Council of Ministers.

Nordin BEC \& Marshall DH (1988) Dietary requirements for calcium. In Calcium in Human Biology, pp. 447-464 [BEC Nordin, editor]. Berlin: Springer-Verlag.

Departamento de Nutrición de la Universitad de Complutense (1995) Tablas de Ingestas Recomendadas en Energia y Nutrientes par la Poblacion Espanola. Madrid: Departamento de Bromatologia, Universitad Complutense de Madrid.

Official Paper of Republic of Serbia (1996) National References for Social Nutrition for Children in Preschool Child Centres 50/94, 1643-1656.

Ritz P \& Coward WA (1995) Doubly labelled water measurement of total energy expenditure. Diabete Metab 21, 241-251.

Scientific Committee on Food (1993) Nutrient and Energy Intakes for the European Community. Report Series no. 31. Brussels: Commission of the European Communities.

Scientific Committee on Food (2000) Opinion of the Scientific Committee on Food on the Tolerable Upper Level Intake of Folate, expressed on 19 October. Brussels: European Commission, Health \& Consumer Protection Directorate General.

Società Italiana di Nutrizione Umana (1996) Livelli di Assunzione Giornallieri Raccomandati di Nutrienti per la populazione Italiana (LARN) (Tables - Dietary Recommendations in Italy). Milan: EDRA.

Società Italiana di Nutrizione Umana (1998) Livelli di Assunzione Raccomandati di Energia e Nutrienti per la populazione Italiana $(L A R N)$. Milan: EDRA.

Trichopoulou A \& Vassilakou T (1990) Recommended dietary intakes in the European Community Member States: an overview. Eur J Clin Nutr 44, Suppl. 2, 51-126.

Ziemlanski S, Bulhak-Jachymczyk B, Budynska-Topolowska J, Panczenko-Kresowska B \& Wartanowicz M (1996) Recommended Dietary Allowances for the Polish Population (energy, protein, fat, vitamins and minerals), pp. 1-27 [S Ziemianski, editor]. Warsaw: New Medicine. 

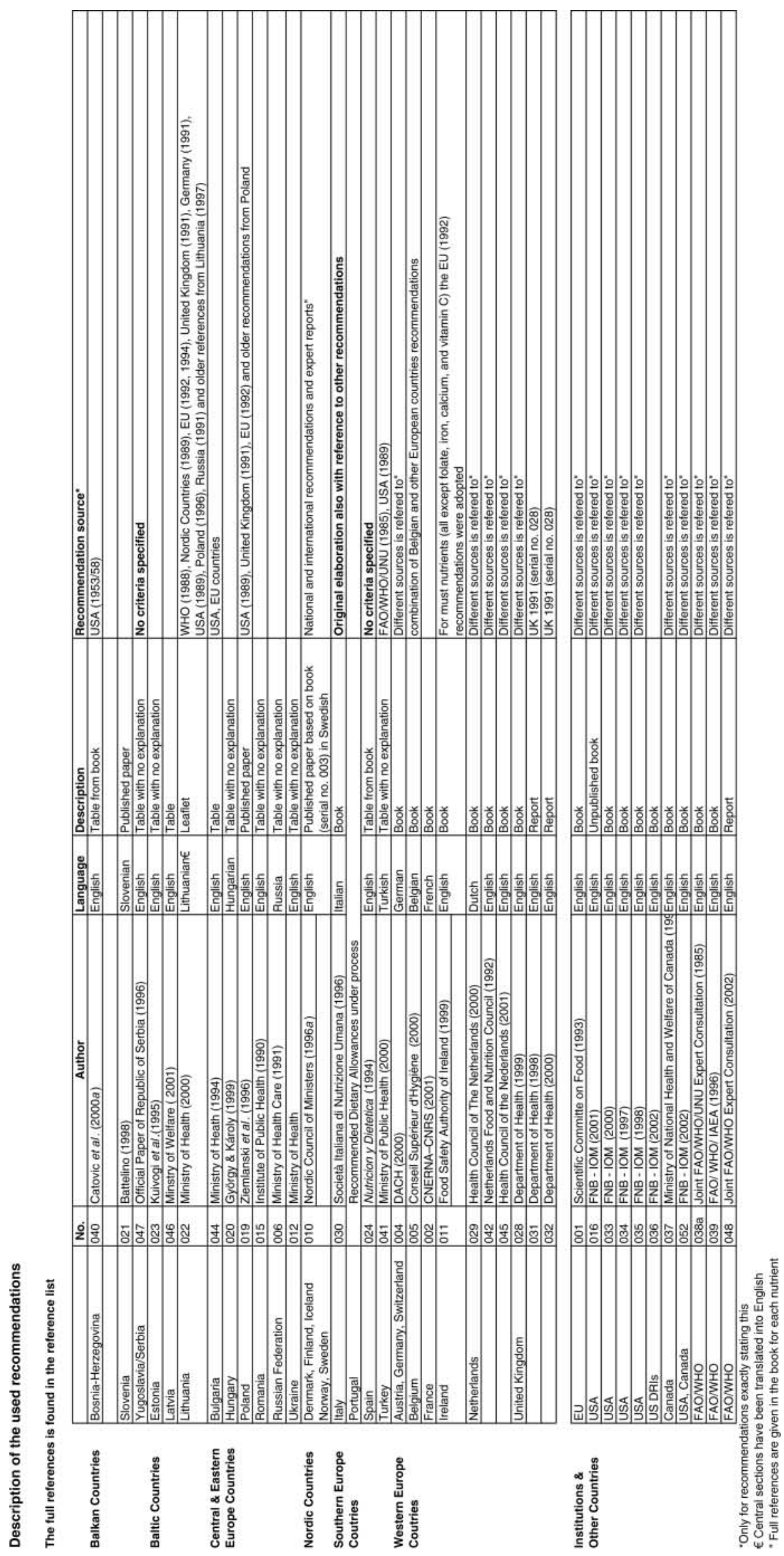

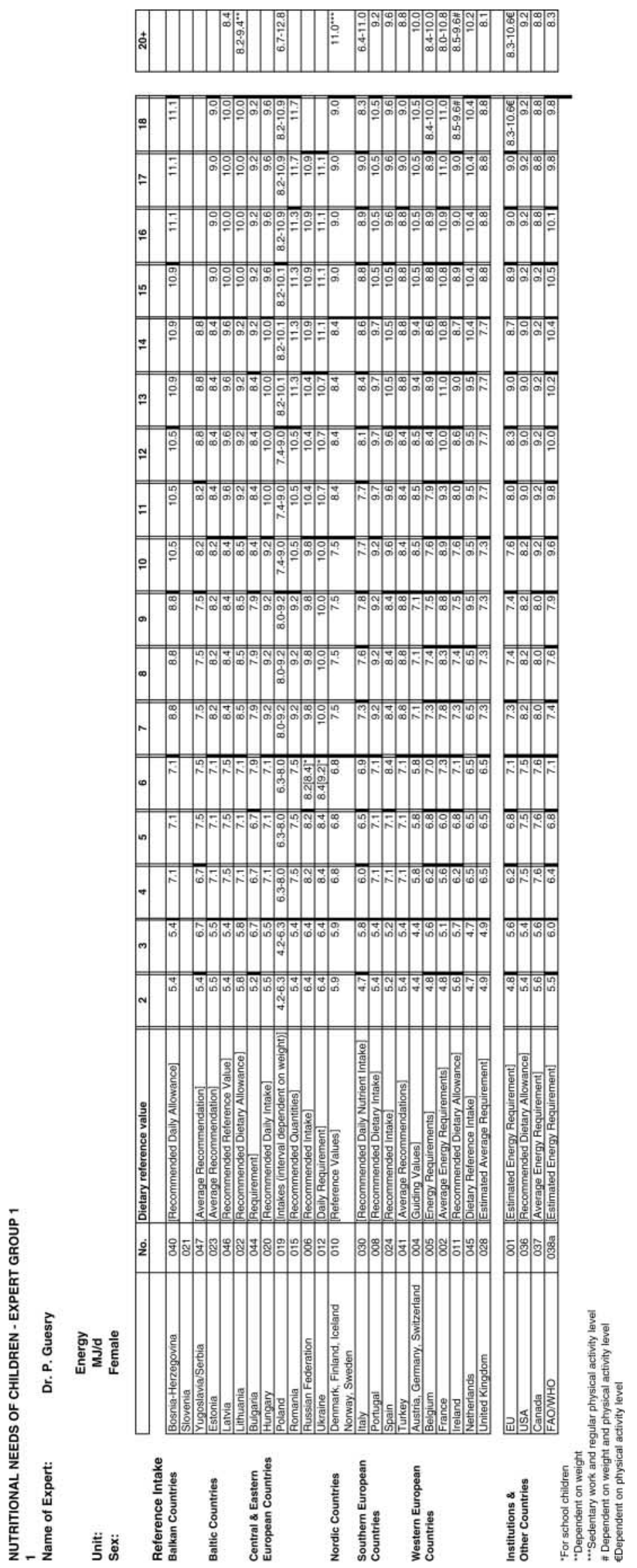


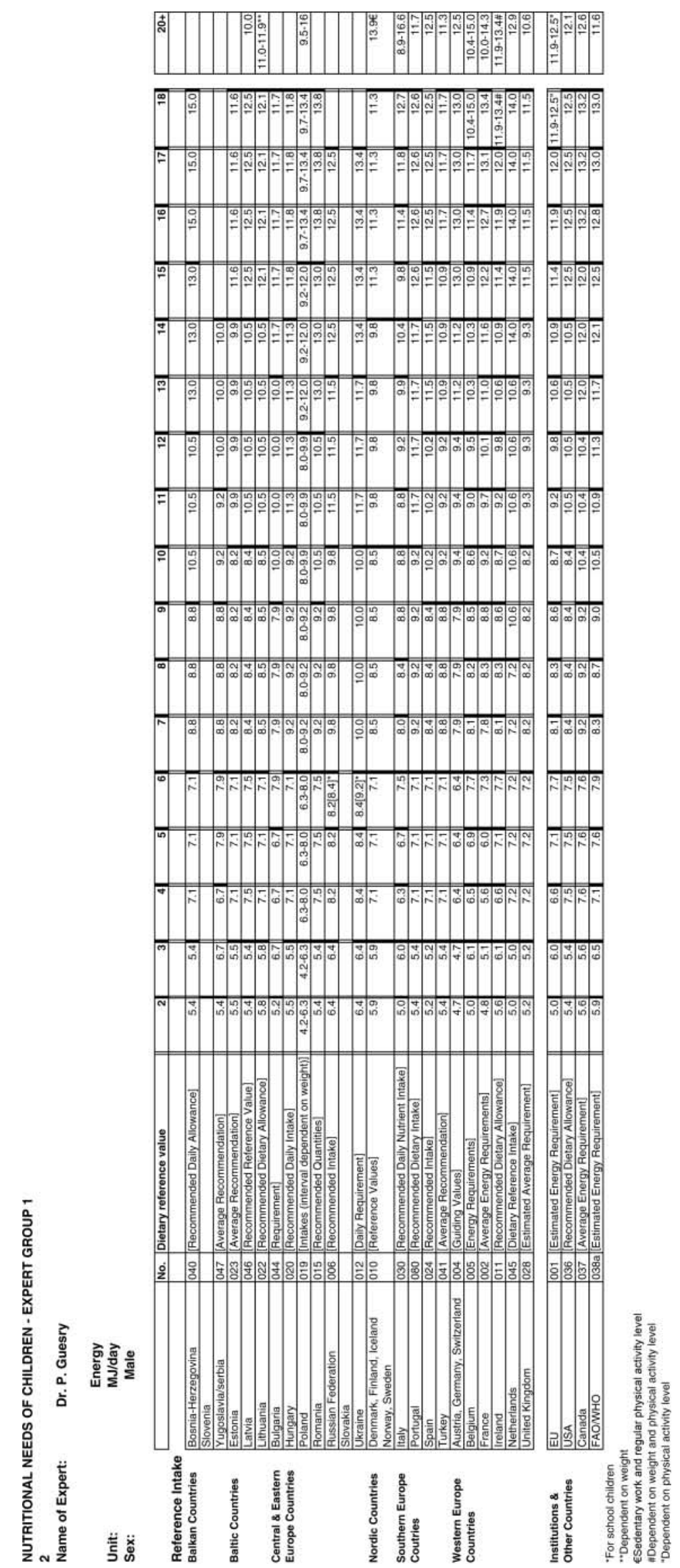




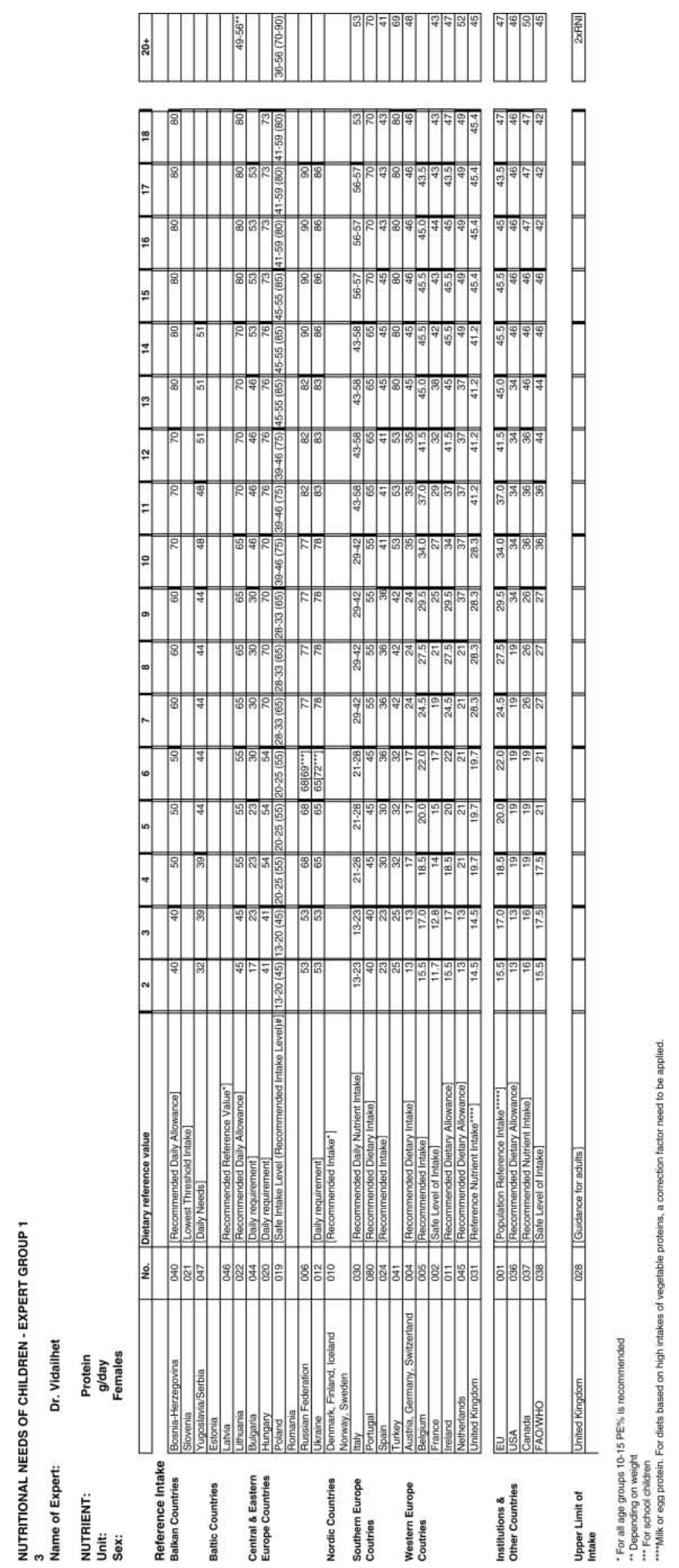


A. Prentice et al.



A. Prentice et al.

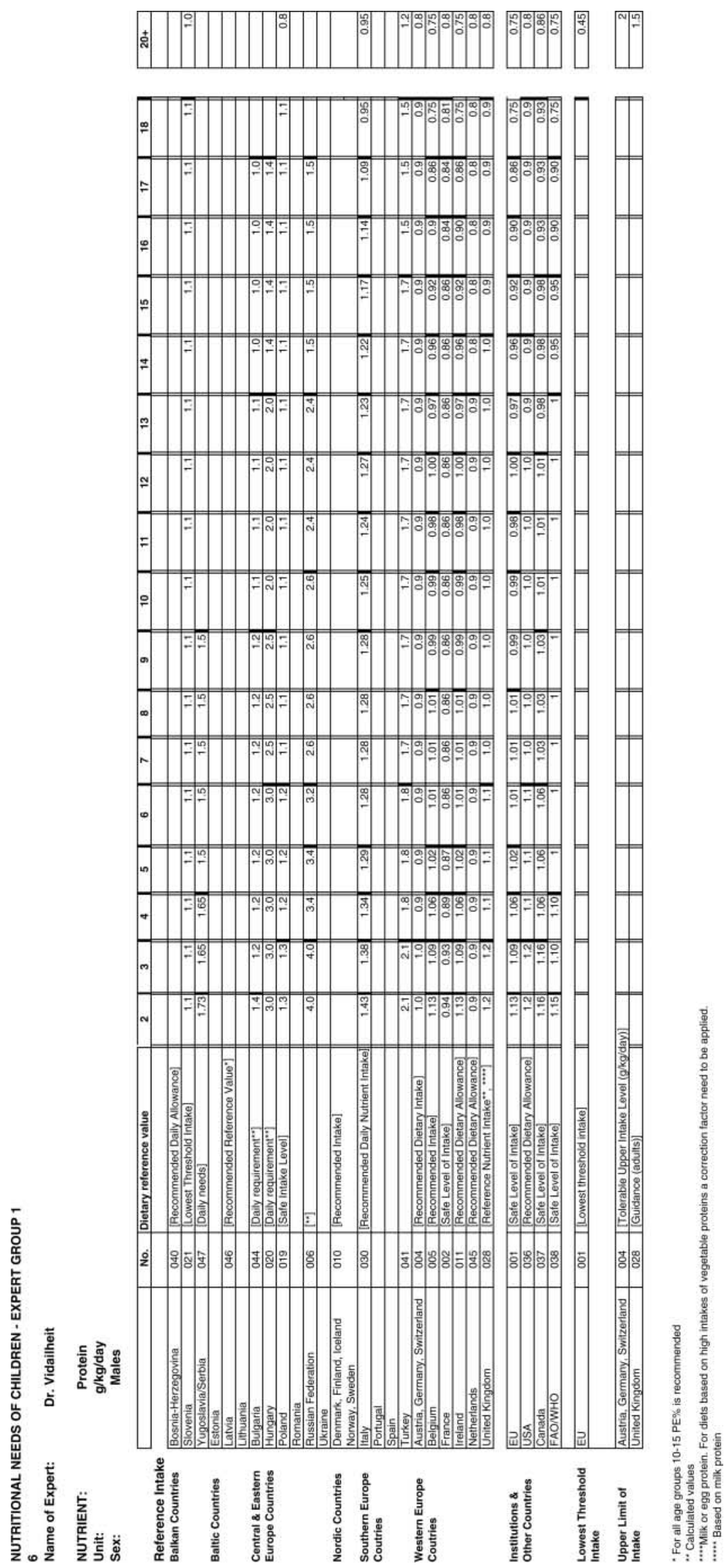




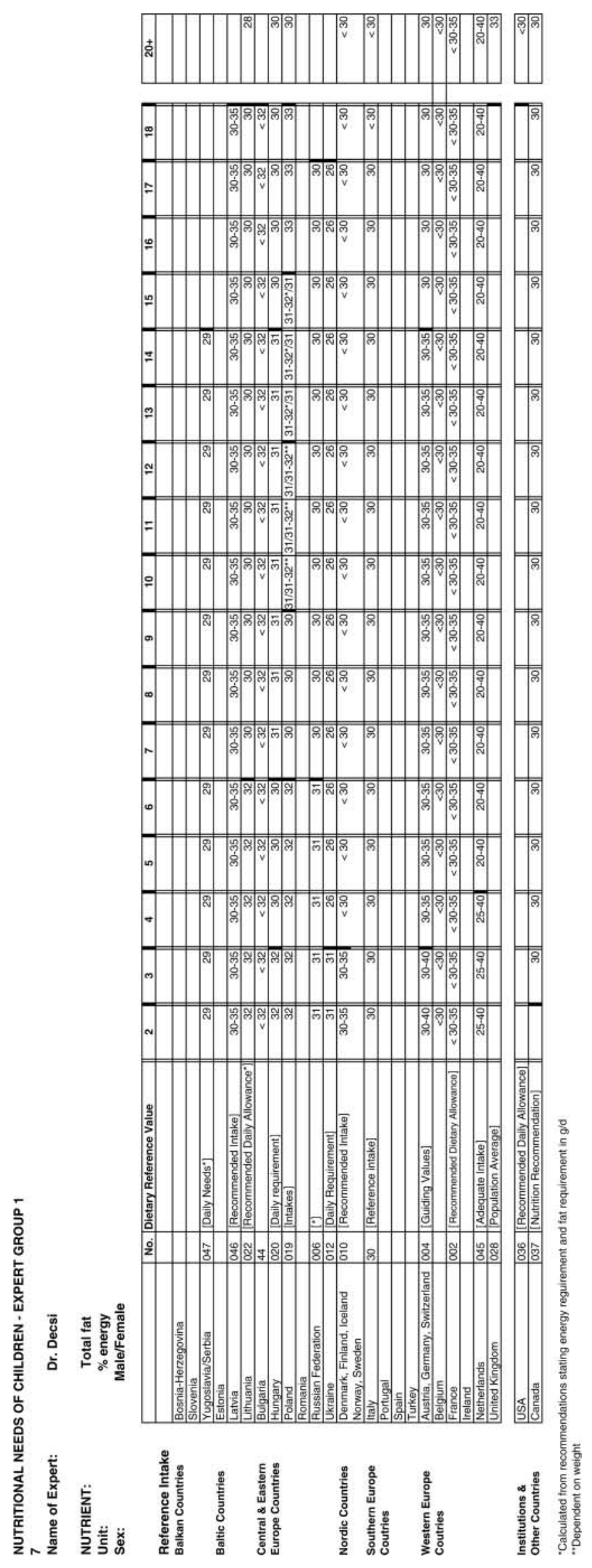


A. Prentice et al.
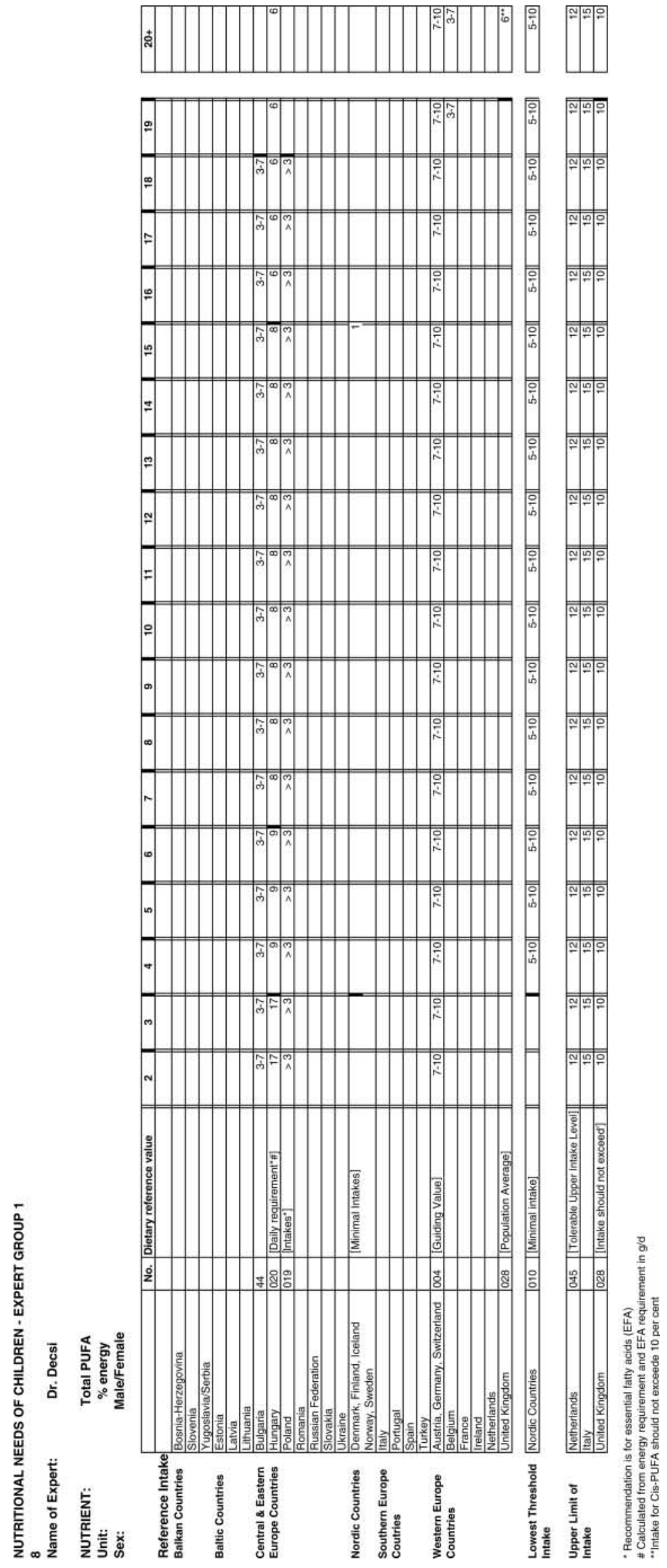


A. Prentice et al.
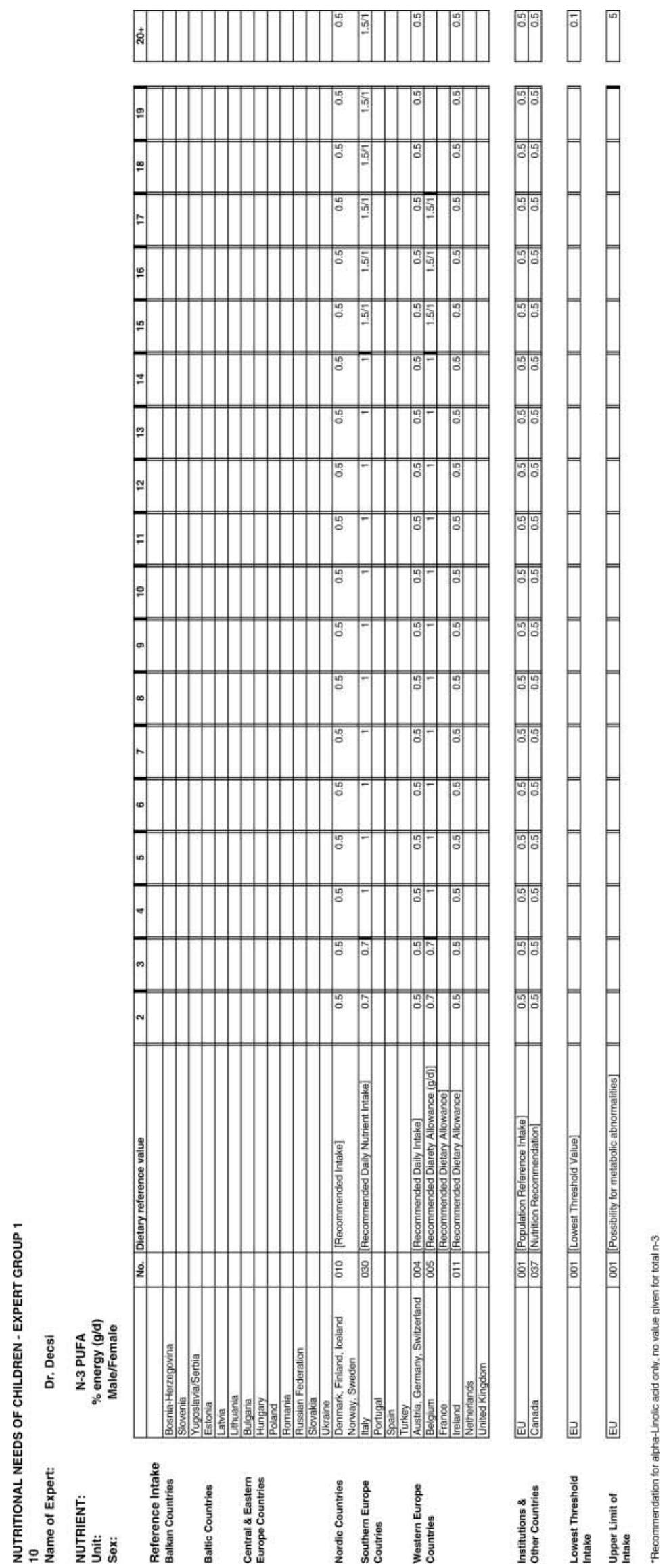


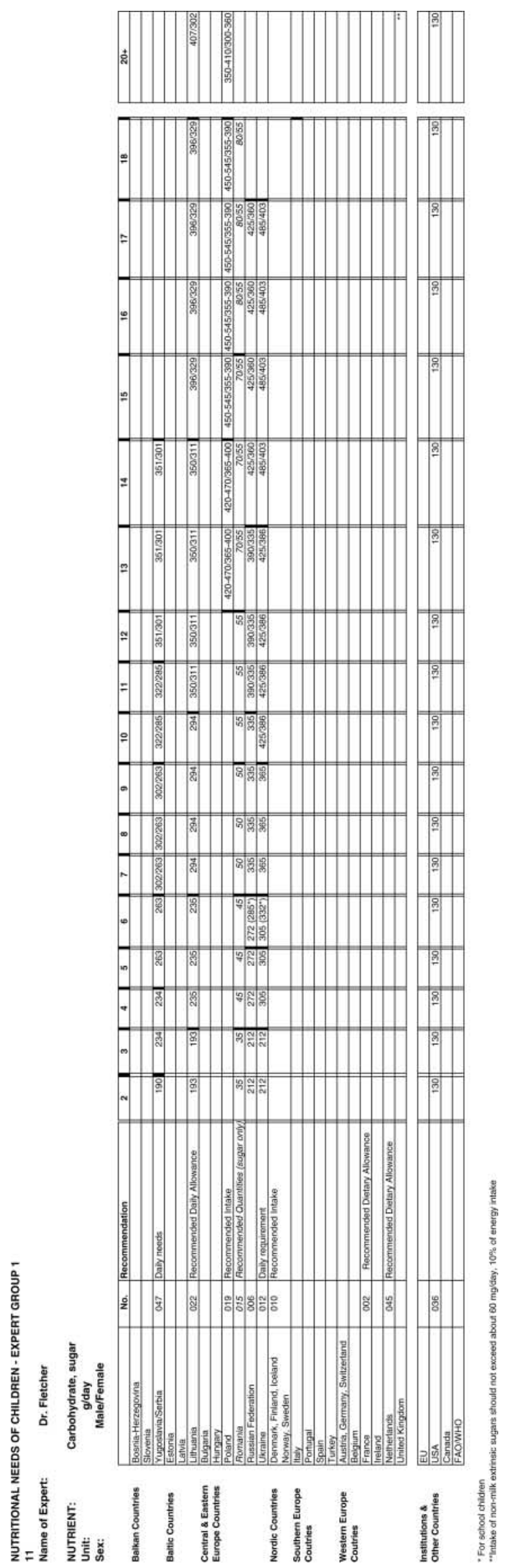



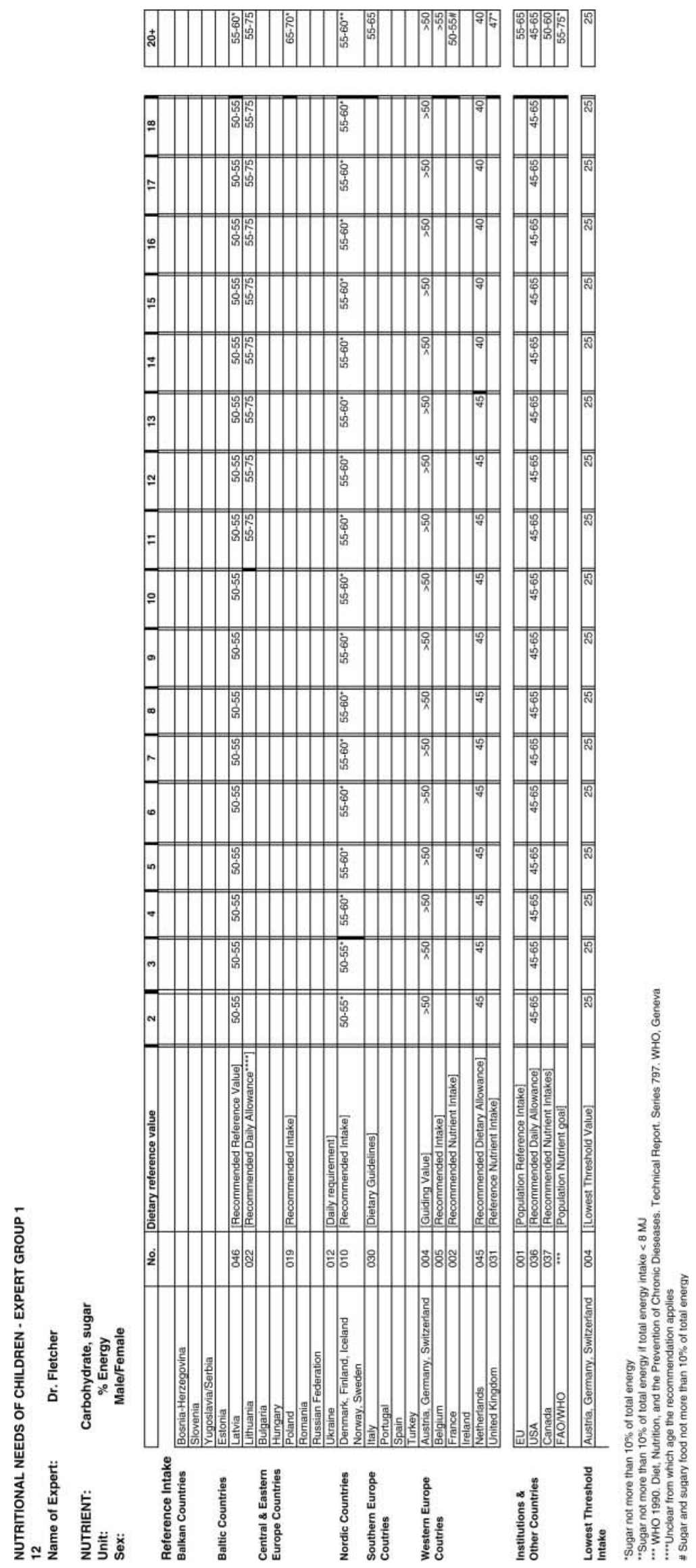

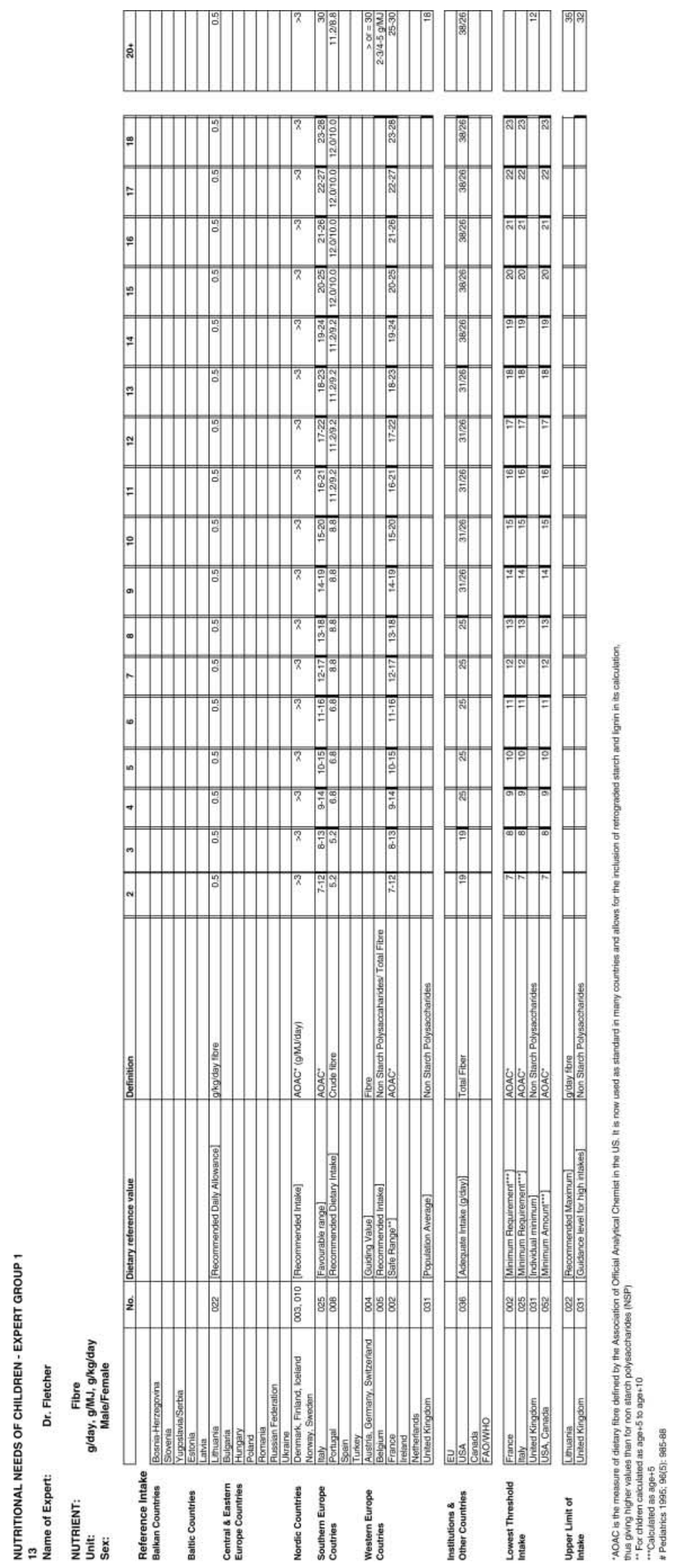
A. Prentice et al.

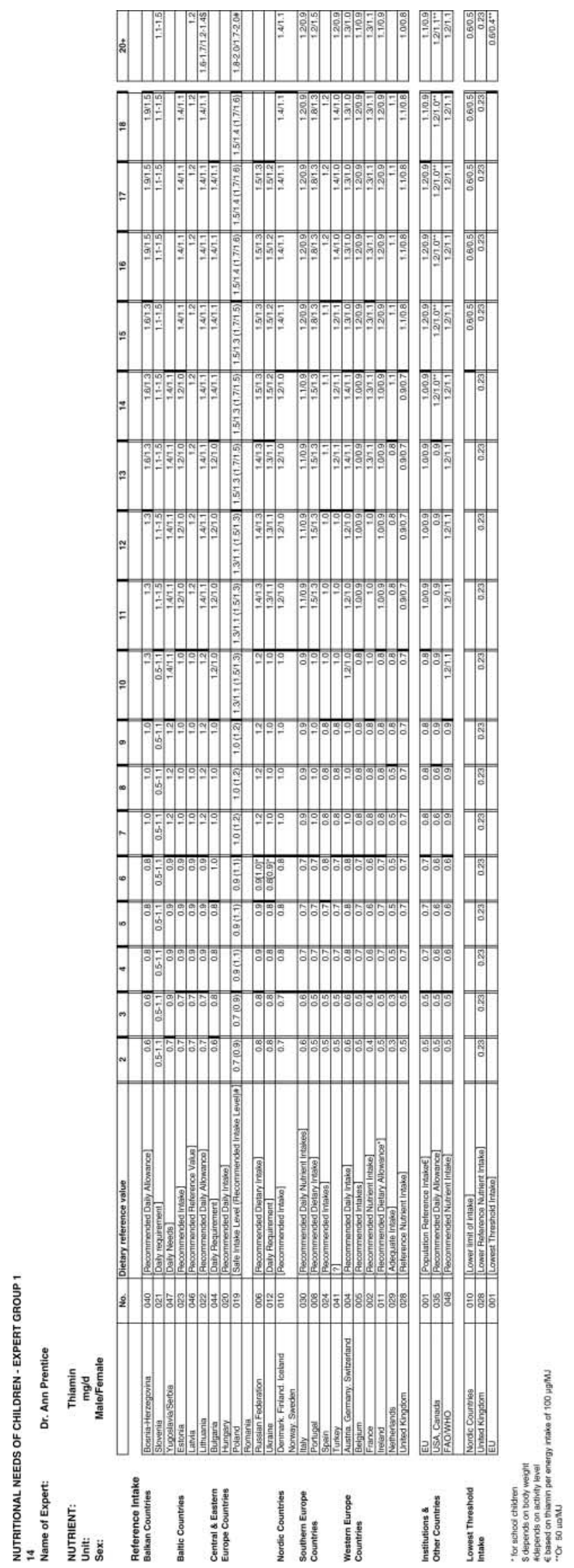




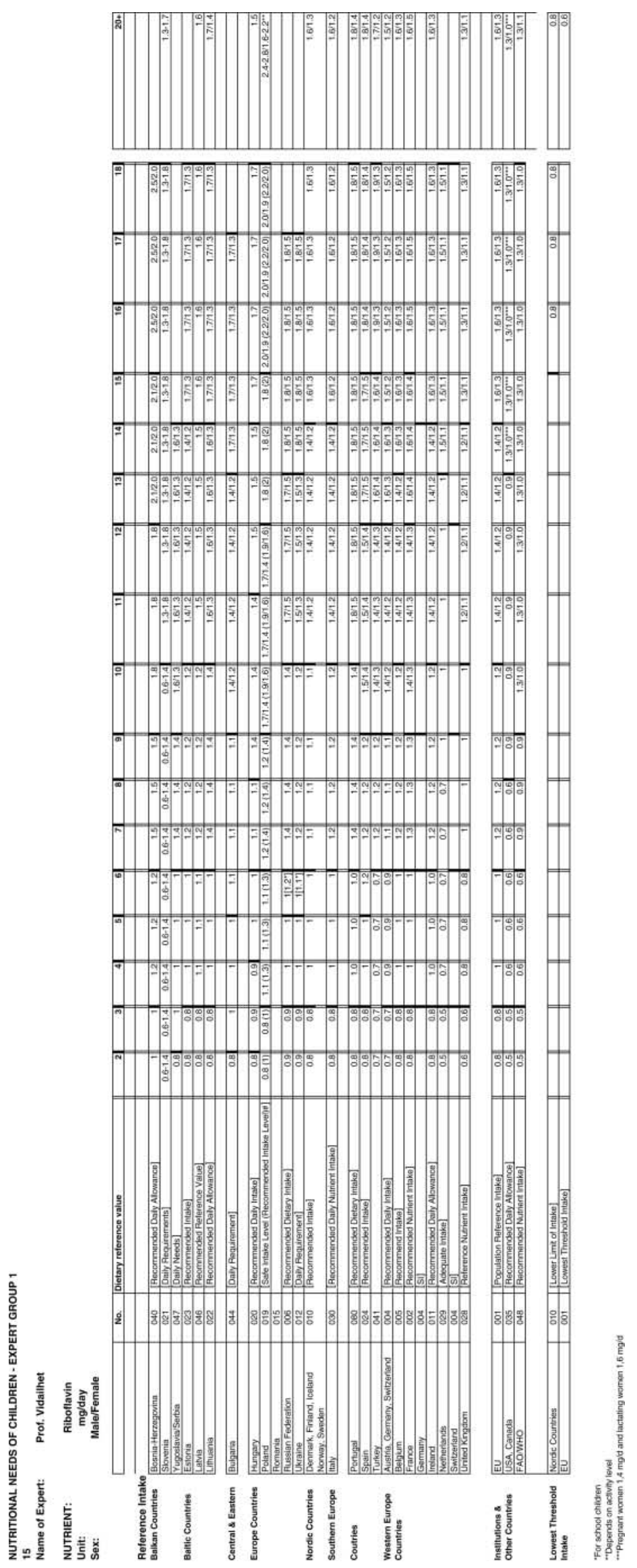


A. Prentice et al.

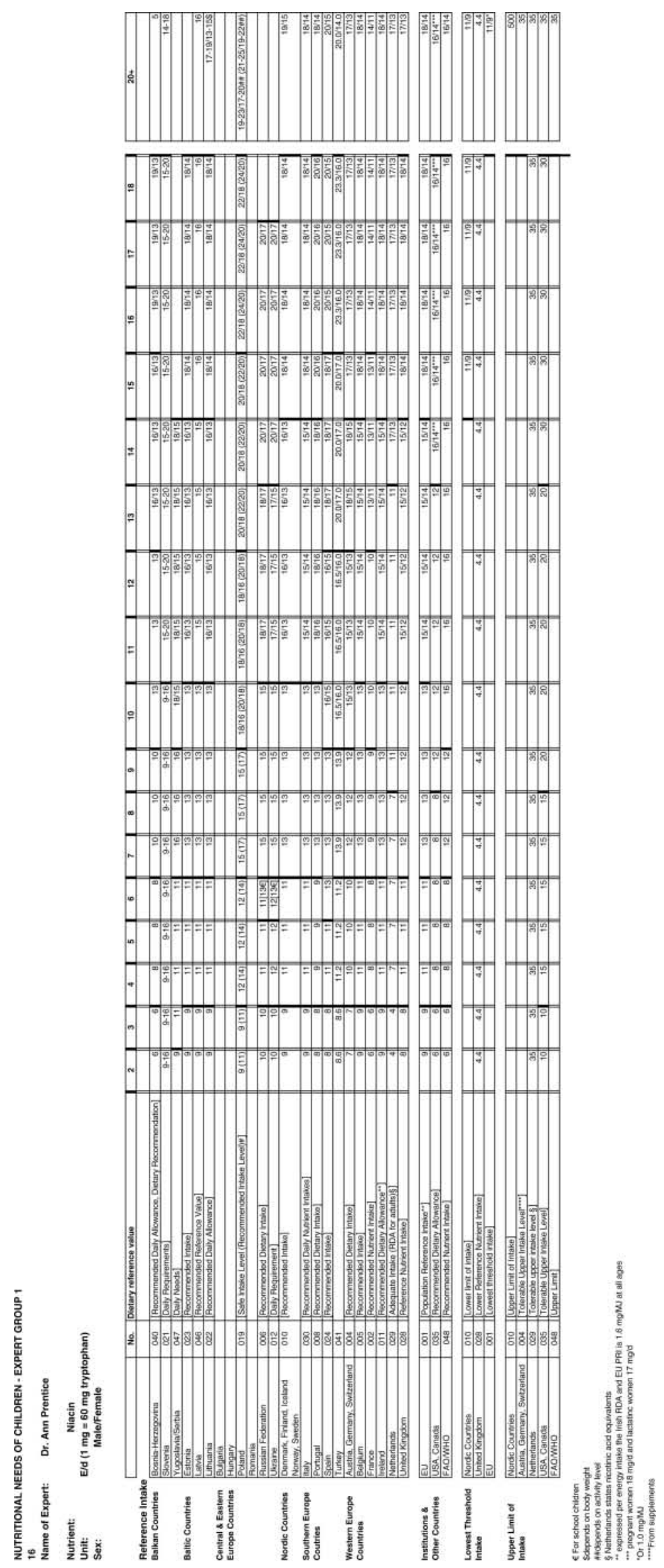









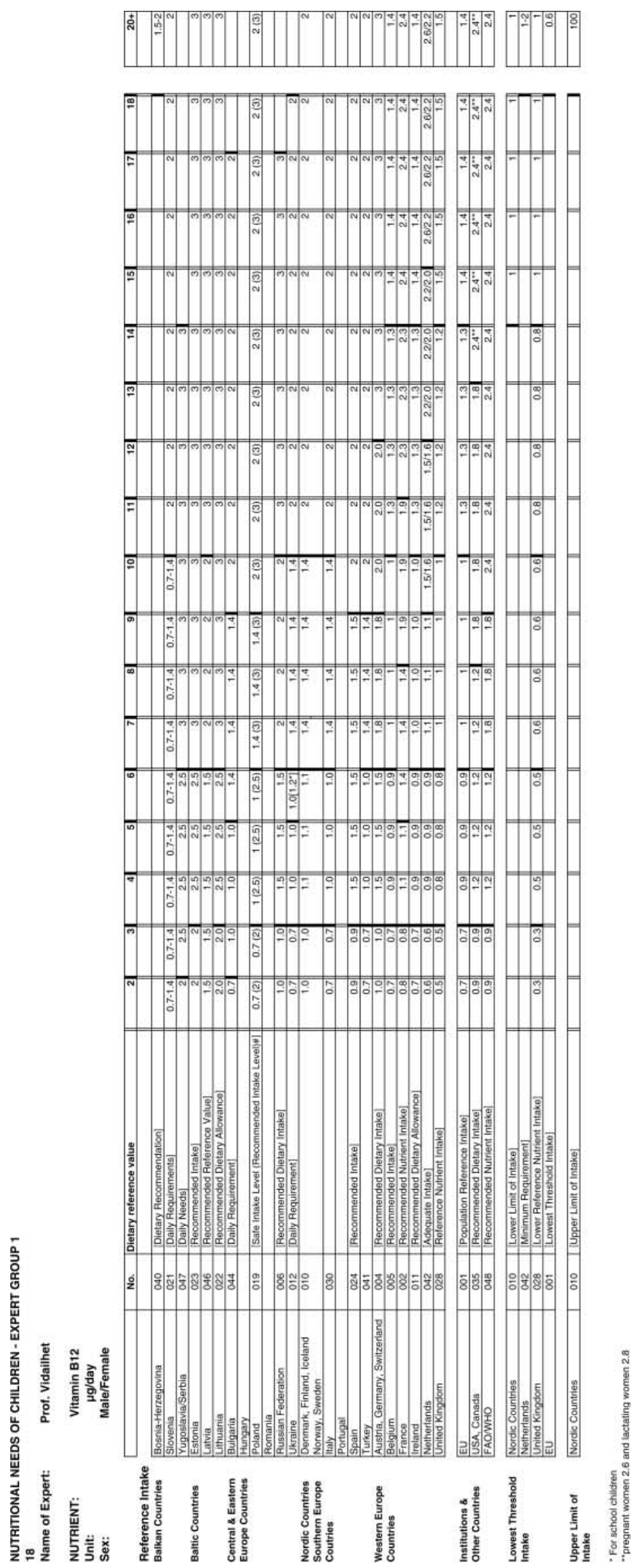




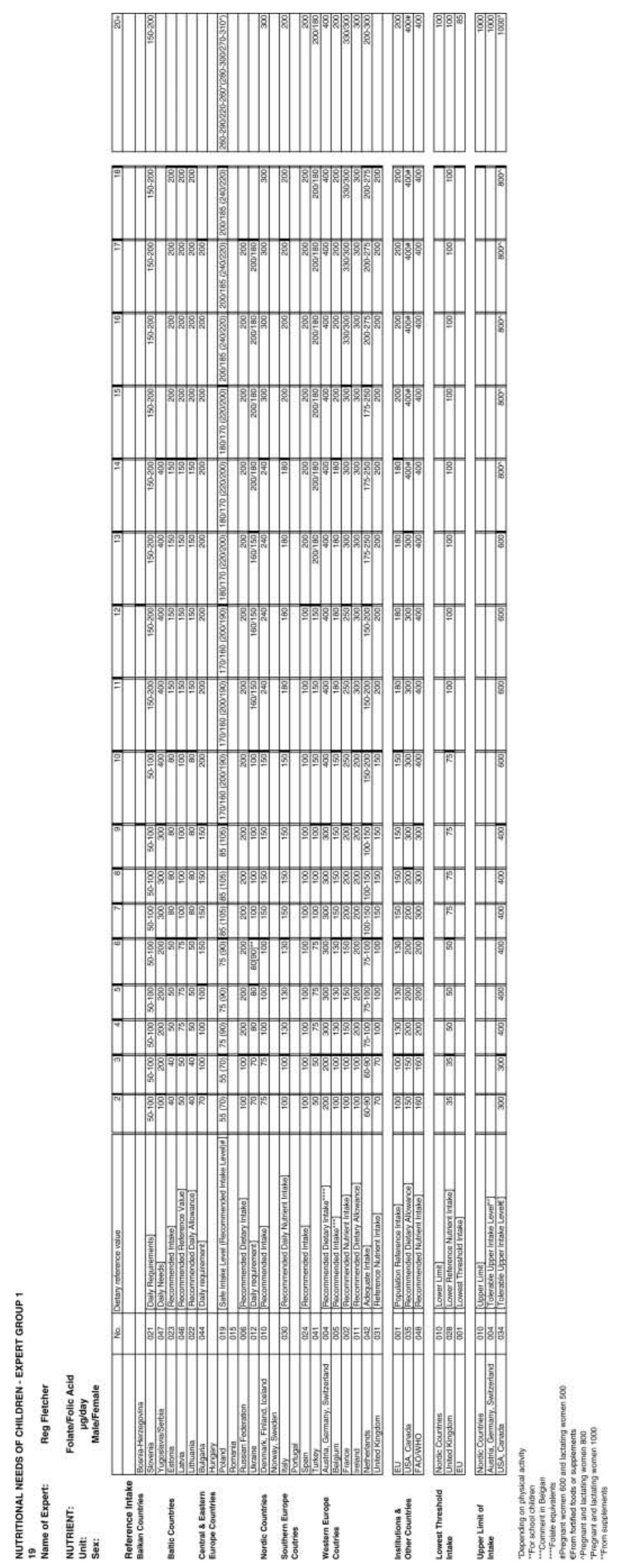



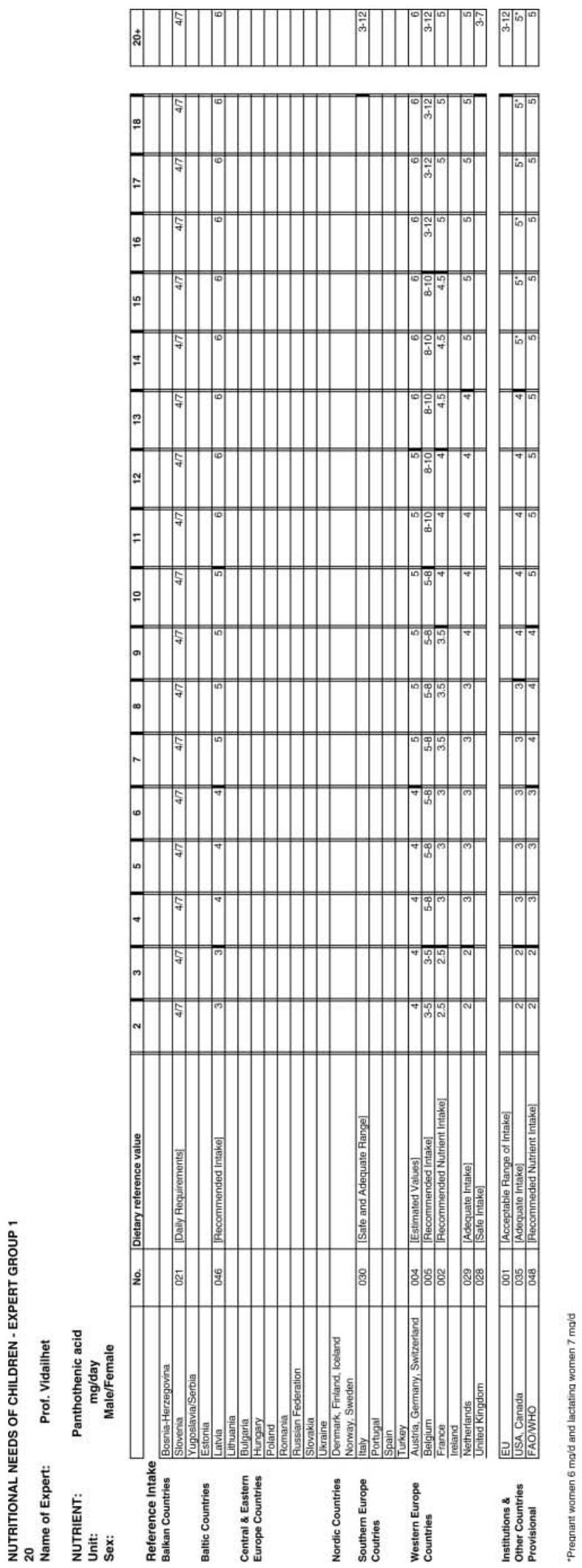

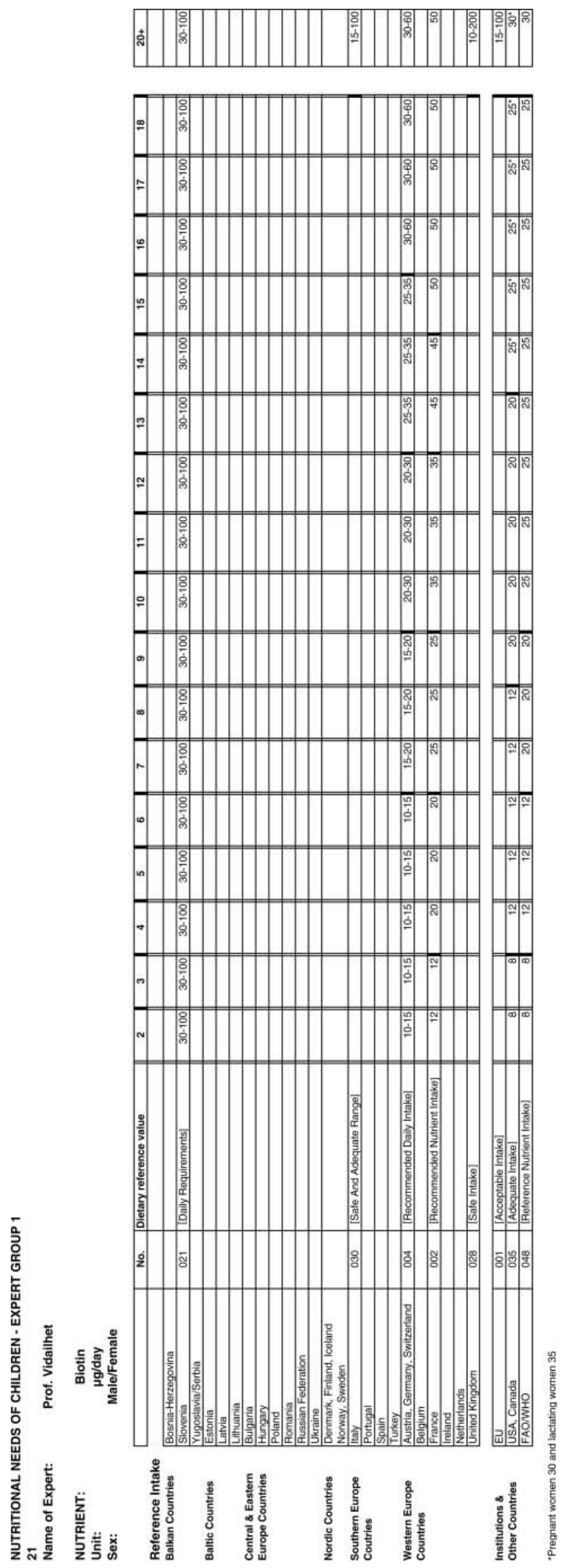


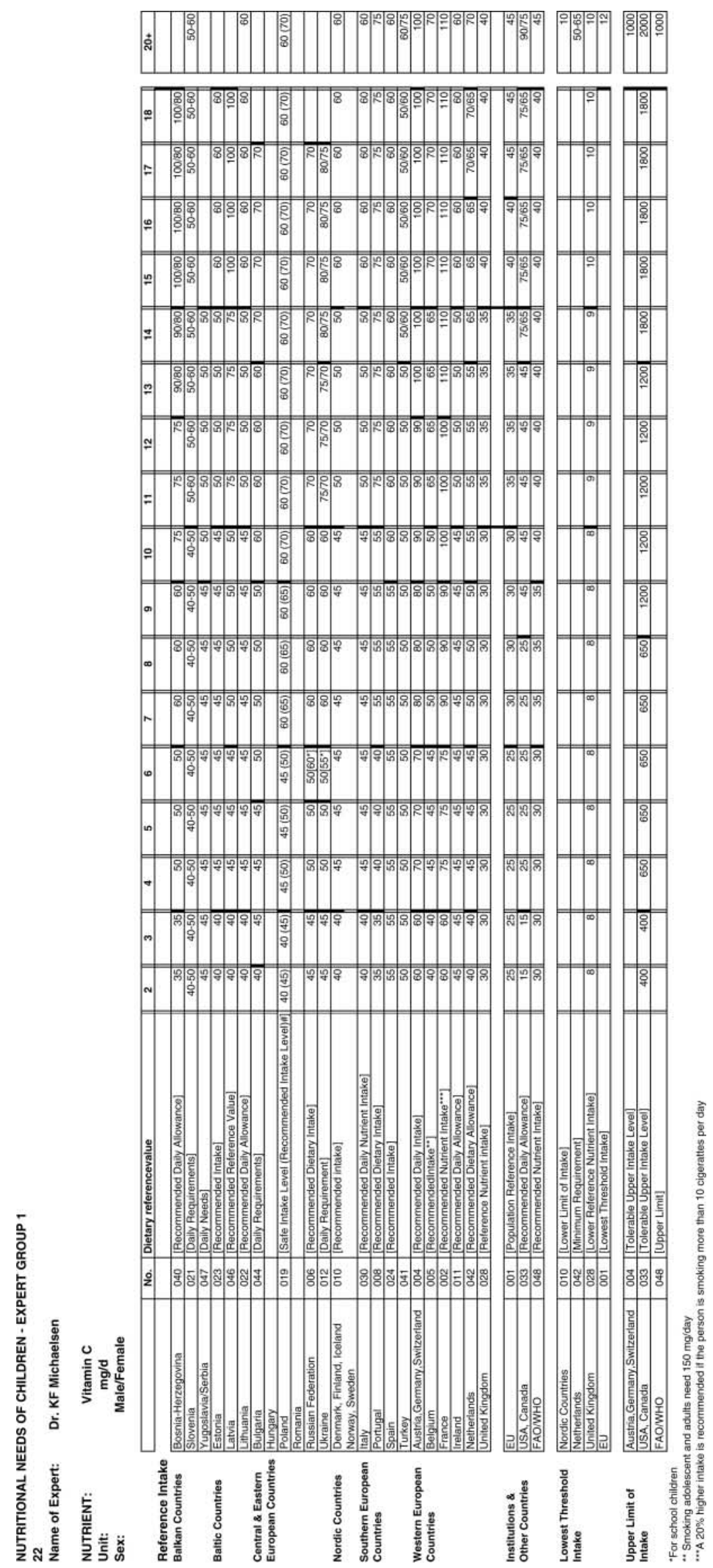



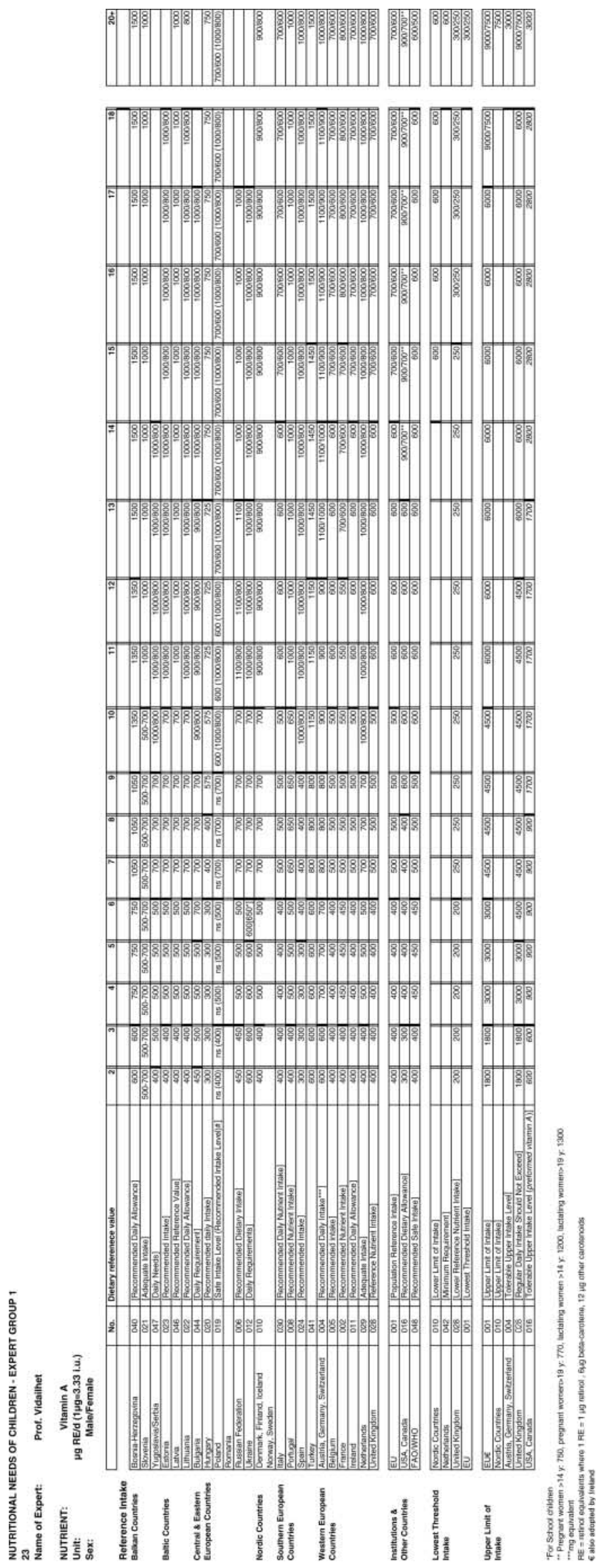


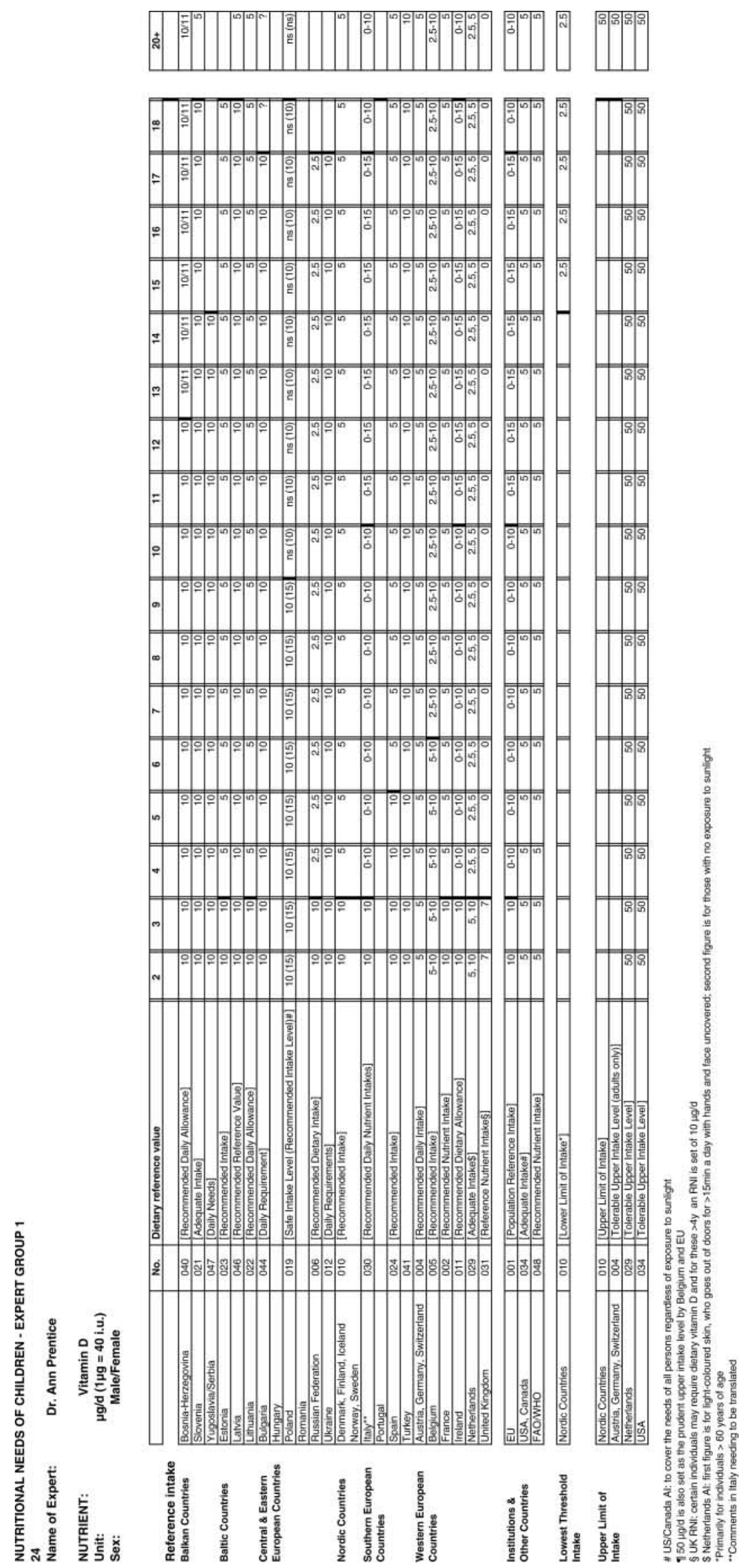







A. Prentice et al.








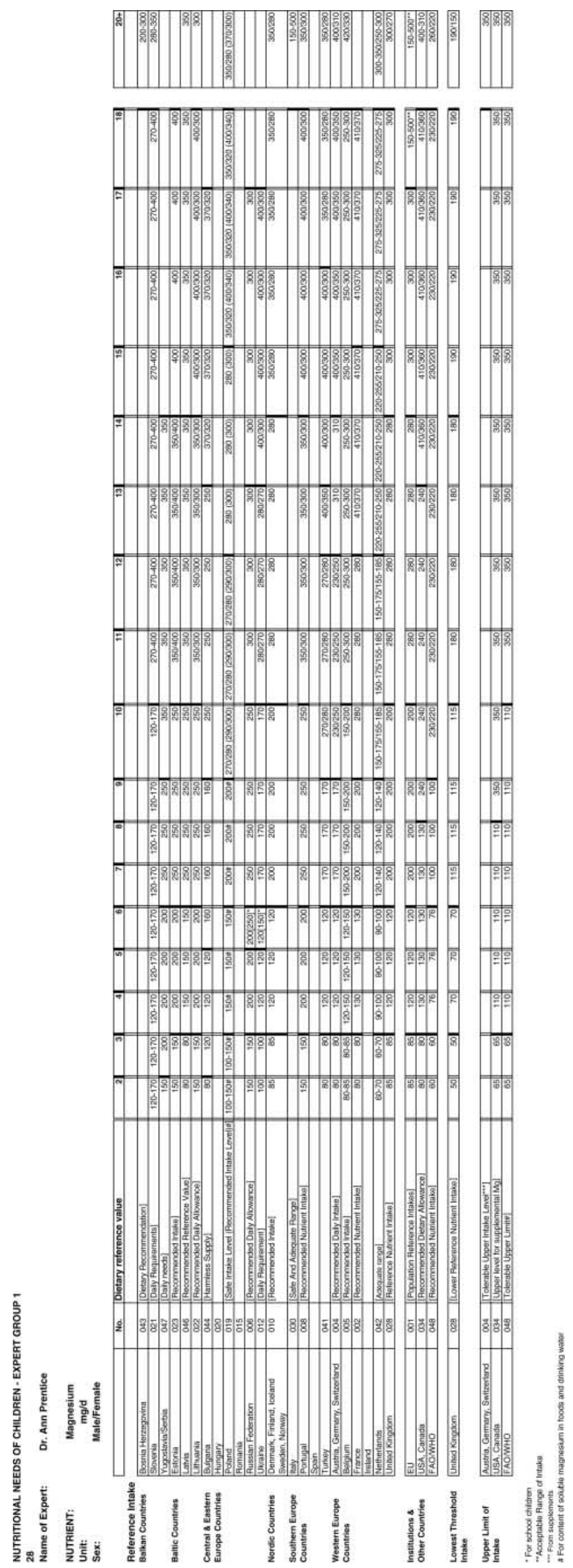




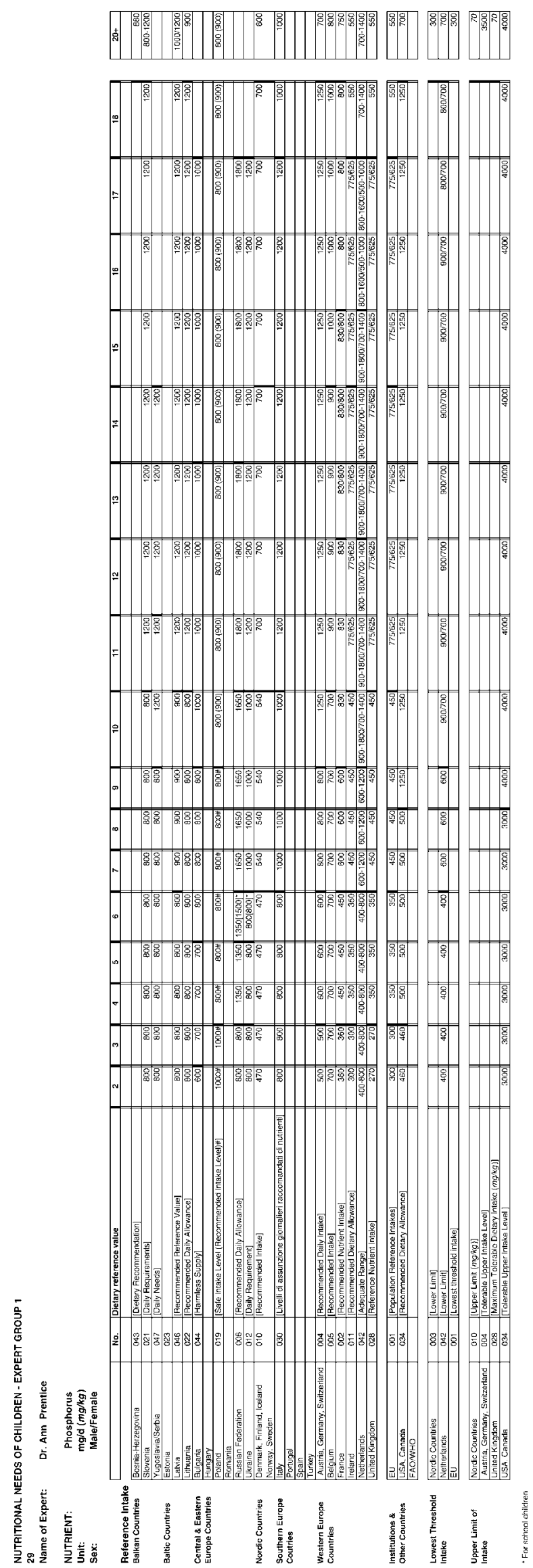


A. Prentice et al.









A. Prentice et al.

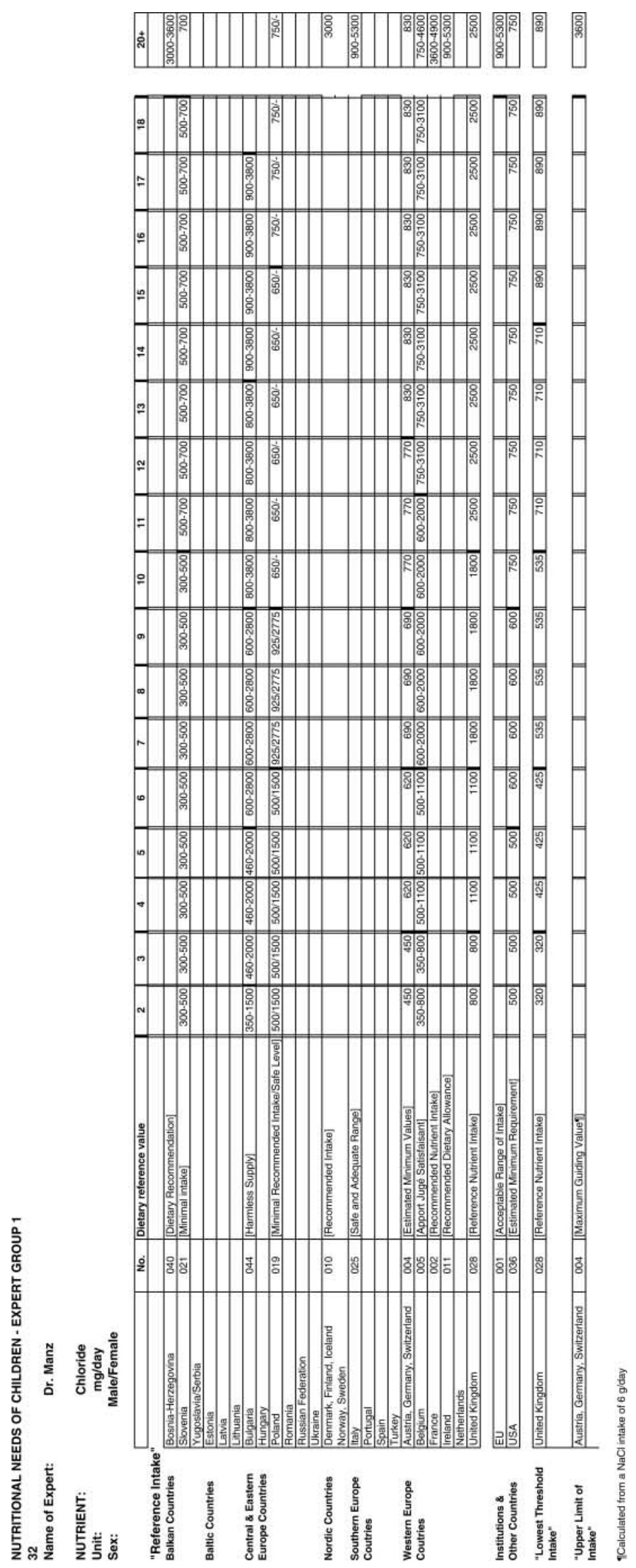



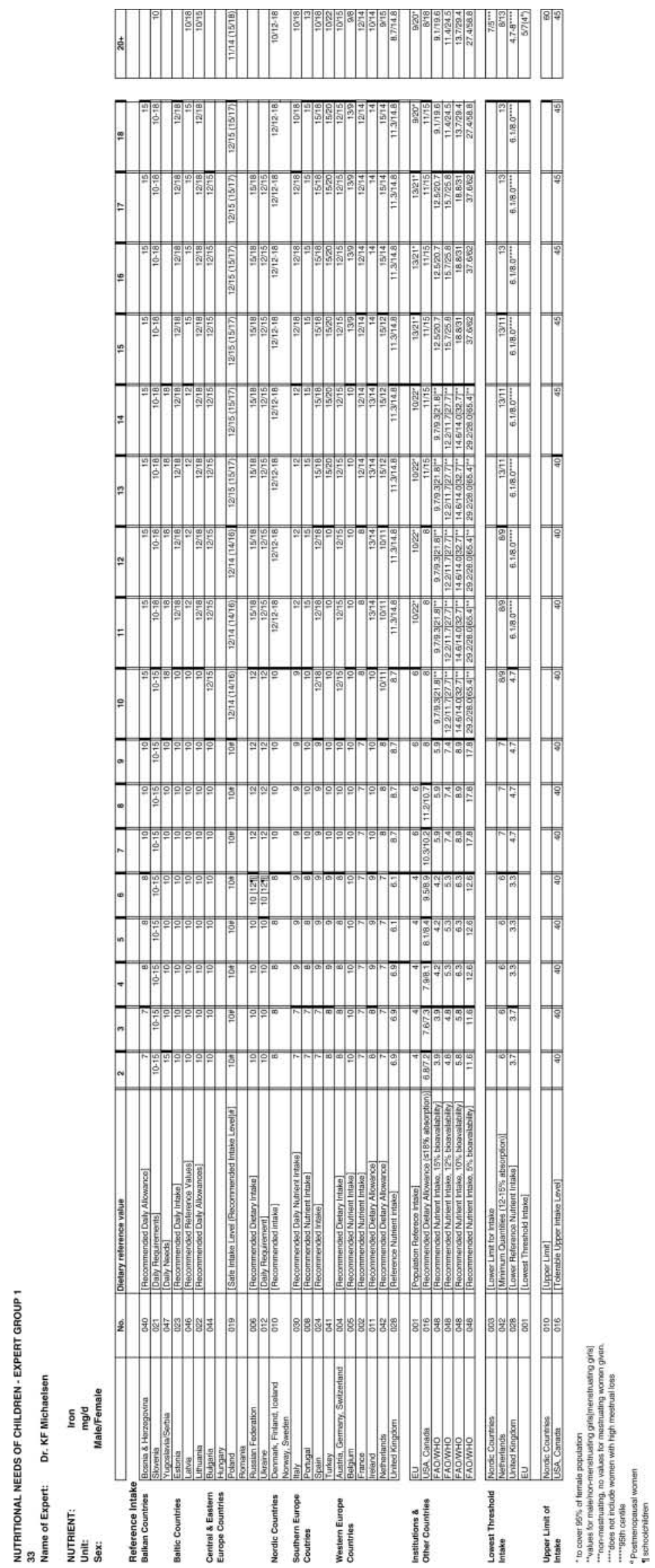


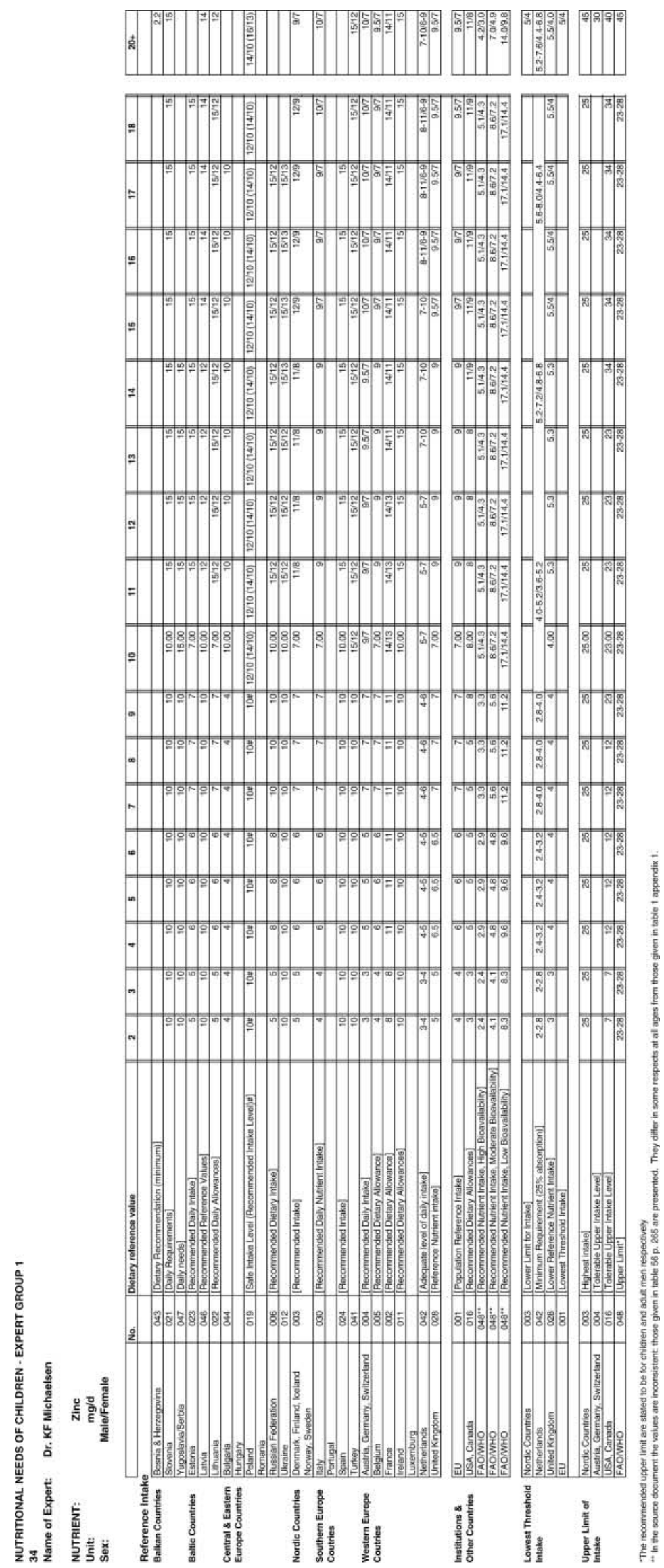




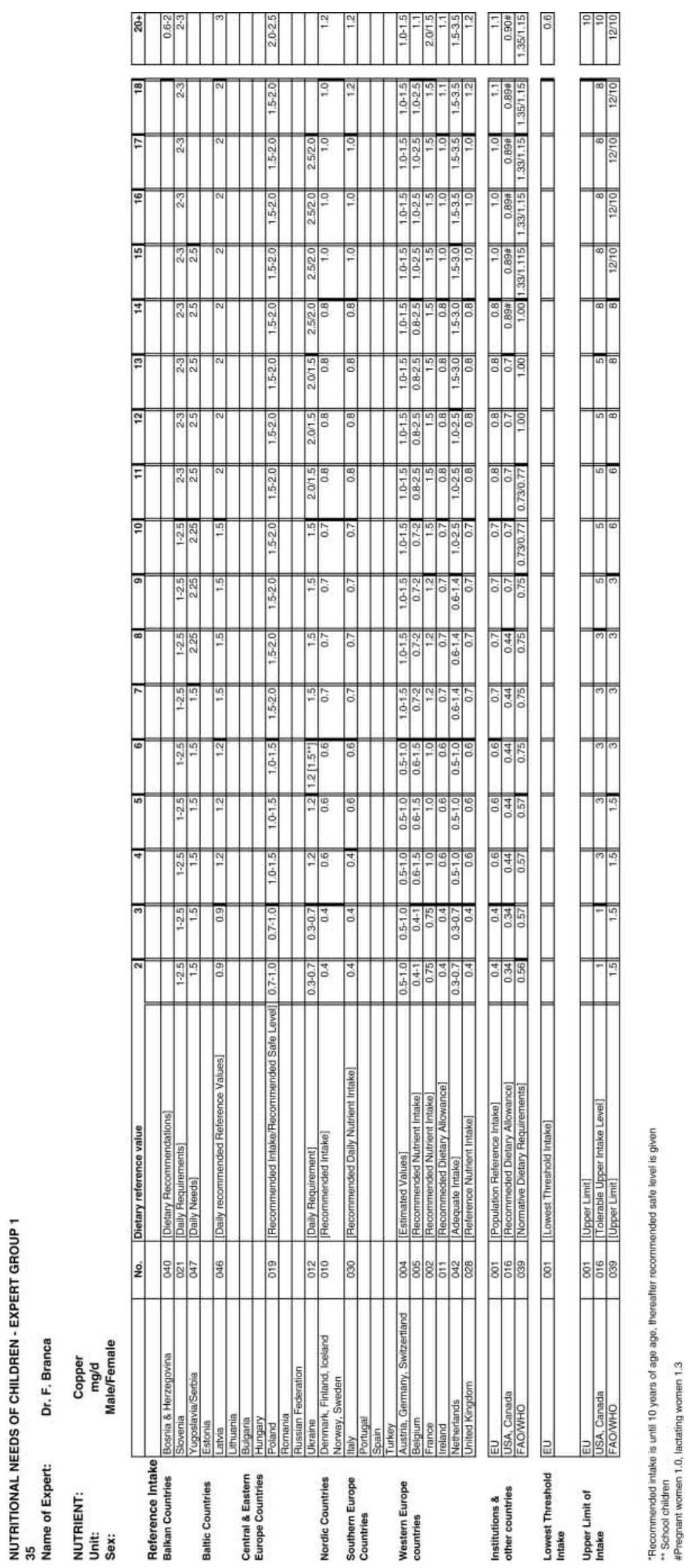


A. Prentice et al.
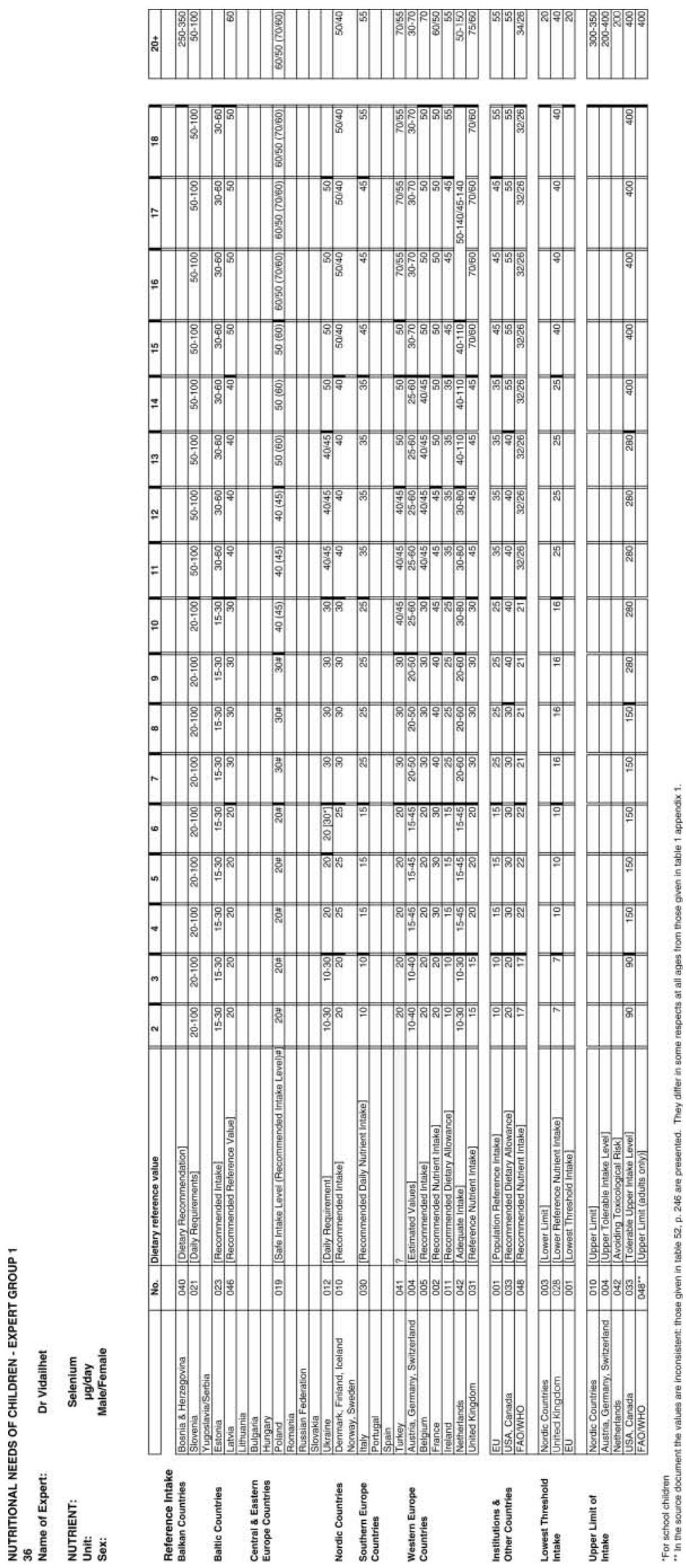


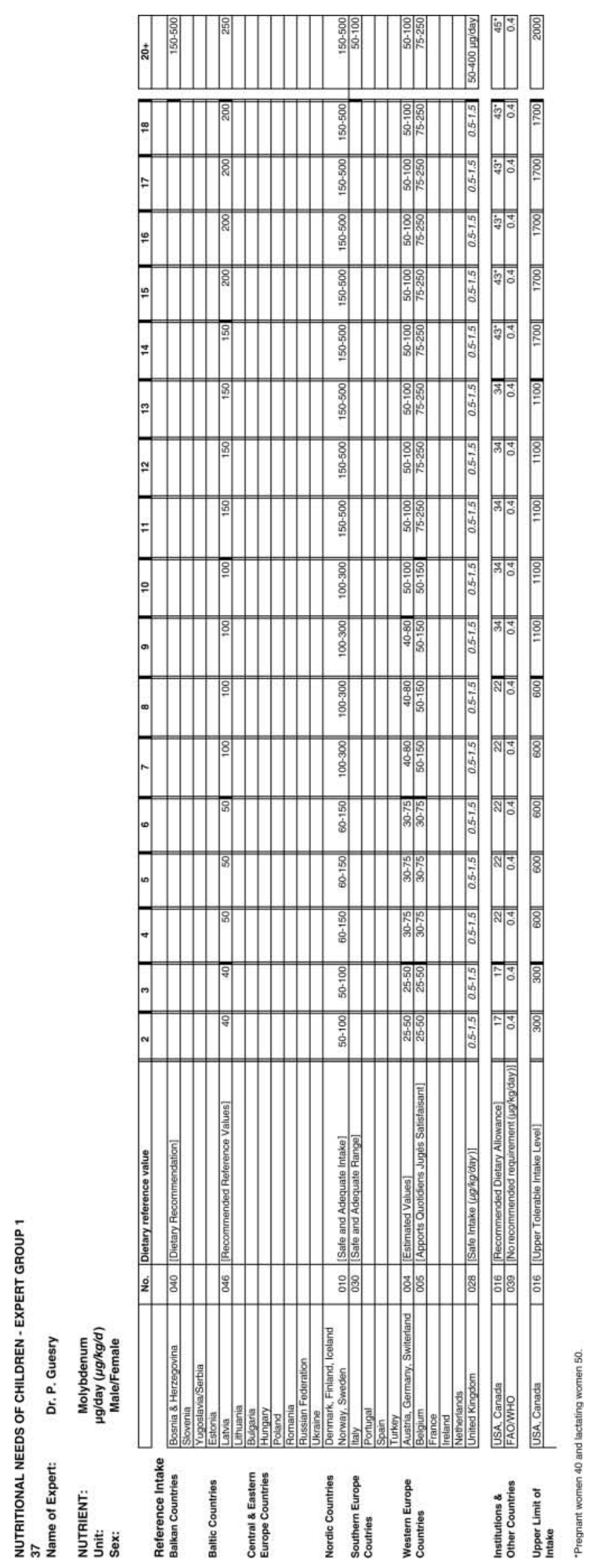


A. Prentice et al.
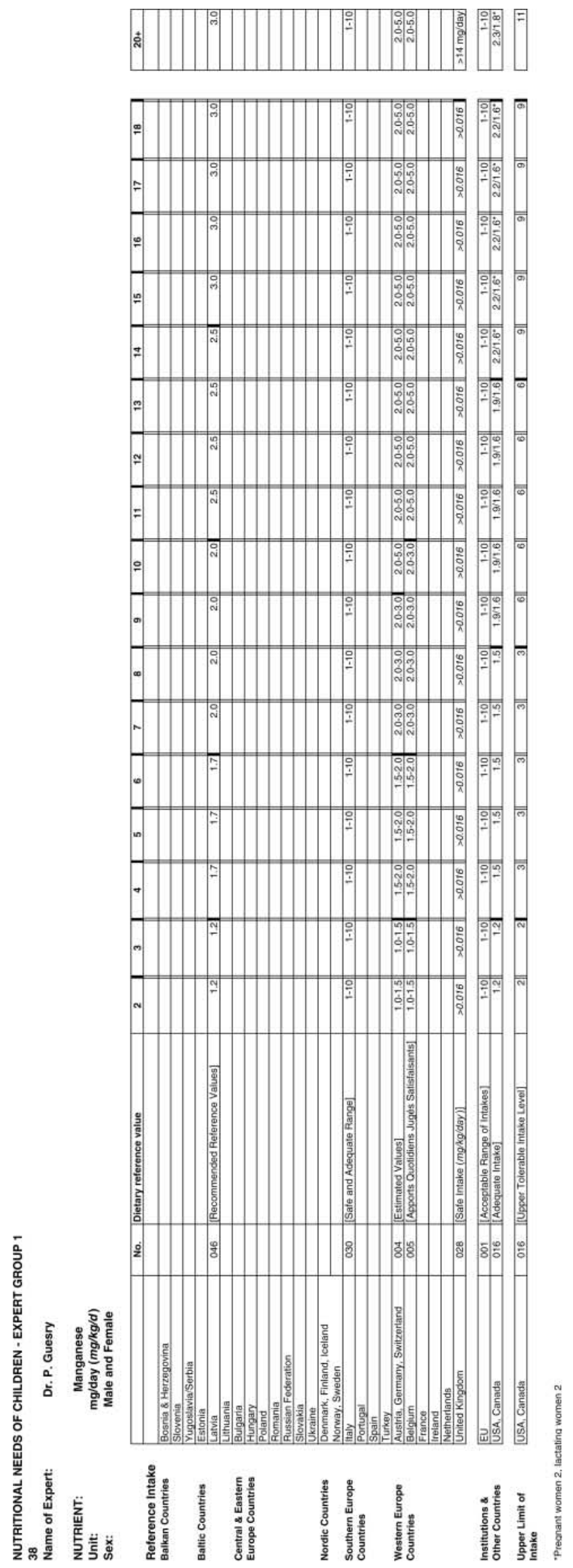


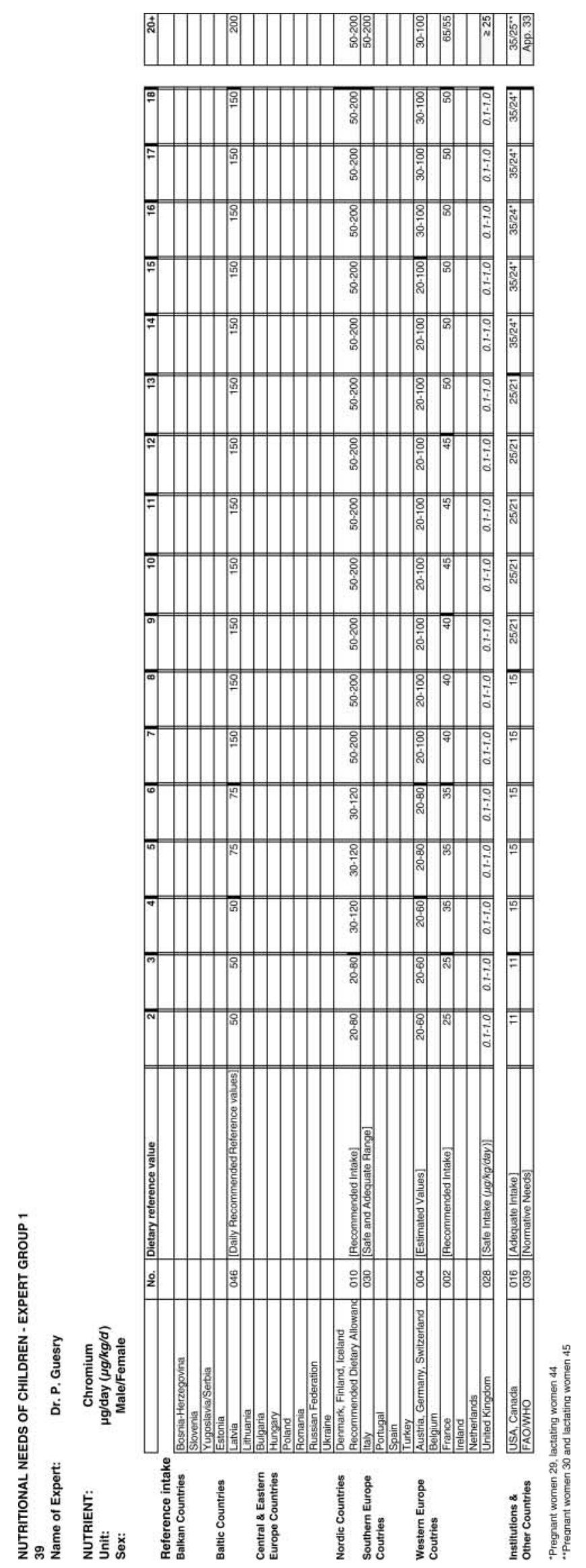


A. Prentice et al.
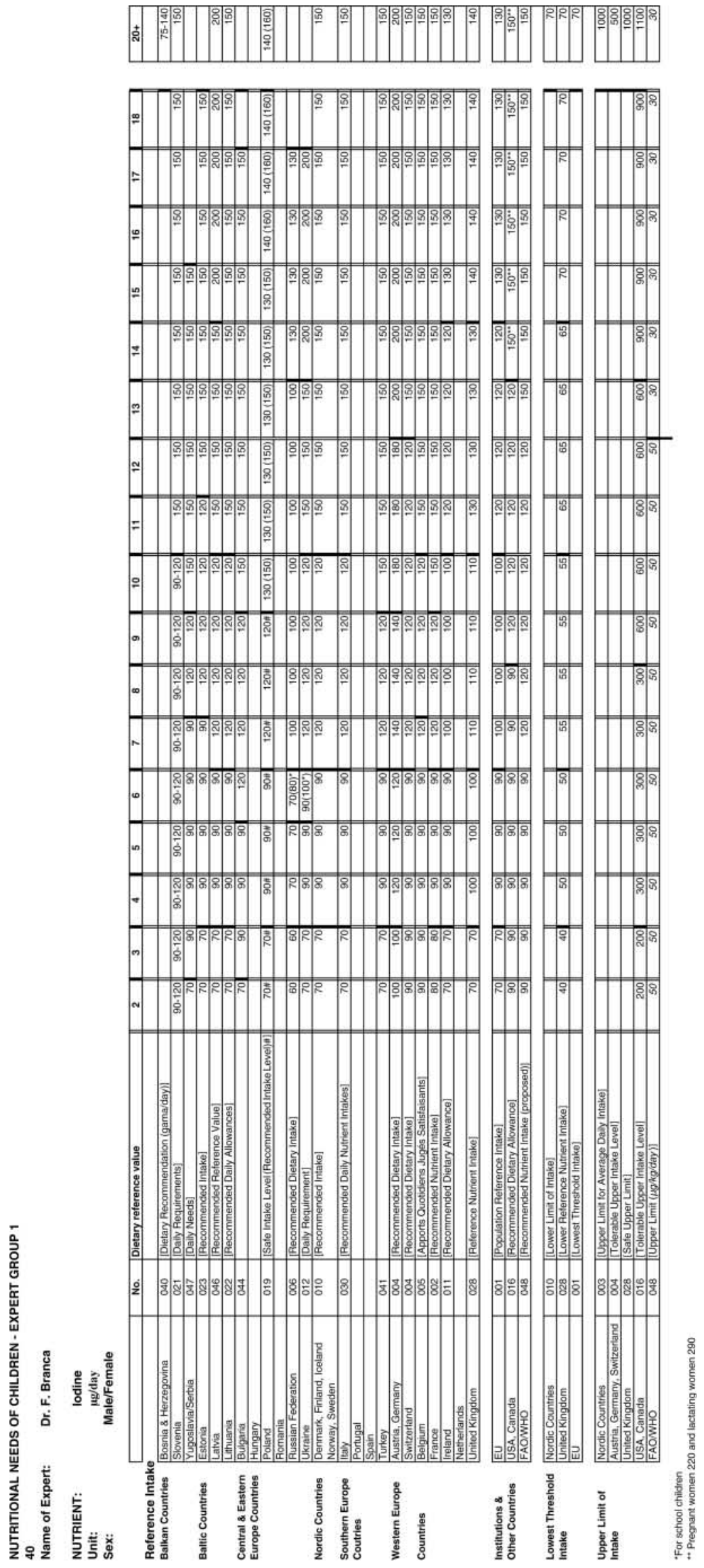




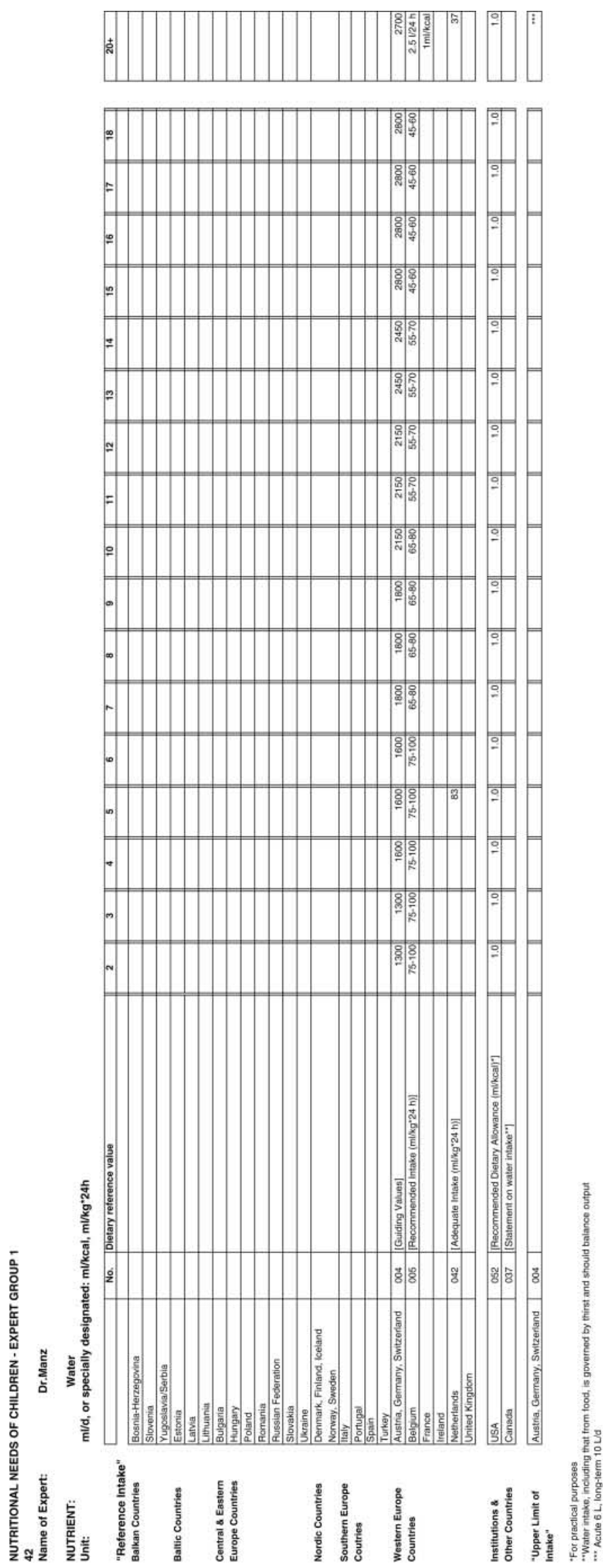

